\title{
Calabaria and the phylogeny of erycine snakes
}

\author{
ARNOLD G. KLUGE \\ Museum of Zoology and Department of Biology, University of Michigan, Ann Arbor, \\ MI 48109 U.S.A.
}

Received October 1991, revised manuscript accepted May 1992

\begin{abstract}
Two major subgroups of erycine snakes, designated Charina and Eryx, are delimited with a cladistic analysis of 75 morphological characters. The hypotheses of species relationships within the two clades are (reinhardiii (boltae, trivirgata)) and (colubrinus, conicus, elegans, jayakari, muelleri, somalicus (miliaris (tataricus (jaculus, johnii)))), respectively. This pattern of grouping obtains without assuming multistate character additivity. At least 16 synapomorphies indicate that reinhardii is an erycine and that it is the sister lineage of the (bottae, trivirgata) clade. Calabaria and Lichanura are synonymized with Charina for reasons of taxonomic efficiency, and to emphasize the New-Old World geographic distribution of the three species in that assemblage. Further resolution of Eryx species relationships is required before Gongylophis (type species conicus) can be recognized.
\end{abstract}

ADDITIONAL KEY WORDS:--Biogeography - Cladistics - erycines - fossils - taxonomy.

\section{GONTEN'TS}

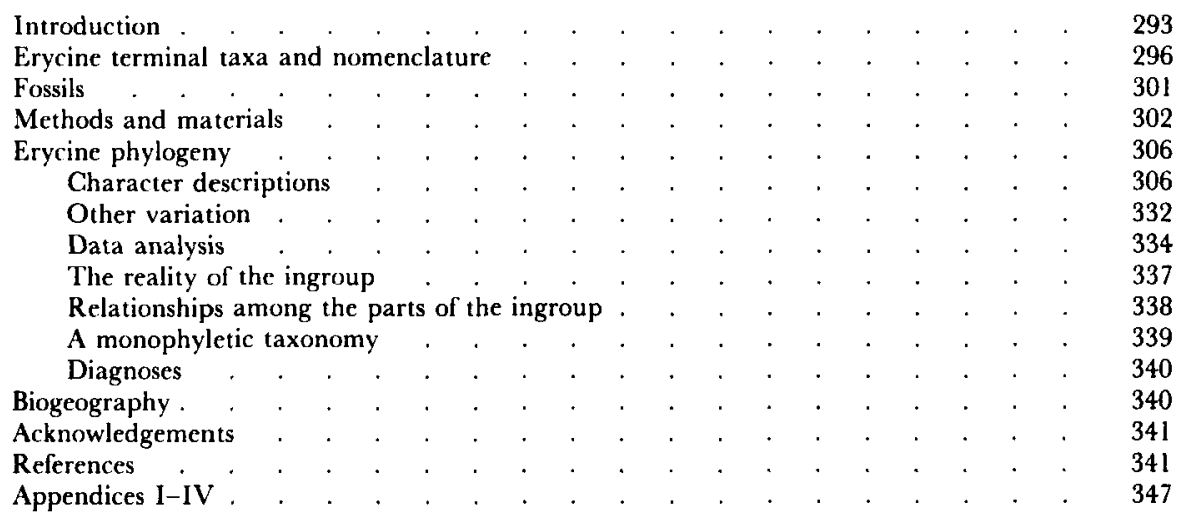

\section{INTRODUCTION}

Frazzeta (1959: fig. 10) concluded from his summary of the history of major changes in 'boid' snake classification that Calabaria has always been referred to the Pythoninae. While there are explicit exceptions to Frazzetta's generalization [e.g. Gray (1858) and Cope (1900: 722); see also more recent publications by Dowling \& Gibson (1970), Dowling (1975a, b), Underwood (1976: 152, 168), Dowling \& Duellman (1978), and Groombridge (1979b)], the majority of snake systematists have considered Calabaria to be a pythonine [e.g. Boulenger (1893), 
Hoffstetter (1946, 1955), Lesson (1950: ix), Underwood (1950, 1967), Brongersma (1951), Romer (1956), Villiers (1963), Hoffstetter \& Rage (1972: 121), Frazzetta (1975: fig. 2); Rieppel (1976), McDowell (1979), de Silva (1980), Welch (1982) and Stafford (1986)]. Even the most widely used common names for Calabaria, Calabar burrowing, or ground, python (Villiers, 1963; Stafford, 1986), emphasize the taxon's presumed affinities to pythonines.

The first clue that Calabaria's classification as a pythonine may be incorrect concerns the fact that the only known species in the genus, $C$. reinhardtii, was originally described by Schlegel (1851) as an Eryx, a taxon which has for many years been considered part of the boine radiation (Boulenger, 1893). Schlegel's placement was based on detailed comparisons with Eryx conicus, E. jaculus, E. johnii and E. thebaicus ( =E. colubrinus). Moreover, Peters' (1858) designation of a new genus for C. reinhardtii (Rhoptrura, now considered a synonym of Calabaria) was based on that species having much enlarged head shields, a clubshaped tail, and lack of palatine teeth. None of these features characterize pythonines; however, the short, stubby tail and reduced number of palatine teeth are typical of erycines. Likewise, Gray's (1858) description of Calabaria does not allude to pythonine affinities. Further, the Calabar burrowing python seems to have been the only form originally described as an erycine that has been treated subsequently as a pythonine (Stimson, 1969). In other words, erycine snakes have long been recognized as a distinct taxon.

A variety of data has been mentioned in support of the Calabaria-pythonine hypothesis of relationship (Underwood, 1967: 69), and the shared presence of the supraorbital bone [the 'super-orbital bone' of Gray (1849: 85 ); also exhibited by Dinilysia and Loxocemus] has been most often cited as evidence of that affinity [beginning with Boulenger (1893: 72)]. Assuming the evolution of the supraorbital bone was a unique and unreversed event, its presence provides unambiguous evidence for the pythonine relationship of Calabaria, a group which would also have to include Dinilysia and Loxocemus. McDowell (1975: 51) endorsed such a pythonine relationship for Calabaria. In particular, he concluded that Calabaria is closely related to the Python molurus group [specifically P. regius; McDowell (1978: 28)], based on similar hemipenis ornamentation, which is reduced to the distally directed fold that forms the edge of an oblique distal capitation. However, McDowell (1975) was forced to admit that such a placement of Calabaria within pythonines added hypotheses of homoplasy. For example, the absence of a dorsal lobe [i.e. lappet (Frazzetta, 1966: fig. 18)] on the prefrontal bone in Calabaria had to be interpreted as a loss, so that the posterior ends of the nasal bones are secondarily exposed rather than overlayed as in both boines and pythonines.

Of course, alternative hypotheses of Calabaria relationships may be obtained if one or both of the assumptions of 'unique and unreversed' evolution of the supraorbital are relaxed. For example, M. A. Smith (1943: 103) not only asserted that the supraorbital had been lost independently, but in different genera'. If true, the supraorbital could then be said to diagnose a large group of snakes; however, the presence of that bone in Calabaria would not provide evidence for more specific affinities, with or within that group of taxa traditionally considered pythonines [sensu Underwood (1976), and Underwood \& Stimson (1990)].

Rieppel's (1978a) study of erycine history provides another example of how 


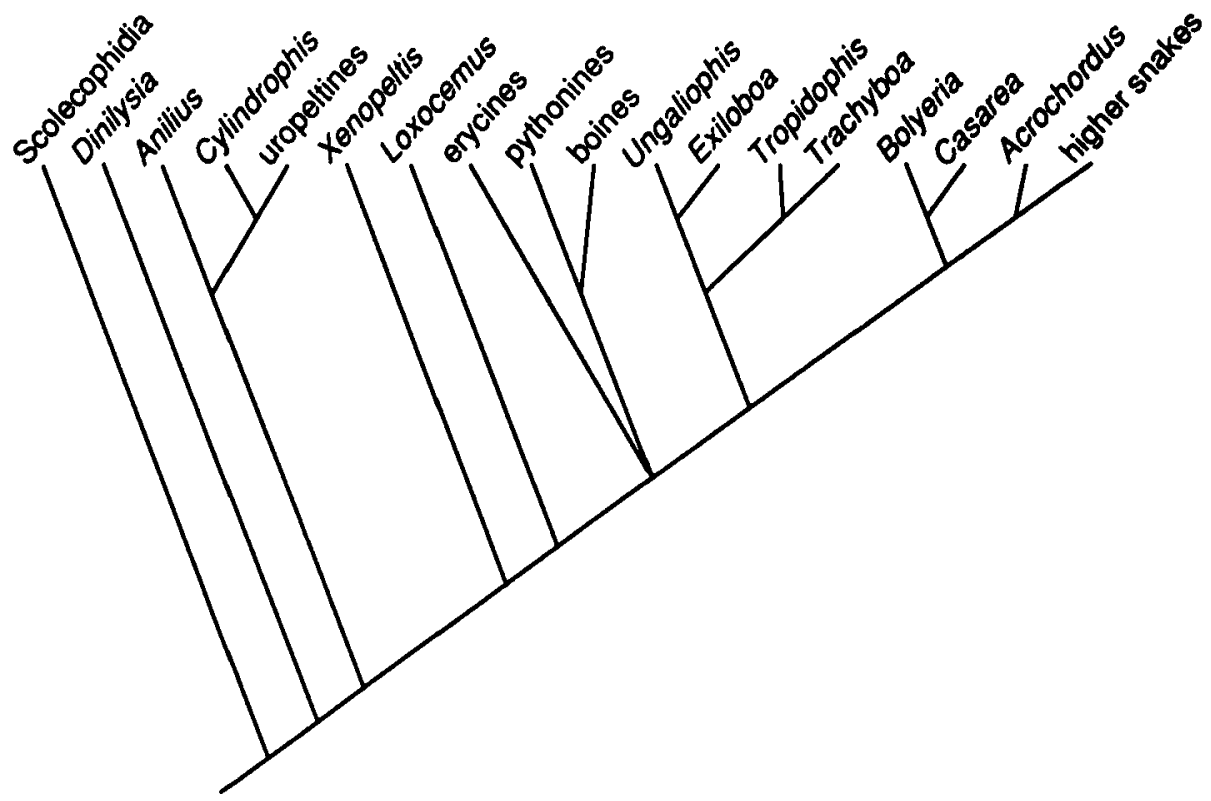

Figure 1. A preliminary hypothesis of relationships of the major groups of snakes $(C=0.75$, $R=0.86$ ), which is summarized here as a strict consensus tree. See Kluge (1991: fig. 4) for information on the evidence for this hypothesis, and further resolution of boines, pythonines and Scolecophidia. The affinities discovered within erycines are (Calabaria ((Charina, Lichanura) ((Eryx colubrinus, E. jaculus, E. jayakari, E. johnii, E. tataricus) (Gongylophis conicus)))).

assumptions of character evolution have significantly affected our understanding Calabaria's affinities. He (p. 206) simply excluded Calabaria from possible consideration because he interpreted its similarities to erycines as independently evolved; "phenetic similarity [that] indicates a similarity of the genetic background which makes parallel evolution of a functionally correlated character [sic] responding to similar selective pressures more easily understood". McDowell (personal communication) also takes the position that the similarities between Calabaria and Eryx can be accounted for as adaptations to burrowing.

I believe Calabaria's relationships remain an open question. Some similarities between that taxon and erycines have been recognized for many years (Schlegel, 1851; Gray, 1858; Peters, 1858), and my preliminary study of primitive snake synapomorphies (Kluge, 1991) confirmed that affinity (Fig. 1). In the following review of the evidence of erycine monophyly and species relationships, I will try to minimize the number of a priori propositions concerning character history. I will not assume the evolution of the supraorbital bone was a unique and unreversed event, nor will I discard evidence a priori because plausible process explanations might apply (as per Rieppel, 1978a).

Additional questions considered in this study include: (1) Do Charina, Eryx, Gongylophis and Lichanura form a monophyletic group? (2) Are the New World erycines, Charina and Lichanura, sister taxa, as suggested by Bogert (1968)? (3) Is Eryx monophyletic, and is Gongylophis conicus its sister lineage? Hoffstetter (1955, 1962) considered Charina, Eryx and Lichanura to be each other's closest relatives, while Underwood (1967) and Bogert (1968: 30) expressed some doubt as to the placement of Lichanura. Rage (1972) believed Eryx conicus to be so distinct 
osteologically from $E$. jaculus and $E$. johnii as to warrant placing it in its own monotypic genus, Gongylophis.

According to Rieppel (1978a: 196-198), the erycine snout is variably adapted for burrowing, and he proposed the following linear morphocline of species (Maslin, 1952) as an example of that hypothesized transformation: Lichanura $\rightarrow$ Charina $\rightarrow$ Eryx (tataricus $\rightarrow$ conicus $\rightarrow$ jayakari and somalicus $\rightarrow$ colubrinus and muelleri $\rightarrow$ miliaris $\rightarrow$ jaculus $\rightarrow$ johnii). Recently, Tokar (1989) took numerous measurements on Eryx skulls, and based on a phenetic analysis of those observations he recognized four groups of species, Gongylophis (conicus), Neogongylophis (colubrinus and muelleri), Eryx (elegans, jaculus, johnii, miliaris, somalicus tataricus, vittatus) and Pseudogongylophis (jayakari). Rieppel's and Tokar's conclusions concerning Eryx (sensu lato) species relationships are substantially different, and the further study of this part of erycine history is also demanded.

\section{ERYCINE TERMINAL TAXA AND NOMENGLATURE}

The following abbreviated taxonomy summarizes the erycine species group entities employed as terminal taxa in the present study. I have no a priori reason to doubt the historical individuality of any of these taxa (Kluge, 1990), with the exception of Eryx tataricus (see that species' Remarks section), and I am not concerned with those diagnoses. Complete genus and species group synonymies of erycines can be found in Stimson (1969), Gasperetti (1988) and Tokar (1989). I make no attempt to judge the long overlooked species names used by Higgins (1873) because the descriptions of those taxa provide too little evidence on which to base an informed nomenclatural decision.

As noted above, there is little agreement concerning the monophyly of Eryx and Gongylophis, and how many clades can be delimited within Eryx (Tokar, 1989). I frequently cite this taxonomically inconsistent literature, especially in the character descriptions section, and to avoid confusing the reader with more than one binominal combination and different spellings of species names, I employ the species nomenclature in the following list until the monophyletic taxonomy section of this paper is reached. Furthermore, prior to that section, I use only the species epithets, without generic designation, to avoid biasing the reader toward any particular phylogenetic hypothesis. In that mononominal context, I adopt the original spelling of the species name to avoid having to choose among the various endings demanded by the different binominal combinations (e.g. I use colubrina instead of colubrinus, conica instead of conicus, and tatarica instead of tataricus). Rieppel (1978a) consistently misspelled tatarica as tartaricus in his review of erycine evolution. A monophyletic taxonomy of erycine species groups will be proposed later in this paper. I only use generic names when referring to outgroups and when citing literature that has mentioned ingroup generic names alone. Citations to the authorship of secondary synonyms are omitted from the references section.

\section{bottae}

Tortrix bottae Blainville, 1835, Nouv. Ann. Mus. Hist. Nat. Paris, 4: 289.

Holotype: MHNP 730.

Type locality: California; restricted by Schmidt (1953) to Coast Range, opposite Monterey. 
Synonyms: Wenona plumbea Baird \& Girard (1852); Wenona isabella Baird \& Girard (1852); Charina brachyops Cope (1888); Charina bottae umbratica Klauber (1943); Charina bottae utahensis Van Denburgh (1920). In addition to the nominate form, one subspecies, umbratica, is usually recognized [Stewart, 1977; Collins, 1990; see however, Stebbins (1985)].

Objective genus group relations: Tortrix bottae Blainville for Charina Gray (1849), by monotypy, and for Pseudoeryx Jan [1862; non Fitzinger (1826)], by monotypy.

Geographic range: From southern British Columbia (vicinity of Quesnel), Canada, to the Bighorn Mountains of Wyoming, Panguitch Lake in southern Utah, central Nevada and the San Jacinto Mountains in southern California (Stewart, 1977; Stebbins, 1985).

\section{colubrina}

Anguis colubrina Linnaeus, 1758, Syst. Nat., 10th Ed., 1, p. 228.

Type: Presumed lost.

Type locality: Egypt.

Synonyms: Eryx thebaicus Reuss (1834); Eryx scutata Gray (1842); Eryx jaculus var. sennaariensis Jan (1863); Eryx thebaicus loveridgei Stull (1932); Eryx rufescens Ahl (1933). The eastern Africa form is usually recognized as a distinct subspecies, loveridgei (Stimson, 1969).

Objective genus group relations: Anguis colubrina Linnaeus (1758) for Neogongylophis Tokar (1989), by original designation.

Geographic range: Northern and eastern Africa; Arabia.

Remarks: Unfortunately, Jan's type of sennaariensis, from Sennar, Sudan, was lost when the Museo Civico di Storia Naturale, Milano, was destroyed during World War II (L. Cagnolaro, pesonal communication). Jan's illustration of sennaariensis is not particularly helpful in establishing that taxon's relationships because the drawings exhibit the following peculiar combination of features not found in any erycine population I have studied: (1) small interocular scales, (2) smooth dorsal body scales, (3) a mental groove, with asymmetrical small scales on either side, (4) wide ventrals, (5) pointed tail and (6) uniform colour pattern consisting of a dark background and small white spots. Features 1,4 and 5 are characteristic of all colubrina, and 6 is vaguely similar to the pattern present in more southern and eastern individuals of colubrina, to which the name rufescens has been applied. Features 2 and 3 are not found in colubrina; however, the asymmetry of the small chin shields is characteristic of all erycines without a mental groove, including colubrina. I am inclined to interpret features 2 and 3 as artistic errors. Therefore, on the slim weight of anatomical evidence, sennaariensis is tentatively referred to the synonymy of colubrina [see also Boulenger (1893)]. However, it may be significant that Sennar, Sudan, is also the type locality of muelleri, a species which is similar to colubrina.

conica

Boa Conica Schneider, 1801, Hist. Amph., 2: 268.

Syntype: ZMB 1470 (second syntype not traced).

Type locality: Tronquebar [Tranquebar, Tanjore district, SE Madras], India. Synonyms: Boa Viperina Shaw (1802); Boa ornata Daudin (1803); Eryx 
bengalensis Guerin-Meneville (1830); Eryx conicus brevis Deraniyagala (1951). The Sri Lankan form, brevis, is usually recognized as a distinct subspecies (Welch, 1988).

Objective genus group relations: Boa Conica Schneider (1801) for Gongylophis Wagler (1830), by subsequent designation (Fitzinger, 1843).

Geographic range: Pakistan; India; Sri Lanka.

\section{elegans}

Cusoria elegans Gray, 1849, Cat. Snakes Brit. Mus., p. 107.

Holotype: BMNH 43.7.21.70.

Type locality: Afghanistan.

Synonyms: Eryx jaculus czarewskii Nikolsky (1916).

Objective genus group relations: Cusoria elegans Gray (1849) for Cusoria Gray (1849), by monotypy.

Geographic range: Turkmenia (U.S.S.R.); north-eastern Iran; Afghanistan; northwestern India.

jaculus

Anguis jaculus Linnaeus, 1758, Syst. Nat., 10th Ed., 1, p. 228.

Type: Presumed lost.

Type locality: Egypt.

Synonyms: Anguis Cerastes Linnaeus (1758); Boa turcica Olivier (1801); Eryx familiaris Eichwald (1831); Eryx jaculus var. teherana Jan (1865); Eryx jaculus proprius Carevsky (1916); Eryx jaculus urmianus Rostombekov (1928). In addition to the nominate form, two subspecies, familiaris and turcicus, are usually recognized (Welch, 1983).

Objective genus group relations: Boa turcica Olivier (1801) for Eryx Daudin (1803), by subsequent designation (Fitzinger, 1843).

Geographic range: South-eastern Europe; south-western Asia; North Africa.

$$
\text { jayakari }
$$

Eryx Jayakari Boulenger, 1888, Ann. Mag. Nat. Hist., ser. 6, 2: 508.

Holotype: BMNH 1946.1.7.99.

Type locality: Muscat.

Synonyms: Eryx fodiens Annandale (1913).

Objective genus group relations: Eryx jayakari Boulenger (1888) for Pseudogongylophis Tokar (1989).

Geographic range: Southern Saudi Arabia north to southern Hejaz in the west and to Kuwait in the east.

$$
\text { johnii }
$$

Boa Johnii Russell, 1801, Indian Serp., 2: 18.

Type: Not traced.

Type locality: Tranquebar (Tanjore district, SE Madras), India.

Synonyms: Boa Anguiformis Schneider (1801); Tortrix eryx indicus Schlegel (1837); Eryx maculatus Hallowell (1849); Eryx persicus Nikolsky (1907). More western populations are usually referred to the subspecies persicus (Welch, 1983). 
Objective genus group relations: Boa Anguiformis Schneider (1801) for Clothonia Daudin (1803), by monotypy.

Geographic range: Iran; Pakistan; India.

\section{miliaris}

Anguis miliaris Pallas, 1773, Reise Versch. Prov. Russ. Reich., 2: 718.

Holotype: Presumed lost.

Type locality: near the Caspian Sea.

Synonyms: Anguis helluo Pallas (1814); Eryx miliaris var. koslowi Bedgriaga (1907); Eryx miliaris var. roborowskii Bedriaga (1907); Eryx miliaris nogaiorum Nikolsky (1910); Eryx miliaris rarus Carevsky (1916); Eryx miliaris tritus Carevsky (1916); Eryx miliaris incerta Carevsky (1916); Eryx tataricus bogdanovi Carevsky (1916); Eryx rickmersi Werner (1930).

Geographic range: North coast of the Caspian Sea, east through Kazakh to western Inner Mongolia, south to Turkmenia and Afghanistan.

Remarks: Ross and Marzec (1990) recognized the black sand boa, Eryx miliaris nogaiorum, as a distinct species; however, they gave no reference to document that change in status.

muelleri

Gongylophis Muelleri Boulenger, 1892, Ann. Mag. Nat. Hist., ser. 6, 9: 74.

Holotype: BMNH 91.11.20.2.

Type locality: Sennar, Sudan.

Synonyms: Eryse muelleri subniger Angel (1938). In addition to the nominate form, subniger is usually recognized as a subspecies [Stimson, 1969; see however, Welch (1982)].

Geographic range: West Africa to the Sudan.

\section{reinhardtii}

Eryx reinhardtii Schlegel, 1851, Bijdr. Dierk., 1: 2.

Holotype: Probably Leiden Museum.

Type locality: "Gold Coast".

Synonyms: Calabaria fusca Gray (1858); Rhoptrura Petiti Sauvage (1884).

Objective genus group relations: Calabaria fusca Gray (1858) for Calabaria Gray (1858), by monotypy; Eryx reinhardtii Schlegel (1851) for Rhoptrura Peters (1858), by monotypy.

Geographic range: Mostly forested regions, from Liberia in the west to Cameroun (including Fernando Po); Gabon and Zaire, east almost to Lake Kivu.

somalicus

Eryx somalicus Scortecci, 1939, Ann. Mus. Giv. Stor. Nat. Giacomo Doria, Genova, 58: 269.

Syntypes: Not traced (possibly in Museo Civico di Storia Naturale, Milano). 
Type locality: Mahaddei Wen and Mogadiscio neighbourhood, Somalia.

Geographic range: Somali Republic.

\section{tatarica}

Boa tatarica Lichtenstein, 1823, Verz. Doubl. Zool. Mus. Berlin, p. 104.

Type: Not traced.

Type locality: Tataria.

Synonyms: Eryx speciosus Carevsky (1916); Eryx tataricus vittatus Chernov (1959). In addition to the nominate form, two subspecies, speciosus and vitlatus, are usually recognized (Stimson, 1969; Welch, 1988).

Geographic range: Kazakh; central Asia; western China; Iran; Afghanistan; north-western West Pakistan.

Remarks: Bimodal variation in the skeletal material catalogued as tatarica suggests the presence of two taxa. Numbers of pterygoid (4 or 7$)$ and dentary (13 or 16) teeth provide the most obvious distinctions (Appendix I). IZANU 4152 (from Tadzhik), 4153 and 4155 (eastern Kazakh), and UMMZ 190414 (no data) represent the low tooth number form, which I refer to as tatarica $\mathrm{A}$, while IZANU 4154 (Tashkent) and NMB 17538 ('southern U.S.S.R.') represent the high tooth number lineage, which I call tatarica $B$. It is unclear which, if either, of tatarica's junior synonyms (speciosus or vittatus) might apply to the additional taxon. Tokar (1989) elevated vittatus to species rank; however, my subdivision of the specimens examined does not correspond to his entities (p. 47). A taxonomic solution is not obvious, given the limited number of skeletons at hand and the lack of obvious geographic separation in the available material (Stimson, 1969; Bannikov et al., 1977), and I am forced to use the informal tags A and B when referring to tatarica. In the character descriptions to follow, the reader can assume the two entities are indistinguishable when the name tatarica is employed without a tag.

The issue of the number of tatarica-like taxa is further complicated by NMB 17538 (skin and skull). The anterior margin of the transverse process of the premaxilla is vertical in that specimen, like bottae, reinhardtii and trivirgata, whereas it is horizontal in all other erycines examined, including other tatarica (both A and B). The anterior labial margin of the premaxilla is not quite as high in NMB 17538 as it is in bottae, reinhardtii and trivirgata. However, the anterior surface and the dorsal edge of the premaxilla in NMB 17538 are rugose, and such ornamentation has only been observed among erycines in bottae, reinhardtii and trivirgata. Obviously, the elevated condition of the anterior margin of the transverse process of the premaxilla in NMB 17538 influenced Rieppel's (1978a: 196-198, figs 4c, 5a) placement of tatarica at the beginning of the Eryx species morphocline (see Introduction).

I consider the premaxilla of NMB 17538 to be an abnormal variant, and the premaxillary states (characters 1-5) recorded herein for tatarica $B$ are taken from IZANU 4154. My interpretation is consistent with the fact that the rostral scales on the skin of NMB 17538 appear to be unusual, highly irregular in both shape and location. A spatulate shaped rostral scale is typical of all those erycines with a horizontal anterior margin to the premaxilla (e.g. elegans, jaculus, johnii and miliaris). Further, NMB 17923 (also from 'southern U.S.S.R.') and 17538 are similar in size, scalation (other than the rostral region), and colour pattern, and 
the former specimen exhibits a horizontal transverse process of the premaxilla and a spatulate rostral scale (Rieppel, 1978a: fig. 3c).

\section{trivirgata}

Lichanura trivirgata Cope, 1861, Proc. Acad. Nat. Sci. Philadelphia, p. 304. Syntypes: ANSP 6698 and USNM 15502 (formerly 5023); [see however, Yingling (1982)].

Type locality: Cape San Lucas, Baja California.

Synonyms: Lichanura roseofusca Cope (1868); Lichanura myriolepis Cope (1868); Lichanura orcutti Stejneger (1889); Lichanura simplex Stejneger (1889); Lichanura roseofusca gracia Klauber (1931). In addition to the nominate form, two subspecies, gracia and roseofusca, are generally recognized (Yingling, 1982; Stebbins, 1985). The nature of Spiteri's (1991) new races, bostici and saslowi, have yet to be evaluated by other herpetologists.

Objective genus group relations: Lichanura trivirgata Cope (1861) for Lichanura Cope (1861), by monotypy.

Geographic range: Southern California, and north-western Arizona to the tip of Baja California and to Guaymas, Sonora, Mexico (Yingling, 1982; Stebbins, 1985).

\section{FOSSILS}

Several extinct taxa from northern Arica and Europe, Albaneryx (Middle and Upper Miocene), Bransateryx (Middle Oligocene to Lower Miocene), Cadurceryx (Middle and Upper Eocene) and Calamagras (Lower Eocene), have the specialized caudal vertebrae typical of erycines, and it is on the basis of this shared apomorphic similarity (actually a complex of traits; see characters 51-57 and Appendix II) that they have been hypothesized to be a part of the erycine clade [Hoffstetter \& Rage, 1972; Rage, 1977; Szyndlar, 1987, 1991a, b; see also Auffenberg (1963)]. In addition, Bransateryx shares two apomorphic similarities with muelleri and conica: a folded pterygoid and six palatine teeth. Szyndlar (1987: fig. 3, 1991a) used the presence of subcotylar processes to relate Bransateryx septentrionalis to Charina. However, I believe those small projections are individual variants [see also conica (CM 43833)]-occasional anterior serial expressions of the haemapophyses, which also develop from the hypapophysis. I am unaware of any living erycine that consistently exhibits subcotylar processes. Szyndlar (1987: 60) attached special significance to a 'prominent haemal knee' in a trunk vertebra of Bransateryx septentrionalis. Unfortunately, the importance of this characteristic is negated unless the vertebra can be placed exactly in the serial sequence because all erycines develop such keels in a few vertebrae in the cloacal region. Moreover, those keels vary considerably in height and width, even within species. Szyndlar's (199la, b) claim that the caudal vertebrae of Albaneryx resemble those of Lichanura requires further study [see for example Zerova (1989)]. Eryx (including Gongylophis) and cf. Eryx material have also been reported from the Miocene of Morocco and Lower Miocene to Upper Quaternary of Europe (Hoffstetter, 1961; Hoffstetter \& Rage, 1972; Szyndlar, $1991 \mathrm{a}, \mathrm{b})$.

Kluge (1988) considered trivirgata and Paraepicrates brevispondylus to be sister 
species. The latter taxon is known only from a single mid-trunk vertebra from the Eocene of North America (AMNH 3829), and the (brevispondylus, trivirgata) clade was diagnosed on the basis of the two taxa having a narrow-based neural spine and a shallow posterior notch in the neural arch. Also, the following taxa, all North American, have been referred to as erycines (Rage, 1977): Calamagras (Middle Eocene to the Lower Miocene), Charina (Middle Miocene), Helagras (Palaeocene), Huberophis (Upper Eocene), Lithophis (Middle Eocene), Ogmophis (Lower Oligocene to at least the Pliocene) and Pterygoboa (Middle Miocene). Except for the Calamagras and Ogmophis of Breithaupt \& Duvall (1986), all of these references are based on trunk vertebrae. There is considerable ontogenetic and serial variation in the morphology of vertebrae, including the specialized caudal elements. It is difficult to identify synapomorphies with any confidence in the aforementioned fossils, without being able to control for such variation (LaDuke, 1991; see also Szyndlar, 1991b: 262). Even the wide, short and shallow vertebral body said to be typical of the erycine group is not without ingroup exceptions (Rage, 1977). Therefore, I have little confidence that precise species affinities of the isolated fossil trunk vertebrae from North America can be identified, and I believe their placement in the erycine group must be tentative as well [see however, Auffenberg (1963)].

Three, virtually complete, articulated skeletons from the Oligocene of Wyoming have been referred to Calamagras and Ogmophis by Breithaupt \& Duvall (1986), and these authors unhesitatingly classified the two taxa as erycines. Unfortunately, Breithaupt and Duvall did not describe these fossils, and it is impossible to judge their claim that the specimens are erycines. Only detailed comparisons with extant erycines and Old World erycine fossils, particularly those described as Calamagras, will reveal their sister group affinities. My repeated attempts to examine the marvellous Wyoming material have been denied (B. Breithaupt, personal communication).

\section{METHODS AND MATERIALS}

The same methods used in my investigation of boine and pythonine phylogeny (Kluge, 1991, ms) are employed in this study. I adopt the principles of cladistics: special similarity (Farris, 1977: 836), monophyly (Hennig, 1966), and character congruence (Kluge, 1989). Further, I do not prejudge the phylogenetic informativeness of relevant classes of characters by differential exclusion. Rather, I pursue the ideal of total evidence, which in a practical sense amounts to seeking the best fitting cladogram for a data matrix consisting of all available evidence (Kluge, 1989). Additions and corrections to the matrix are expected, and hopefully subsequent cycles of research concerning erycine phylogeny (Kluge, 1991) will focus on that enlarged and refined body of data.

I began my search for evidence on erycine relationships with a review of the literature. The following articles provided background information on many potential characters: Zacharias (1897), Beddard (1904, 1906), H. M. Smith \& Warner (1948), Bellairs \& Boyd (1950), Johnson (1955), Hoffstetter (1962, 1968), Gasc (1974, 1981), Kamal \& Hammouda (1965), Underwood (1967, 1976), Langebartel (1968), Hoffstetter \& Gasc (1969), McDowell (1972, 1975, 1987), Rage (1972), Rieppel (1976, 1977, 1978a, 1979a-d, 1980, 1987, 1988), 
Groombridge (1979a-c, 1984), Bellairs \& Kamal (1981), Jayne (1982), Shine (1985), and Tokar (1989). Genetic distances [e.g. Dessaurer et al. (1987)] were rejected because they cannot be analysed in terms of character congruence and total evidence (see above). Relatively conservative and independent characters with few discrete states were sought, and autapomorphies were excluded. The informative characters are summarized below in the appproximate order in which I found it convenient to observe them and score their states in the data matrix (Appendix II).

Synapomorphies were sought at three levels of taxonomic generality: among erycines, erycines as a group, and erycines and relevant outgroups (see below). The results of the latter survey will be published elsewhere. Homology is dealt with only indirectly by character congruence, the ultimate arbiter of character history (Patterson, 1982). The anatomical nomenclature employed follows that of Frazzetta (1959, 1966, 1975), Hoffstetter \& Gasc (1969), Bellairs \& Kamal (1981), Szyndlar (1987), Cundall \& Irish (1989) and Kluge (1991).

It is difficult to judge the states of a continuously varying qualitative character (e.g. characters 14 and 66), and representative species have to be in hand to be able to appreciate the subtle discontinuities that occur between the conditions recognized. A quantitative character can also present a coding problem because numerous states are evident in the variation. Often, that number is greater than phylogenetic inference software will allow (0-9 states), and stands in sharp contrast to the binary subdivision of most qualitative variables. I employ four quantitative characters in the present study, the number of maxillary (character 13), palatine (37), pterygoid (42) and dentary (50) teeth, which have the following observed ranges of variation among erycines: 7-21, 0-6, 0-16 and 10-21, respectively (Appendix I). Even using the mode, or median, number of teeth to characterize each erycine species, there are spans of $11,7,14$ and 9 integers, respectively. As an objective basis for their recoding, I use a character's pooled within-group standard deviation (times three) to define the interval to which an integer state is applied (Farris, 1990). Only samples greater than 10 are analysed, and the coefficient of variation is required to adjust for a significant relationship between mean and variance. The interval is three for all four characters, and it is initialized at zero for each variable.

The skeletal material examined in the present study is listed in Appendix IV. Repository abbreviations are AMNH: American Museum of Natural History, New York; ANSP: Academy of Natural Sciences, Philadelphia; BMNH: Natural History Museum, London; CAS: California Academy of Sciences, San Francisco; CM: Carnegie Museum, Pittsburgh; FMNH: Field Museum of Natural History, Chicago; HGD: Herndon G. Dowling, personal collection; IZANU: Zoological Museum, Schmalhausen Institute of Zoology, Ukrainian Academy of Sciences, Kiev; MCZ: Museum of Comparative Zoology, Harvard University, Cambridge, Massachusetts; MHNP: Muséum National d'Histoire naturelle, Paris; MVZ: Museum of Vertebrate Zoology, University of California, Berkeley; MZUF: Museo Zoologico de "La Specola", Museo di Storia Naturale, Universita degli Studi di Firenze; NMB: Naturhistorisches Museum Basel; SDSNH: San Diego Natural History Museum, San Diego; UF: Florida Museum of Natural History, University of Florida, Gainesville; UMMZ: Univesity of Michigan Museum of Zoology, Ann Arbor; USNM: United States National Museum, Washington, D.C.; ZMB: Zoologisches Museum, Berlin. 
The outgroup criterion (Farris, 1982; Maddison et al., 1984) was used to infer polarity, and I was successful in discovering an unambiguous hypothesis of plesiomorphy for most characters (only nos 12, 17, 21, 42, 46, 49, 63, 71 and 73 remain unpolarized). The outgroup taxa, all parts of the Alethinophidia (sensu Rieppel, 1988), that were examined are listed in Kluge (1991, ms). I use the informal term booids (not of Rieppel, 1988) in the text to follow, which can be taken to mean all alethinophians, except erycines and caenophidians. The binominal nomenclature for pythonines follows Underwood \& Stimson (1990), even though major changes are anticipated (Kluge, ms). The nomenclature for boines is from Kluge (1991), and that of other non-erycine booids from Stimson (1969).

I do not accept Rieppel's (1978a: 202) use of Marx \& Rabb's (1970: 531) 'Morphological specialization' criterion for determining polarity because that rule requires hypotheses of adaptive specialization which are difficult to evaluate critically. I did not discard unpolarized characters because all matches can count in the application of parsimony algorithms (Donoghue, 1990). Some aspects of the snake phenotype are subject to considerable ontogenetic variation (Kluge, 1989), the increasing size of bony crests and processes being the most obviously correlated with age. In the absence of developmental series of erycines (some newborn and juvenile specimens of bottae, colubrina and jaculus were available), I have accepted the largest individuals available for each taxon as comparable semaphoronts.

According to my preliminary study (Fig. 1; Kluge, 1991: fig. 4), the relationships of erycines are not completely resolved. In terms of the strict consensus of the best fitting hypotheses, that lineage is the sister group of the (boine, pythonine), (tropidophiine (bolyeriine (Acrochordus, higher snakes))), or ((boine, pythonine) (tropidophiine (bolyeriine (Acrochordus, higher snakes)))) clades.* Thus, the (boine, pythonine) and (tropidophiine (bolyeriine (Acrochordus, higher snakes))) assemblages share equally, as the first outgroup, in estimating the plesiomorphic state in erycines. In order to simplify the following text, the (tropidophiine (bolyeriine (Acrochordus, higher snakes))) lineage may be referred to as the "advanced snake" clade. My preliminary research on the higher classification of snakes also indicated that Loxocemus, Xenopeltis and (Anilius (Cylindrophis, uropeltines)) are the second, third and fourth outgroups of erycines, respectively. The (Anilius (Cylindrophis, uropeltines)) clade is usually abbreviated as anilioids in the text to follow, and it does not include Anomochilus (see review by Cadle et al., 1990). The hypothesized common ancestral state of the advanced snake clade was usually a function of the condition observed in bolyeriines (Bolyeria, Casarea) and tropidophiines ((Exiliboa, Ungaliophis) (Trachyboa, Tropidophis)), rarely Acrochordus, and never higher snakes (caenophidians of some authors; e.g. Underwood, 1967). Also, in my preliminary study, Aspidiles was judged to be the sister lineage of all other pythonines, and Morelia spilota and $M$. viridis the most apomorphic sister group within pythonines. The complicated dichotomous and trichotomous pattern of booid relationships discovered in my preliminary study requires that polarity be estimated on a character-by-

\footnotetext{
* The content of the higher snake group follows Marx \& Rabb's definition of colubroid [1970; see also Rieppel (1988)].
} 
character basis, and therefore a brief statement of outgroup variation is included in each of the following character descriptions. The inferred common ancestral condition is listed in the data matrix (Appendix II), and ? is recorded when polarity is ambiguous.

Rieppel (1978a: 202) claimed that 'almost all characters in the skull of the genus Eryx correlated with burrowing habits can be shown to exhibit linear oriented changes' (presumably an orthogenetic history). In order to test Rieppel's hypothesis, I treat all multistate characters as non-additive. However, only those synapomorphies unambiguously diagnostic of the same clade under both assumptions of additivity and non-additivity are interpreted as homologues. As a corollary, I purposely avoid discussing characters that cannot be optimized unambiguously because their phylogenetic informativeness is undecided.

All cladistic analyses are performed with Farris' (1988) phylogenetic inference software, Hennig86. The exact 'implicit enumeration' (ie) algorithm is used to find the best-fitting phylogenetic hypotheses. Fit to data is measured in terms of consistency and retention indices. Character consistency, $c$, is defined as $\mathrm{m} / \mathrm{s}$, where $s$ is the minimum number of steps a character can exhibit on a particular tree hypothesis, and $m$ is the minimum number of steps that character can show on any tree hypothesis (Kluge \& Farris, 1969). Character retention, $r$, is defined as $(g-s) /(g-m)$, where $g$ is the greatest number of steps a character can have on any tree (Farris, 1989; Seberg, 1989; Steve Farris, personal communication). The ensemble consistency, $C$, and ensemble retention, $R$, indices are simply the quantities for a single character, $m, g$ and $s$, summed over all characters in the matrix, thus yielding corresponding totals, $M, G$ and $S$. Therefore, $C=M / S$, and $R=(G-S) /(G-M)$.

The successive weighting algorithm (xs w) in Hennig86 is based on the concept of 'cladistic reliability' (Farris, 1969: 374)-those characters which are highly consistent are given the most weight. Platnick's (1989: 149; see also Carpenter, 1988) reason for using this weighting technique, "to determine which of the equally parsimonious cladograms found are best supported by the most consistent characters", does not take account of the fact that $x s w$ can lead, if only rarely, to a novel branching pattern (Farris, 1969). In other words, xs $w$ is employed for accuracy, not precision. In successive weighting, a character's weight is the product of its rescaled consistency and retention indices (times 10), where the smallest $s$ is used [not the 'average value' (Carpenter, 1988: 292)]. The effectiveness of this weighting procedure, in finding the cladogram(s) supported by the most cladistically reliable characters, is owing to the fact that it closely approximates a concave bounded function (see Farris, 1969: fig. 4). In the present study, successive weighting is applied to additive multistate characters that have undergone additive binary coding so that each step in the data matrix is evaluated separately (Farris, 1969: 382; see also Carpenter, 1988: 294-295). Unfortunately, efficient parsimony algorithms are unavailable for analysing multistate characters that have been non-additively coded (Sankoff \& Rousseau, 1975), and therefore successive weighting is not performed on that class of data. Swofford \& Olsen's (1990: 499-500) negative comments concerning the a posteriori, successive approximations, form of weighting used herein seem to be ill-founded (Farris et al., ms). In any case, Swofford \& Olsen's (p. 499) 'extreme [counter] example' does not relate to the $x s w$ algorithm. 


\section{ERYGINE PHYLOGENY}

\section{Character descriptions}

The following 75 characters are employed in my study erycine phylogeny (Appendices I-II, Figs 2-16). Characters 1-57 are skeletal in nature, and the remainder concern various aspects of the external and internal soft anatomy. There are 51 binary (nos $1-4,7-10,12,16-17,19,21-28,30-32,34-35,38-41$, 46-49, 51-56, 59, 61-64, 67-69, and 72-75), 21 three-state (nos 5-6, 11, 14-15, $18,20,29,33,36-37,43-45,57-58,60,65-66$, and 70-71), two four-state (nos 13 and 50) and one five-state (no. 42) characters. While four states are recognized in character 50, a minimum of only two steps is possible because no taxon unequivocally exhibits state 3 . Therefore, the total size $(M)$ of the data set is 102. The hypothesized histories of three state characters 18,57 and 66 are coded in an unusual manner; state 1 is hypothesized to be plesiomorphic, states 0 and 2 independently derived apomorphs. Ambiguous variation within the ingroup terminal taxa is described in the character descriptions; except for certain teeth characters, 13, 42 and 50, ambiguity is not recorded in Appendix II.

(1) Premaxilla: A conspicuously vertical anterior margin of the transverse process of the premaxilla (Frazzetta, 1975: fig. 3) is absent (0) or present (1). The premaxilla of bottae, reinhardtii and trivirgata (see Kluge, 1991: fig. 9, and Rieppel, 1978a: figs 11-13) not only have an obvious vertical anterior margin (Fig. 2), but the outer surface and dorsal edge of the lamina are irregular in appearance. Among the outgroups, a vertically oriented margin characterizes the boine (Kluge, 1991, character 3) and advanced snake clades; however, the lamina is always shallow, and none (except Exiliboa) have an irregular outer surface and dorsal edge. Pythonines have no elevated margin, and a lamina is weakly developed, if present at all, in Loxocemus and Xenopeltis. Therefore, I assume state 0 is plesiomorphic in erycines. This character and number 60 may not be independent.

(2) Premaxilla: The general outline of the anterior margin of the transverse process of the
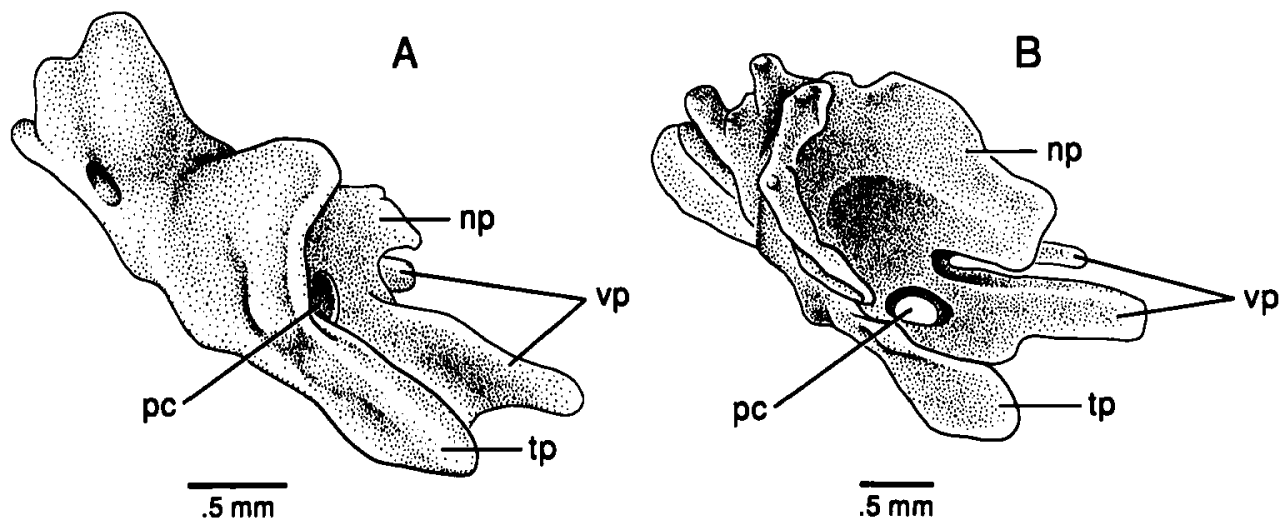

Figure 2. Left anterodorsal view of the premaxilla of representative erycines. A, reinhardtii; UMMZ 149642 (incorrectly labelled in Kluge, 1991: fig. 9). B, trivirgata; UMMZ 189644. np= nasal process; $\mathrm{pc}=$ premaxilla channel; $\mathrm{t} \mathrm{p}=$ transverse process; $\mathrm{vp}=$ vomerine process. 
premaxilla (Frazzetta, 1975: fig. 3) is gently rounded (0) or more nearly straight to broadly concave (1). The fact that the nasals often overlap the premaxilla anteriorly requires that this variation be observed from a ventral view, and I emphasize that it is the outline of the anteromost margin that is at issue. Even though the margin of the premaxilla in bottae, reinhardtii and trivirgata is irregular, its appearance is obviously curved. Some erycines have a small indentation on the midline (e.g. elegans and muelleri); however, this does not constitute a broad concavity (Rieppel, 1978a: fig. 4). There is usually a tiny anterodorsal projection on the midline that inserts between the nasals of jaculus and johnii (see, however, Rieppel, 1978a: fig. 2c); the process may be absent in smaller individuals. The 0 state characterizes all of the booids examined, and $I$ assume it is the plesiomorphic condition in erycines.

(3) Premaxilla: The transverse process of the premaxilla (Frazzetta, 1975: fig. 3) is short (0) or long (1). The transverse process usually extends laterally, far beyond the anterior tip of the maxilla in state 1 (Rieppel, 1978a: fig. 4); somalicus cannot be scored because both processes appear to be broken in the only available skeleton. Boines (Kluge, 1991, character 4) and pythonines cannot be characterized unambiguously; however, the plesiomorphic condition in advanced snakes appears to be state 0 (Trachyboa may be an exception). The fact that state 0 also applies to anilioids, Loxocemus and Xenopeltis suggests that a short process is plesiomorphic in erycines.

(4) Premaxilla: The internarial septum of the premaxilla (Kluge, 1991) is present (0) or absent (1). As I indicated elsewhere (Kluge, 1991: 21), the internarial septum is not to be confused with the nasal septum of the premaxilla, which is a chondrocranial element (Bellairs \& Kamal, 1981). The internarial septum is formed by the ascending and nasal processes of the premaxilla (Frazzetta, 1959, 1975). The premaxilla should be removed from the skull to be certain that the septum is absent. In erycines, state 1 may consist of a wide, mound-like process, but it never achieves much height or length (Rieppel, 1978a: figs 5, 10-13). Among the booids, a conspicuous internarial septum is present in boines (Kluge, 1991, character 6) and a few tropidophiines (Exiliboa and Ungaliophis). A septum is present, but much less well developed, in pythonines (except Aspidites), the remainder of the tropidophiines, bolyeriines (see however, Anthony \& Guibé, 1952: figs 2, 4, and Rieppel, 1987b: fig. 6), Loxocemus and Xenopeltis. Therefore, I assume the presence of a septum is plesiomorphic in erycines.

(5) Premaxilla: The nasal process of the premaxilla (Frazzetta, 1959: fig. 3) is long (0), short (1), or absent (2). In examples of state 0 , the process originates from the ascending of transverse processes and projects far posteriorly beneath or between the nasals, whereas in state 2 only a broad mound or narrow ridge of bone originates from the floor of the premaxilla (Rieppel, 1978a: figs 10, 12-13; Kluge, 1991: 21), and that protuberance is not set off from it as a separate process (Fig. 2). State 1 consists of a short, but nonetheless distinct, nasal process which originates from the transverse processes, and it usually abuts the nasals. Given these descriptions, bottae, reinhardtii and trivirgata are very similar. State 0 characterizes advanced snakes (except Exiliboa and Ungaliophis, which exhibit state 1), Loxocemus, pythonines and Xenopeltis. The nasal process in boines is considerably shorter than it is in pythonines, and unlike that taxon the process usually abuts the nasal lamina, rather than insert between the nasals. While a shortened nasal process may describe boines (Kluge, 1991, character 8 ) and 
erycines, the process in boines is longer and taller than in any erycine. Therefore, I consider state 0 to be plesiomorphic relative to the states observed in erycines.

(6) Premaxilla: The vomerine processes of the premaxilla (Kluge, 1991: fig. 9; the palatine processes of Frazzetta, 1959: fig. 3) are short and wide (0), of modest length (1), or long and narrow (2). The processes are often broken when the skull is prepared by hand, and a broad nasal process may also make character state determination particularly difficult because it obscures the origin of the vomerine process from the floor of the premaxilla (Rieppel, 1978a: figs 2, 4-5, 10, 12-13). The processes in both muelleri skulls are nearly identical to the condition observed in trivirgata, and accordingly the two taxa are scored as having the same state $(0)$. Among the booids, the vomerine processes are short and wide in bolyeriines and tropidophiines, somewhat longer, but wide, in most boines (Kluge, 1991, character 10; see also Underwood, 1976, character 38), Loxocemus and Xenopeltis, and long and narrow in most pythonines. Therefore, the short and wide condition is tentatively accepted as plesiomorphic in erycines.

(7) Nasal: The anterior one-third to one-half of the ventral lamina of the nasal (Underwood, 1976: 158; see also Rieppel, 1978a: figs 5, 10-13; Kluge, 1991: 21) is nearly uniform in depth (0) or it decreases anteriorly and may be absent altogether (1). This variable may not be independent of character 8 . All outgroups have a nasal lamina which is deep anteriorly. While the nasal turns downward in Aspidites, the lamina itself seems to maintain its depth in that region. Therefore, I assume state 0 is plesiomorphic in erycines.

(8) Nasal: The anterior end of the horizontal lamina of the nasal (Kluge, 1991: 22), as seen from a dorsal view, gradually narrows (0) or slightly or markedly expands (1) at the tip. Underwood (1976: 157) referred to the horizontal lamina as the wing of the nasal. Among booids, state 1 occurs only in Aspidites, and therefore I assume the narrow condition is plesiomorphic in erycines. This variable may not be independent of character 7.

(9) Nasal: A slight notch (Underwood, 1976: fig. 1A) is present (0) or absent (1) between the anterior ends of the horizontal laminae of the nasals (Kluge, 1991: 22-23). The nasals exhibit a straight anterior margin in state 1; there is little or no indentation where the two bones meet. In some species scored as state l (e.g. johnii), the nasals may actually project beyond the anterior edge of the transverse process of the premaxilla. The nasals seem to be separated by some part of the premaxilla in all booids, which creates the impression of the notched condition, and therefore $I$ assume state 0 is plesiomorphic in erycines.

(10) Nasal: The anterolateral edge of the horizontal lamina of the nasal (Kluge, 1991: 22-23), as seen in dorsolateral view, is gently rounded (0) or bulges outward (1). The condition in johnii and somalicus does not involve an outward bulge, as it does in the other Eryx and Gongylophis. In johnii, the bulge may be obscured by the well developed notch located immediately above the spatulate portion of the nasal (character 8 , state 1). The bulge is weakly developed in small conica, but conspicuous in large individuals of that species, which suggests there is a strong ontogenetic component to the variation in this character. The inconspicuous nature of the bulge in somalicus may be due to the fact that the only available skull of that species is small. No member of the outgroup exhibits an inflated anterolateral margin of the nasal, and I conclude state 0 is plesiomorphic in erycines.

(11) Nasal: The lateroposterior margin of the horizontal lamina of the nasal (Kluge, 
1991: 22-23), adjacent to the prefrontal, is nearly horizontal (0), or it is oriented vertically in the form of a small (1) or large (2) wall. State 2 is usually characterized by a posteriorly directed hook-like process (Rieppel, 1978a: figs 5, 10). The process could have been scored as a separate character; however, it can also be considered a correlate of having a larger wall. State 2 can be seen projecting laterally below the level of the prefrontal. A few bottae exhibit a tiny vertical plate, but it seems to be a product of the prefrontal overlaying the nasal (Rieppel, 1978a: fig. 12). States 1 and 2 appear to strengthen the nasalprefrontal contact. All booids, except Aspidites melanocephalus, have an unmodified horizontal dorsal lamina opposite the prefrontal, and therefore state 0 is assumed to be plesiomorphic in erycines.

(12) Nasal: The posterior margin of the horizontal lamina of the nasal (Kluge, 1991: 22-23), adjacent to the midline, is straight (0) or forms a short to long posterior process (1). A dorsal view provides the best perspective from which to judge the states of this character (Underwood, 1976: fig. 1). The length of the process varies intraspecifically, and therefore no attempt was made to divide that variation into additional states. The condition in boines and pythonines is scored as $\mathrm{N}$ because those two taxa share a narrow posterior margin of the nasal which makes it impossible to distinguish states 0 and 1 . Bolyeriines and tropidophiines (except Trachyboa) exhibit state 0 , and therefore the advanced snake clade is assumed to be diagnosed by that evolutionary reversal. Loxocemus and Xenopeltis possess state 1, whereas anilioids appear to be variable $(0$ in Cylindrophis and 1 in Anilius). Therefore, the polarity of this character in erycines is ambiguous.

(13) Maxilla: The model, or median, number of adult maxillary teeth is 18 or more (0), $17-15$ (1), 14-12 (2), or 11-9 (3). The number of maxillary teeth in tatarica is either 10 (form A) or 13 (form B). The only available skull of somalicus is without maxillae, and I accept Rieppel's (1978a: 188) claim that nine teeth occur in that species. My observations on variation in number of teeth in erycines is summarized in Appendix I, which do not always agree with those of other authors (e.g. Underwood, 1976, and Rieppel, 1978a). This character is equivalent to Underwood's (1976) character 52. The following summarizes outgroup variation: all boines, except Epicrates fordii, exhibit state 0 (Kluge, 1991); the simplest interpretation is that state 0 also characterizes pythonines, with lower numbers having evolved independently in only a few species, Aspidites melanocephalus (15), Morelia amethistina (16), M. carinatus (15), M. oenpelliensis (16-17) and $M$. papuanus (15); likewise, the advanced snake clade also appears to be characterized by state 0 , with Trachyboa boulengeri (15), Tropidophis haetianus (14) and Ungaliophis continentalis (13) being most simply interpreted as independently evolved exceptions; both Loxocemus and Xenopeltis exhibit state 0. Therefore, I assume that 17 or more teeth is plesiomorphic in erycines.

(14) Prefrontal: The anterolateral lamina of the prefrontal is large (0), of modest size (1), or small to nearly absent (2). Lamina size refers to depth, and it is estimated, when viewed laterally, from the amount of space between the ventrolateral shelf of the prefrontal (Frazzetta, 1966: fig. 18) and the dorsal edge of the maxilla, and the amount of the prefrontal that is in contact with the maxilla (Fig. 3). In states 1 and 2, there is an increase in the angle formed by the ventral edge of the prefrontal, relative to the horizontal plane. The lateral and medial foot processes of the prefrontal (Frazzetta, 1966: fig. 18) are only loosely connected to the maxilla in erycines, and the latter bone can be moved easily in all species, except 

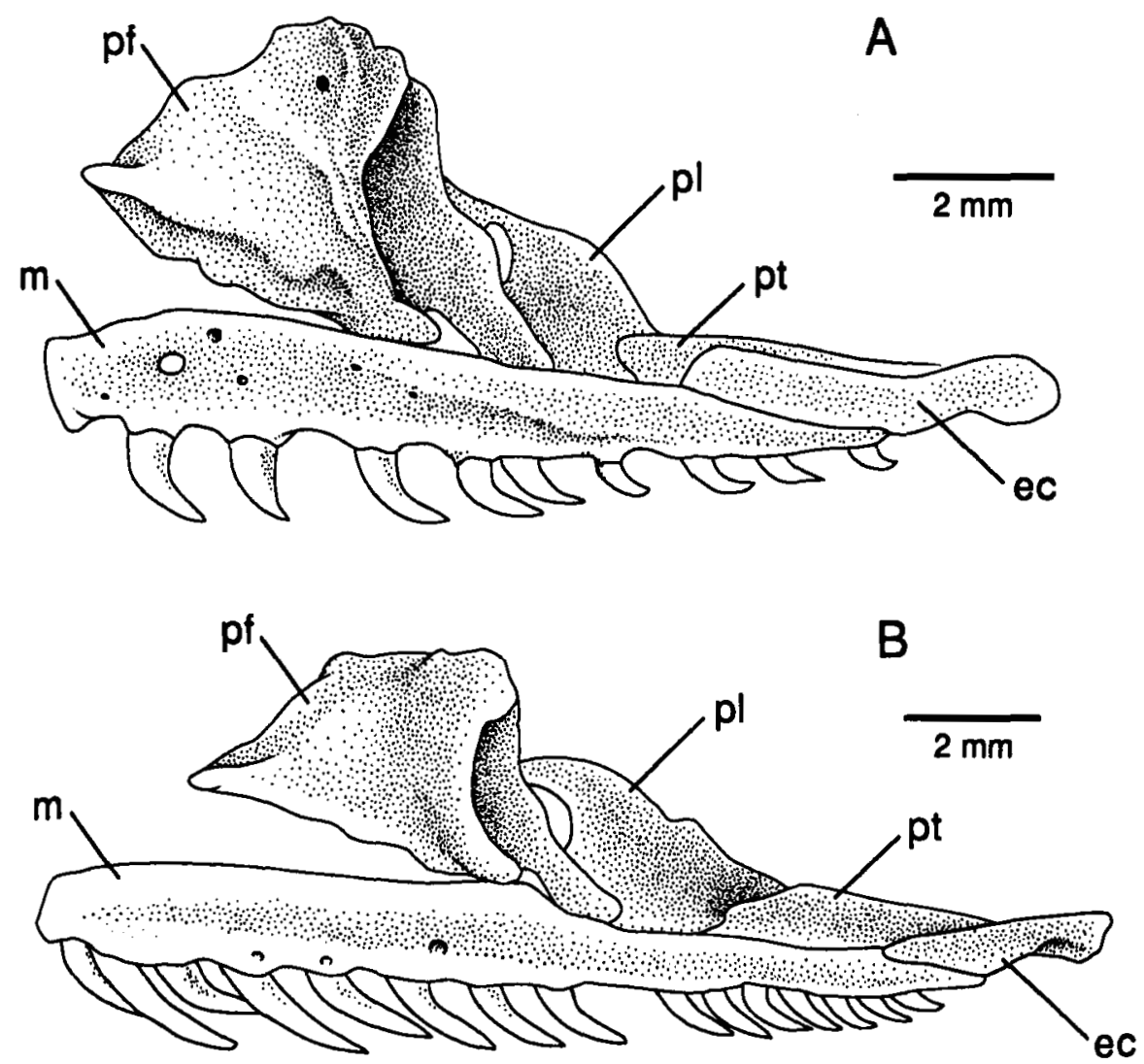

Figure 3. Left lateral view of the prefrontal and maxilla (in situ) of representative erycines. A, reinhardtii; UMMZ 149642. B, trivirgata; UMMZ 189644. ec = ectopterygoid; $m=$ maxilla; pf $=$ prefrontal; $\mathrm{pl}=$ palatine; $\mathbf{p t}=$ pterygoid.

bottae, reinhardtii and trivirgata. Every effort must be taken to insure that the prefrontal is in its natural position, with respect to the maxilla, when assessing this character. Further, the ventrolateral shelf is larger in reinhardtii than in almost all other snakes, and the size of the shelf gives the false impression that there is little distance between the prefrontal and maxilla in that species. Throughout much of its length, the prefrontal lies close to, if not actually in contact with, the maxilla in advanced snakes, boines and pythonines. In anilioids, Loxocemus and Xenopeltis, the prefrontal rests entirely on top of the maxilla, and in most of those species the two elements are actually firmly interdigitated. Therefore, state 0 is assumed to be plesiomorphic relative to the other states observed in erycines. The close, but somewhat looser, contact between the prefrontal and maxilla appears to characterize the group consisting of advanced snakes, boines, erycines, and pythonines.

(15) Prefrontal: The dorsal lappet of the prefrontal (Frazzetta, 1966: fig. 18), the dorsolateral margin where it contacts the frontal and nasal, is slightly convex (0), approximately straight (1), or decidedly concave (2). This transformation series is best judged from a slightly dorsolateral view (see also Kluge, 1991, character 23). The concave state has a narrow pillar of bone in contact with the frontal. I 
assume the convex condition is a remnant of the situation where the dorsal lappet of the prefrontal closely approaches its counterpart on the dorsal midline (McDowell, 1975: fig. 17), as is clearly evident in boines, Loxocemus, pythonines and Xenopeltis. Therefore, I assume state 0 is plesiomorphic in erycines. The weakly developed dorsal lappet in erycines (state 0 ) also characterizes bolyeriines and tropidophiines, and provides evidence that the advanced snake and erycine lineages are sister taxa.

(16) Prefrontal: The anterolateral (see character 14) and medial laminae of the prefrontal form a sharp, nearly 90 degree angle, (0) or gradually rounded (1) corner. The medial lamina is that vertical plate of bone located between the outer and inner orbital lobes above and the lateral and medial foot processes below (Frazzetta, 1966: fig. 18). These character states can be most accurately judged from a dorsal view, when the prefrontal is removed from the skull. Only the condition of the more dorsal corner is at issue, not the edge nearer the lateral foot process which often forms a sharp angle, especially in larger individuals. State 0 is present in advanced snakes, boines and pythonines, and the presence of an outer orbital lobe (Frazzetta, 1966: fig. 18) in those taxa tends to emphasize the severity of the angle. State also occurs in Loxocemus and Xenopeltis; however, the corner is oriented posteroventrally, which makes the state more difficult to observe, and the outer orbital lobe is absent. Therefore, the simplest interpretation is that state 0 is plesiomorphic in erycines.

(17) Prefrontal: The medial lamina of the prefrontal (see character 16) narrowly (0) or broadly (1) undercuts the frontal. The variation can be observed most clearly by looking anteromedially, through the orbit. Boines and pythonines have state 1 , whereas Loxocemus and Xenopeltis possess state 0. Advanced snakes are variable, Trachyboa and Tropidophis are characterized by state 1, and Bolyeria, Casarea, Exiliboa and Ungaliophis exhibit state 0 . This pattern of variation among booids suggests an ambiguous interpretation of polarity for erycines.

(18) Frontal: The frontonasal facet (Rieppel, 1978a: 199), the place where the ventral lamina of the nasal contacts the frontal (Kluge, 1991: 24-25), is small and vertical and lies entirely between the olfactory canals (0), or the facet lies both between and below the olfactory canal and the horizontal-ventral portion of the facet is short (1) or long (2). Rieppel's (1978a) figures of the frontonasal facet (figs 9-10, 12-13) seem to show a much more complex arrangement of articulation surfaces than I can discern. I have recorded the condition in somalicus as unknown because the weakly defined facet in the only available specimen may be owing to its subadult age. Many booid taxa do not have a well defined facet (e.g. Candoia, Corallus, Exiliboa, pythonines, Ungaliophis and Xenopeltis); however, except for Trachyboa, which tends to be more like state 0 , all other outgroups are similar to state 1 [Boa (including the Madagascan B.dumerili, B. madagascariensis and B. manditra), Bolyeria, Casarea, Epicrates, Eunectes, Loxocemus and Tropidophis]. Therefore, it appears that state $l$ is the plesiomorphic condition in erycines. The saddle shaped nature of the frontonasal facet and the absence of a lateral facet for articulation with the preorbital process of the frontal (see character 19) suggest that trivirgata is the only erycine with a highly moveable frontonasal joint. Mobility of the frontonasal joint in trivirgala is further suggested by the large space between the dorsal surfaces of the frontal and nasal. These bones are closely opposed or overlap throughout most or all of their length in all other erycines. 
(19) Frontal: A facet is absent (0) or present (1) on the preorbital process of the frontal. Frazzetta (1966: fig. 11) used the term preorbital ridge rather than process for this projection. I refer to that prominence in erycines as a process because it is well developed. A small process (the ridge of Frazzetta) appears to diagnose the (boine, pythonine) clade. In erycines, the facet represents a specialized point of contact between the frontal and the nasal, and when present in adults, the facet is usually large, flat and nearly vertical. The facet is most developed in jaculus and johnii, and smallest in jayakari, muelleri and tatarica. The state was not recorded for somalicus because the only available specimen is a juvenile and unlikely to exhibit such details because of its age. With the exception of Xenopeltis, no facet was observed in those outgroups which have a well-developed preorbital process. The well developed facet in Trachyboa is not considered the same as the erycine condition because it contacts the prefrontal, not the nasal. Therefore, I assume state 0 is plesiomorphic in erycines.

(20) Frontal: The anterolateral corner of the frontal projects anteromedially (0) or anteriorly, leaving the preorbital process (see character 19) moderately exposed (1) or largely covered (2). This character must be scored from a dorsal view, with the prefrontal removed. The description attempts to characterize the extent to which the preorbital process is exposed from above, the most and least exposed being states 0 and 2 , respectively. In state 0 , there is an obvious notch between the preorbital process and the horizontal portion of the anterolateral corner of the frontal. The notch can be readily seen from an anteroposterior view. The dorsal margin of the prefrontal is wedged into the notch in state 0 , whereas the margin of the prefrontal tends to rest entirely beneath the frontal in state 2 . I believe the plesiomorphic condition in boines and pythonines is incomparable (although Aspidites is identical to state 0 ) because the preorbital process (the ridge of Frazzetta, 1966: fig. 11) is only weakly developed, and the anterolateral corner of the frontal projects laterally, rather than anteriorly above the process, in almost all of those taxa. The advanced snake clade, Loxocemus and Xenopeltis are similar to state 0 , and I assume that is the plesiomorphic condition in erycines.

(21) Supraorbital: The supraorbital is present (0) or absent (1). This is equivalent to Underwood's (1976) character 44 (his postfrontal bone). Some squamate systematists (e.g. Estes et al., 1970; McDowell, 1975: 28; Underwood, 1976: 160, 169) seem to have overlooked Haas' (1930) paper in which he presented the idea that the supraorbital is peculiar to a group of ophidians (see also Frazzetta, $1959,1966,1975)$ and not to be confused with the more general lepidosaurian postfrontal (Rieppel, 1977: fig. 18 provided additional reasons for distinguishing between these two bones). Mineralization occurs dorsal to the orbit and lateral to the frontal in a wide variety of squamates (Romer, 1956: 121). Some of these are true osteoderms, located in the dermis, while others, like the snake supraorbital, lie below the integument (Bauer \& Russell, 1989). Supraorbital variation among the outgroups (present in Loxocemus and pythonines; absent in boines, bolyeriines, tropidophiines and Xenopeltis) is such that this character cannot be polarized unambiguously. A supraorbital also occurs in Dinilysia (Estes et al., 1970: fig. 1); however, Baumeister's (1908: 61-62, figs 13, 15) described and figured 'postfrontal' in subadult uropeltid Rhinophis, which he believed became fused with the parietal later in development, could just as well be a postorbital as it is a supraorbital. M. A. Smith (1943: 103) claimed the supraorbital has been lost independently, and therefore its absence does not 
necessarily express relationships'. Presumably, Smith was underscoring the problem one has pretesting homology with similarity (Patterson, 1982) because a state of secondary loss is difficult to distinguish from one of plesiomorphic absence. The supraorbital does not contact the prefrontal in reinhardtii. While it is identical to Dinilysia in that regard, it is unlike all relevant outgroup taxa in which the bone is present. The supraorbital separates the postorbital and frontal in reinhardiii, like most taxa which have that element.

(22) Postorbital: The postorbital is long (0) or short or absent (1). The postorbital exhibits a long downward projection in state 0 ; however, it does not have to reach the ectopterygoid to be recorded as that state. The posterior end of the postorbital does not extend beyond the edge of the parietal in trivirgata, which I consider the 'short' variant of state 1. While the postorbital is absent in bottae, some specimens (e.g. CAS 28323) exhibit a stout band of unmineralized connective tissue where that bone occurs ordinarily. A long postorbital, one that is in contact with the ectopterygoid, is plesiomorphic in boines and pythonines. The postorbital and ectopterygoid contact is absent in some pythonines, Morelia albertisii, $M$. boa, and the $M$. childreni complex, but the former element is much longer than it is in trivirgata. State 0 also characterizes the advanced snake (Exiliboa being an obvious exception) and Loxocemus clades. Therefore, state 0 is assumed to be plesiomorphic in erycines.

(23) Optic Foramen: The ventral border (floor) of the optic foramen is formed by both the parietal and frontal (0) or by the parietal alone (1). All of the relevant outgroups exhibit state 0 , and therefore it is considered the plesiomorphic condition in erycines (see also character 31 in Kluge, 1991).

(24) Ectopterygoid: The lateral and medial heads on the anterior end of the ectopterygoid (Rieppel, 1979a: 547, fig. 6) are present (0) or absent (1). The ectopterygoid of reinhardtii appears to exhibit a lateral head; however, I suspect this impression is owing to its decidedly upturned anterolateral corner, more so than any other erycine, which makes broad contact with the postorbital (Fig. 4). While there is
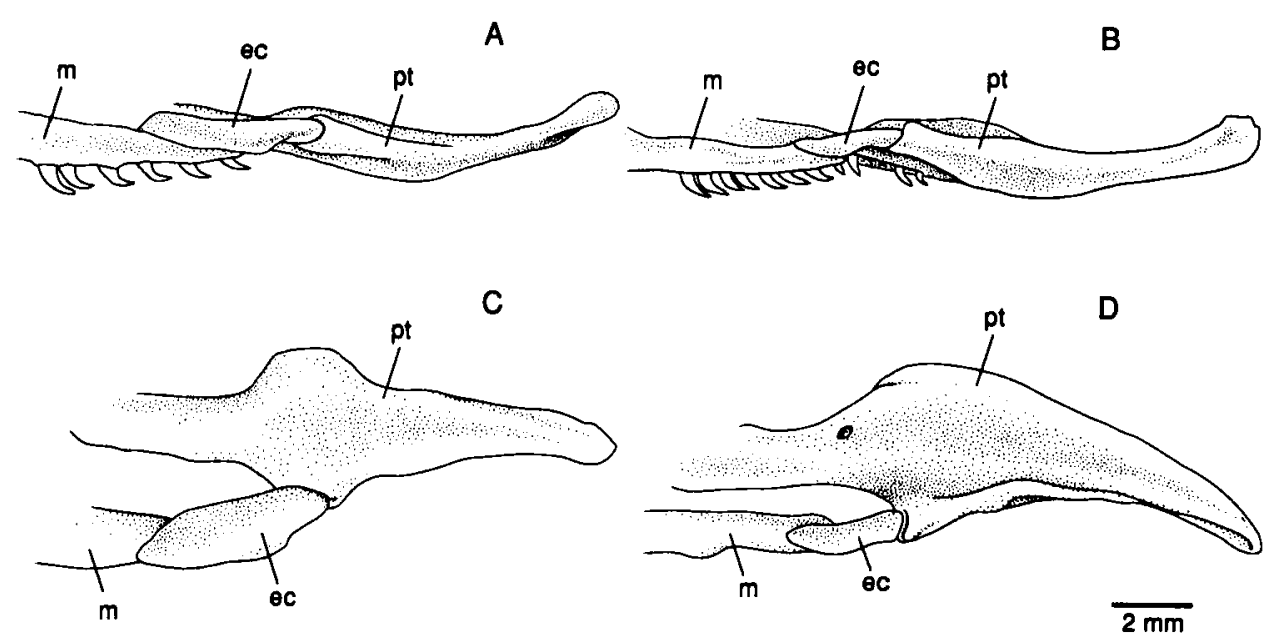

Figure 4. Lateral (A, B) and dorsal (C, D) views of the ectopterygoid and its contact with the pterygoid in representative erycines. A, C, reinhardtii; UMMZ 149642; UMMZ 183242, pterygoid only. B, D, trivirgata; UMMZ 189644. ec = ectopterygoid; $m=$ maxilla; $\mathrm{pt}=$ pterygoid. 
considerable variation among booids (Rieppel, 1979a), state 0 appears to be plesiomorphic in erycines. The single-headed state occurs in Anilius, Boa manditra, Epicrates and Eunectes (Kluge, 1991, character 32). All other boines and all pythonines (except Morelia viridis) have state 0 . Trachyboa and Tropidophis exhibit state 1; however, I consider the advanced snake clade to be characterized by state 0 because a shallow indentation occurs in the anterior end of the ectopterygoid in Exiliboa and Ungaliophis, which suggests two heads, and extremely long medial and short lateral heads occur in Bolyeria and Casarea (contra Kluge, 1991). Loxocemus has a large medial head, but no lateral projection.

(25) Ectopterygoid: The anterior end of the ectopterygoid is wide and round (0) or narrow and pointed (1). The ectopterygoid is at least as wide as the underlying maxilla in state 0 , whereas it is narrower in state 1 . In general, booids exhibit state 0, and it considered the plesiomorphic condition in erycines (Kluge, 1991: 28 ).

(26) Ectopterygoid: The posterior end of the ectopterygoid contacts the dorsal or lateral (0) or anterior (1) surface of the pterygoid. The skull, with the ectopterygoidpterygoid in situ, must be oriented horizontally to accurately determine a taxon's state (Fig. 4). There is considerable outgroup variation, often involving combinations of planes (dorsolateral is common), which is further complicated by subtle changes with age. Therefore, the following generalizations must be considered provisional because of the limited ontogenetic series available for most species. Aspidites possess a distinctly dorsal contact, while all other pythonines possess a laterally (or slightly dorsolaterally) directed joint between the two bones. All adult boines have a laterally directed facet, which I no longer consider diagnostic of that clade (Kluge, 1991, character 36). Among the advanced snakes, the contact is dorsolateral in Bolyeria and lateral in Casarea and Ungaliophis, whereas it is dorsal or anterodorsal in Exiliboa, Trachyboa and Tropidophis. Hoffstetter (1960) claimed the ectopterygoid joins the pterygoid laterally in both bolyeriine species, while McDowell (1975: 17) stated the condition in those taxa was one of dorsal overlap, similar to the caenophidian state. The joint is directed dorsolaterally in adult Loxocemus and Xenopeltis. Therefore, state 0 is assumed to be plesiomorphic in erycines.

(27) Parietal: The bulbous middle-third of the parietal (Hoffstetter $\mathcal{E}$ Rage, 1972: fig. 1) is narrow (0) or wide (1). There is considerable variation in state 0 , but the parietal is narrower than the distance between the lacrimal foramina; the alternative state is wider than the distance between those foramina (Fig. 5; Kluge, 1991, character 39). This character applies to adults only because the parietal is bulbous and relatively wide in almost all subadult snakes (Kluge, 1989). State 0 characterizes boines, pythonines, and Xenopeltis, while state 1 is typical of Loxocemus. The advanced snake clade is variable, Bolyeria [Anthony \& Guibé's (1952: fig. 4) illustration does not accurately reflect the narrow adult condition], Casarea (adult alocholic dissected; BMNH 1986.56), Trachyboa and Ungaliophis exhibit state 0, and Exiliboa and Tropidophis have state 1. Therefore, the simplest explanation is that the narrow condition, state 0 , is plesiomorphic in erycines.

(28) Parietal: The postorbital process of the parietal (Underwood, 1967: fig. 5) is absent or small (0) or large (1). A large process usually exhibits a deep cavity on its anterolateral and dorsal surfaces where the postorbital bone firmly rests. The 
A

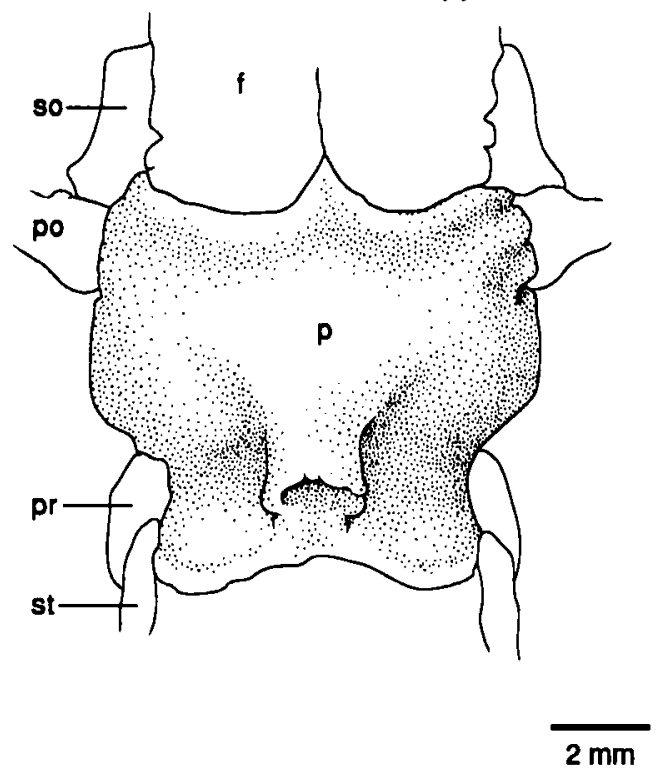

B

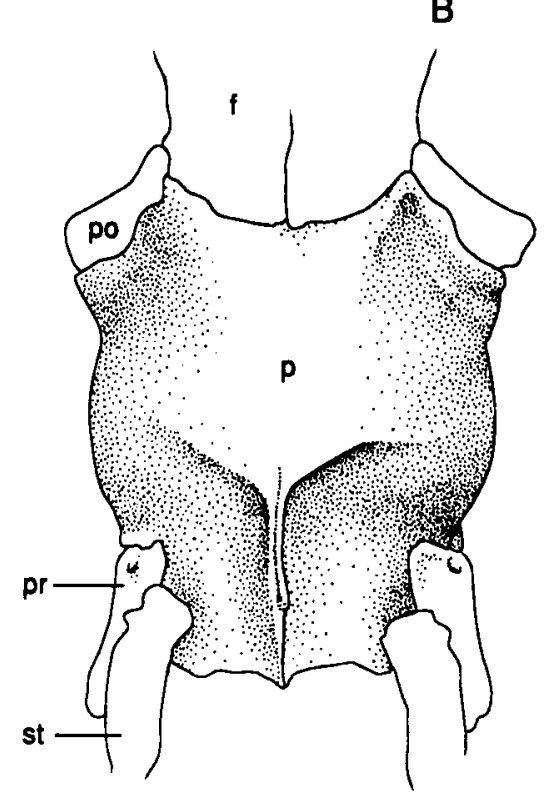

Figure 5. Dorsal view of the parietal of representative erycines. A, reinhardtii; UMMZ 149642. B, trivirgata; UMMZ 189644. $\mathrm{f}=$ frontal; $\mathrm{p}=$ parietal; po = postorbital; $\mathrm{pr}=$ prootic; so $=$ supraorbital; st = supratemporal.

process is absent in Loxocemus and Xenopeltis, small in bolyeriines, Exiliboa and Ungaliophis, and well-developed in boines (Kluge, 1991, character 40), pythonines, Trachyboa and Tropidophis. Therefore, I assume state 0 is plesiomorphic in erycines.

(29) Parietal: A midsagittal crest (Hoffstetter $\&$ Rage, 1972: fig. 5) is absent (0), or weakly (1) or markedly (2) developed on the anterior 1/3 to 1/2 of the parietal. Crest development occurs late in ontogeny in snakes (Kluge, 1989) and this character applies only to adults. Bolyeriines (adult alcoholic Casarea dissected; BMNH 1986.56), Loxocemus, tropidophiines and Xenopeltis have state 0, while boines and pythonines are variable. This distribution among the outgroups suggests the absence of a crest, state 0 , is plesiomorphic in erycines.

(30) Exoccipital: The exoccipitals are separated $(0)$ or in contact (1) on the dorsal surface of the occipital condyle (Rieppel, 1979a: fig. 8c). Gaupp (1908; see also Williams, 1959) referred to the space between the exoccipitals as the fovea dentis. The presence of a fovea dentis is characteristic of each of the relevant outgroups, and therefore it is assumed to be the plesiomorphic state in erycines. Bolyeria is the only exception among booids. Williams (1959) noted the fovea dentis was reduced or absent in Cylindrophis and uropeltines, and Rieppel (1979a: 547, fig. 8; see also Rieppel, 1977: 154; 1988: 86) used this information to support their sister group relationships. While the reduction in the fovea dentis provides evidence for that clade, it can no longer be considered unique among lepidosaurs (contra Williams, 1959: 1; Cadle et al., 1990). Hoffstetter (1939) concluded that the loss of the fovea dentis in uropeltines was owing to the odontoid process (the anterior centrum of the axis) fusing to the occipital condyle. This cannot explain the markedly reduced fovea dentis in Cylindrophis, because a large odontoid process 

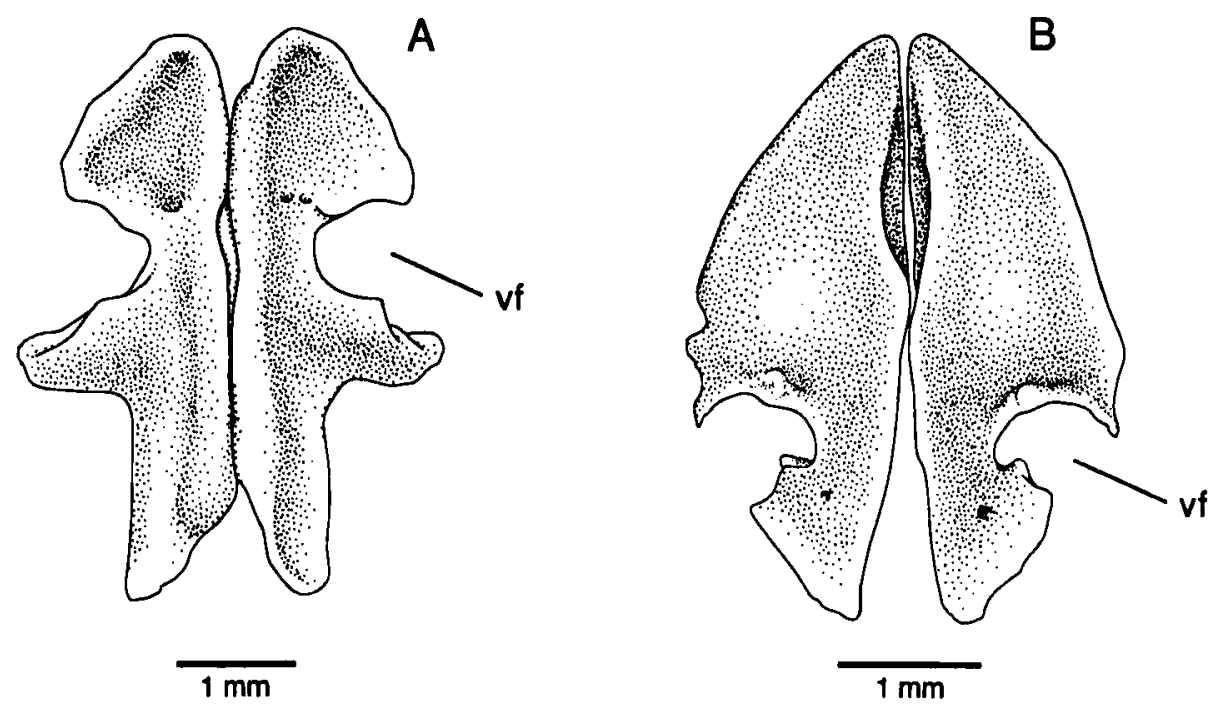

Figure 6. Ventral view of the vomer of representative erycines. A, reinhardii; UMMZ 149642. B, jaculus; UMMZ 192847. vf = vomeronasal fenestra.

is present in representatives of that taxon (larger in C. rufus than C. maculatus; Williams, 1959: fig. 4).

(31) Exoccipital: The crista circumfenestralis (Rieppel, 1979b: figs 2, 4) is large (0) or small or absent (1) in the area between the fenestra pseudorotunda and the foramen for the vagus cranial nerve ( $M c$ Dowell, 1987: fig. 1-1). The lamina of the bone in question is absent in bottae, and only slightly better developed in trivirgata. While the crista circumfenestralis varies among erycines, its ventral extension, the longissimus crest (McDowell, 1987: fig. 1-1), is always well developed (smallest in elegans). A large crista circumfenestralis is generally present among the outgroups; however, a few pythonines (e.g. Aspidites) and the bolyeriines exhibit the alternative state. The lamina of bone is completely absent in Casarea. Therefore, I assume state 0 is plesiomorphic in erycines.

(32) Vomer: The anterior bony margin of the external vomeronasal fenestra (Rieppel, 1978a: figs 2, 4; Groombridge, 1979c: fig. 1) is uneven (0) or even (1). Jacobson's organ is entered through the fenestra. The fenestra is formed by both the vomer and septomaxilla, and the unevenness of the anterior margin is owing to the vomer extending lateroposteriorly into the opening. The fenestra is relatively large, particularly so in bottae and trivirgata, as a consequence of their having an even margin. Variation in other aspects of the vomer and septomaxilla (characters 33 and 37) also affect the size of the fenestra (Fig. 6). All booid outgroups are characterized by the uneven state; only Trachyboa and Tropidophis exhibit state 1. Therefore, I assume state 0 is plesiomorphic in erycines. This character may not be independent of character 33, where the variable is really the size of the external vomeronasal fenestra.

(33) Vomer: The caudal margin of the external vomeronasal fenestra (Groombridge, 1979c: fig. 1) is directed laterally (0), lateroposteriorly (1), or posteriorly (2). There is a positive correlation between the size of the fenestra and the more the margin is oriented posteriorly. State 0 is almost always accompanied by a distinct ridge or 


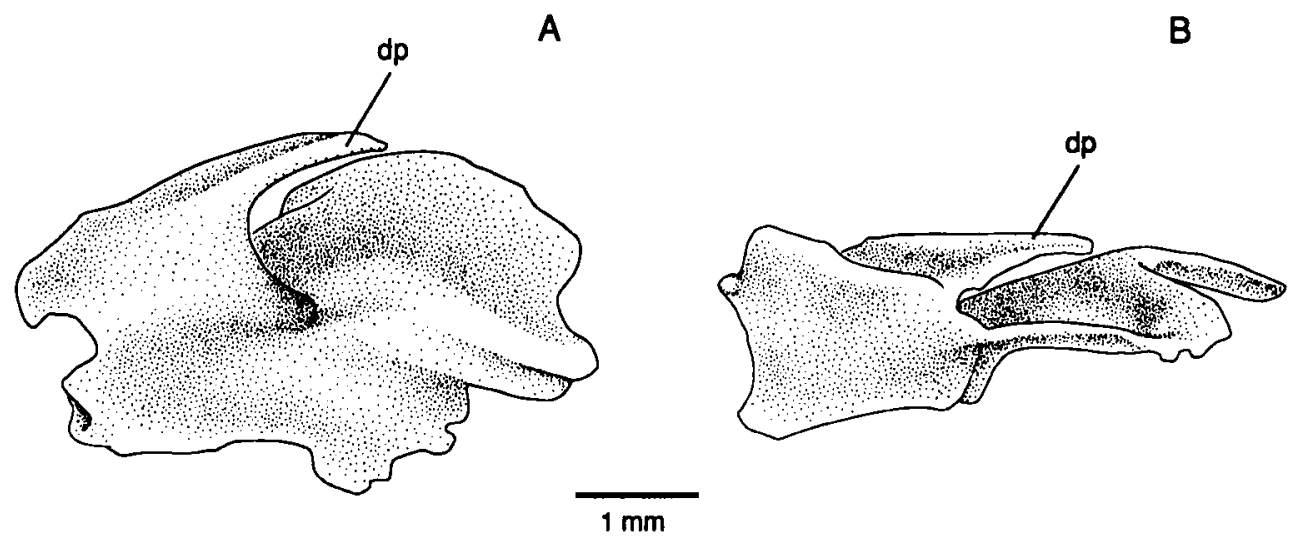

Figure 7. Left lateral view of the septomaxilla of representative erycines. A, reinhardtii; FMNH 31372, UF 54072. B, trivirgata; UMMZ 189644. dp = dorsoposterior process.

process, which projects downward from the posterior margin of the fenestra (Rieppel, 1978a: figs 2, 4). In some species (e.g. conica and johnii), the projection is so large that, from a ventral view, it significantly alters the otherwise rounded profile of the opening leading to Jacobson's organ. All outgroups are diagnosed by state 0 (and the presence of the ridge or process), and therefore it is assumed to be plesiomorphic in erycines. Only Trachyboa and Tropidophis appear to exhibit state 1 . The condition in Casarea could not be determined confidently because that area of the vomer appeared to have been damaged during preparation. This transformation may not be independent of character 32 .

(34) Vomer: The horizontal posterior lamina of the vomer (Rieppel, 1978a: figs 2, 4; Groombridge, 1979c: fig. 1) is wide (0) or narrow (1). The advanced snake clade cannot be diagnosed unambiguously because tropidophiines exhibit state 0 , while bolyeriines have state 1 . All other booids have a wide lamina. Therefore, I assume state 0 is plesiomorphic in erycines (Fig. 6).

(35) Septomaxilla: The septomaxilla is largely exposed (0) or hidden (1) beneath the nasal (McDowell, 1975: fig. 2; Underwood, 1976: fig. 1). The states of this character can only be determined from a dorsal view, when the bones of the snout are in situ. The exposed state characterizes all booid outgroups (Aspidiles being the only possible exception), and therefore I assume state 0 is plesiomorphic in erycines.

(36) Septomaxilla: The dorsoposterior process of the septomaxilla (Frazzetta, 1959: fig. 4A; Rieppel, 1978a: figs 5, 10-13) is extremely long (0), short (1), or absent, or nearly so (2). The process in question is lateral, occurs immediately below the nasal and prefrontal, and it is frequently broken during preparation (Fig. 7). A strictly lateral view of an undamaged specimen, with the nasal and prefrontal removed, is required to accurately score this character. All of the outgroups are characterized by a long process, the only exception being Aspidites, which appears to exhibit either state 1 or 2. Therefore, I believe it is reasonable to assume that an extremely long process is plesiomorphic relative to those states observed in erycines.

(37) Palatine: The modal, or median, number of adult palatine teeth is approximately 6 or more (0), 5-3 (1), or 2-0 (2). My observations on individual erycines are 
summarized in Appendix I. As might be expected, variation in number of palatine teeth is positively correlated with the length of the palatine. I agree with Underwood (1976: 161) that the process is absent, or at least nearly so, in bottae and reinhardtii. The larger number of teeth (state 0 ) is assumed to be plesiomorphic, given the following outgroup variation (see also Underwood, 1976, character 58): boines 5-6; Bolyeria 8-9; Casarea 9; Exiliboa 6-7; Loxocemus 7; pythonines 6; Trachyboa 7; Tropidophis 6-7; Ungaliophis 7; Xenopeltis 13. The presence of six palatine teeth in the Upper Oligocene fossil Bransateryx vireti (Hoffstetter \& Rage, 1972: fig. 8Av) is observed among extant erycines only in colubrina, conica and muelleri (Appendix I).

(38) Palatine: The choanal process of the palatine [see Underwood's (1976: 161) character 57$]$ is large and continuous (0) or tiny and discontinuous (1). Underwood (1976: 161) did not distinguish the continuous-discontinuous states recognized here. The discontinuity occurs approximately half-way along the process, and a separate, distal sliver of bone remains. I believe at least some part of the choanal process, even if disconnected from the body of the palatine, contacts the vomer in all erycines. Underwood's claim that the process is absent in jaculus and johnii is incorrect (e.g. BMNH 1920.1.20.1526 and 1930.5.8.22, respectively). I have also observed a small discontinuous section of the process in colubrina (FMNH 75214), conica (UMMZ 128037), elegans (IZANU 1674/4200), muelleri (CAS 136230) and tatarica (UMMZ 190414). Among the outgroups, most clades are characterized by state 0 (advanced snakes, anilioids, Loxocemus and Xenopeltis), while complete loss of the distal portion of the choanal process diagnoses pythonines. I misjudged the plesiomorphic condition in boines as state 0 (Kluge, 1991: fig. 13, character 51)-it should have been recorded as ambiguous $(0,1$ or discontinuous section absent) under the assumption of non-additivity, or state 1 assuming additivity. This reassessment does not alter the published hypothesis of boine relationships; however, the absence of the distal portion can be no longer considered diagnostic of Boa. In any case, a complete choanal process appears to be plesiomorphic in erycines.

(39) Palatine: The medioposterior corner of the palatine lies entirely lateral to or on a narrow (0) or wide (1) ledge of bone projecting medially from the pterygoid. A conspicuous medioposterior process (Kluge, 1991: fig. 13, character 53) does not always project from the corner of the palatine in booids. In most erycines, the palatine fits into a distinct groove on the dorsal surface of the ledge (Fig. 8). A wide and grooved ledge was observed only among the outgroups in Aspidites, Exiliboa, Trachyboa and Tropidophis (the conditions in Boa and bolyeriines are not considered comparable to either of the states recognized herein). Therefore, state 0 is assumed to be plesiomorphic in erycines.

(40) Palatine: The maxillary process of the palatine (Cundall $\mathscr{E}^{\circ}$ Irish, 1989: fig. 4) is wide (0) or narrow (1). This character can be scored accurately by looking medially, through the orbit, or examining disarticulated material. States 0 and 1 can also be described as flat and convex, respectively. There is considerable variation among the outgroups: Bolyeria, Casarea, Exiliboa, Ungaliophis and Xenopeltis exhibit state 0 , whereas state 1 occurs in Loxocemus, Trachyboa and Tropidophis. Boines and pythonines are scored as state 0; however, the size and completeness of the maxillary foramen (Kluge, 1991, character 52) tends to make some determinations equivocal in those taxa. Variation among the outgroups suggests state 0 is plesiomorphic in erycines. 

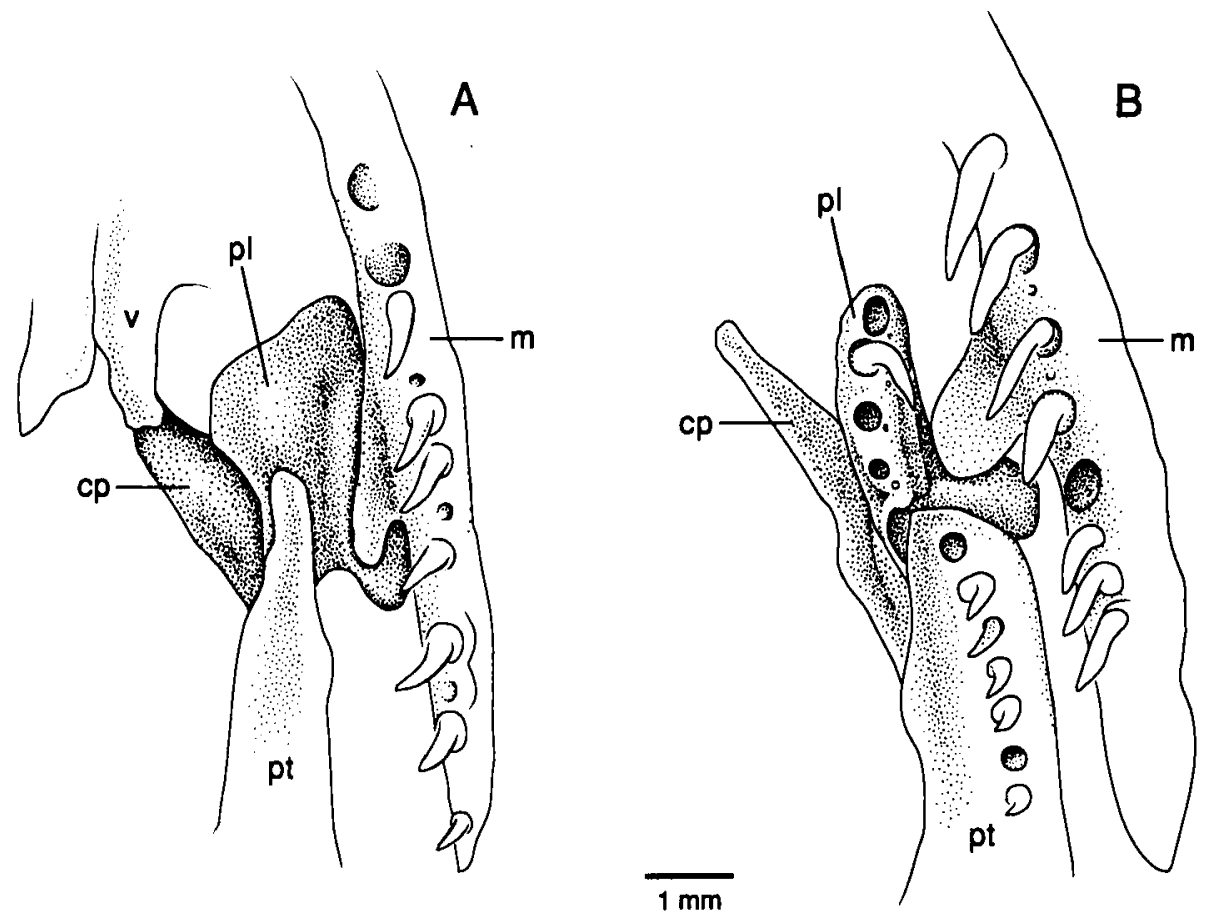

Figure 8. Ventral view of the left palatine of representative erycines. A, reinharditi; UMMZ 149642. $\mathrm{B}$, trivirgata; UMMZ 189644. $\mathrm{cp}=$ choanal process of palatine; $\mathrm{m}=$ maxilla; $\mathrm{pl}=$ palatine; $\mathrm{pt}=$ pterygoid; $\mathrm{v}=$ vomer.

(41) Palatine: The maxillary process of the palatine (Cundall $E^{\circ}$ Irish, 1989: fig. 4) lies anterior to (0) or at (1) the level of the palatine-pterygoid joint. Rotating articulated palatine-pterygoid bones, detached from the remainder of the skull, provides the best content in which to judge the character states (Fig. 8). Bolyeria, Casarea, Loxocemus, pythonines, Trachyboa, Tropidophis, Ungaliophis and Xenopeltis exhibit state 0, whereas boines (Kluge, 1991, character 50) and Exiliboa have state 1. Therefore, state 0 is assumed to be plesiomorphic relative to the state which typifies erycines.

(42) Pterygoid: The modal, or median, number of adult pterygoid teeth is 12 or more (0), 11-9 (1), 8-6 (2), 5-3 (3), or 2-0 (4). Appendix I summarizes the variation in pterygoid tooth number in erycines. Variation in pterygoid tooth number is highly variable among the outgroups: boines probably had 11 (highly variable, from 7 in Boa cropanii to 29 in Candoia carinata; see Kluge, 1991, character 67); Bolyeria 11; Casarea 15; Exiliboa 10; Loxocemus 9; pythonines 8-21; Trachyboa 15; Tropidophis 11-12; Ungaliophis 10-12; Xenopeltis 11-14 (Underwood, 1976, character 59). While a large number of pterygoid teeth is plesiomorphic in erycines, it is unclear whether the best estimate is state 0 or 1 . Therefore, the polarity of this character is left ambiguous. Hoffstetter \& Rage (1972: 100) referred a ptyerygoid with seven teeth to the extinct Bransateryx vireti (see also $\mathrm{pl}$. 2, fig. 2). This number has also been observed in the following extant erycines: bottae, colubrina and tatarica B (see Appendix I).

(43) Pterygoid. The medioventral margin of the posterior one-third of the pterygoid is 
rounded (0) or folded into a shallow (1), or deep (2) groove (Hoffstetter $\mathcal{E}$ Rage, 1972, fig. $8 C$ ). Presumably, Rieppel's (1978a: 187) reference to a 'mesial transverse process of the pterygoid' is equivalent to states 1 and/or 2. The protractor pterygoideus muscle inserts into the groove (Frazzetta, 1966: fig. 30), and $\mathrm{O}$. Rieppel (personal communication) pointed out the position of the muscle is approximately the same, on the medial side of the quadrate ramus of the pterygoid, whether or not the groove is present. I attribute state 1 only to jaculus and johnii, where the groove is nearly absent in the largest specimens of those two species (e.g. UF 47847, a johnii, approaches state 0). The floor to the groove is extremely thick in representatives of elegans, jayakari, miliaris and tatarica, and future studies of a more quantitative nature may be able to document this variation as intermediate between states 1 and 2. The Upper Oligocene pterygoid referred to Bransateryx vireti, a presumed erycine, seems to exhibit a medioventral groove along the pterygoid (Hoffstetter \& Rage, 1972: fig. 8C). Among the outgroups, a distinct groove (state 2) occurs in boines, Exiliboa, and pythonines. In some of these taxa (e.g. Boa dumerili), the fold is so extreme that the groove is delimited by a floor that is much wider than the roof. State 0 occurs in all other outgroups, and the simplest interpretation of polarity is that the round condition is plesiomorphic in erycines. State 2 is characteristic of the (boine, pythonine) clade (Underwood, 1976: fig. 4).

(44) Parasphenoid: The parasphenoid (Underwood, 1967: figs 3-5) is deep throughout its length, the trabecular groove is obvious along its entire length (0), the parasphenoid is shallow anteriorly and deep posteriorly, the groove is absent anteriorly and present posteriorly (1), or the parasphenoid is shallow throughout its length, the groove is absent (2). The distinctness of the depth of the parasphenoid can be assessed as a function of the sharpness of the ventral edge of the trabecular groove. Of those taxa recorded as state 1 , conica is the most similar to the plesiomorphic condition. State 0 is characteristic of all the relevant outgroup taxa, and therefore it is assumed to be plesiomorphic in erycines.

(45) Parasphenoid: The interparietal area of the parasphenoid (Underwood, 1967: fig. 4) is narrow, sides parallel (0), of modest width, sides parallel (1), or very wide, with diverging sides (2). While state 0 is recorded for bottae, the interparietal area is quite wide in some specimens (e.g. UMMZ 135015). Of those erycines recorded as state 1 , elegans exhibits the widest roof. State 0 is typical of all booid outgroups, and therefore it is assumed to be plesiomorphic in erycines.

(46) Basisphenoid: The parasphenoid wing of the basisphenoid (Kluge, 1991) is present (0) or absent (1). The comparability of the wing to the basipterygoid process (sensu Frazzetta, 1959: 470) is discussed elsewhere (Kluge, 1991: 34-35). The wing does not have to project downward to any great extent, as is typical of most boines and pythonines, to qualify as present. In fact, state 0 is recorded when the basisphenoid is rather flat, but projects forward beyond the anterior vidian foramen. The wing is never prominent in erycines, and the most obvious feature that distinguishes the two states in that taxon is whether the foramen is hidden or exposed from a ventral view, respectively. Among the booid outgroups, a modest to well developed wing occurs in Bolyeria, Loxocemus, most boines (Kluge, 1991, character 56) and pythonines. I cannot be sure of the condition in Casarea because the only available, completely prepared, skeletons were from subadults. Further, the basisphenoid is oriented anteroposteriorly in that region in Xenopeltis, like anilioids, and I assume such a position is imcomparable to that in 

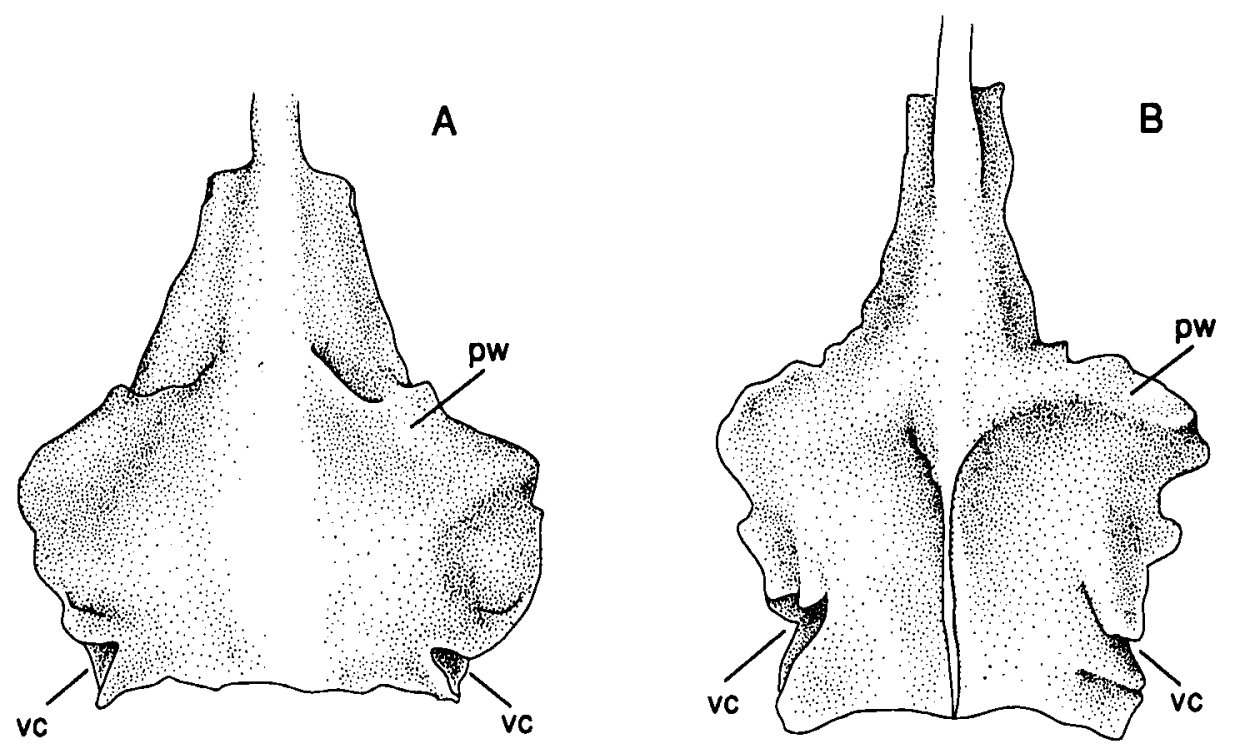

$2 \mathrm{~mm}$

Figure 9. Ventral view of the basisphenoid illustrating the sizes of the right and left posterior vidian canals in representative erycines. A, reinhardtii; UMMZ 183242. B, trivirgata; UMMZ 189644. $\mathrm{pw}=$ parasphenoid $\mathbf{w i n g} ; \mathrm{vc}=$ vidian canal.

erycines. In tropidophiines, the wing is never prominent, and I consider it absent altogether in Exiliboa, a lineage in which the anterior vidian foramen may be absent. Thus, I consider my estimate of polarity to be ambiguous in erycines.

(47) Basisphenoid: The right and left posterior vidian canals are approximately equal in size, or the left is larger than the right (0) or the right is larger than the left (1). The fact that Underwood (1976, table 1; see also Underwood, 1967: 69) mistakenly recorded the vidian canals in reinhardtii as invariably of equal size is difficult to understand because the asymmetry is pronounced in the material he listed as having examined (the right side is 1.6 times wider than the left in BMNH 96.3.9.3 and 1911.10.28.17). Measurements of the openings of 13 adult reinhardtii reveal the right side averages 1.4 times wider than the left; however, the observed range of variation is considerable and the canals are of approximately equal size in two specimens $(1.0,1.0,1.1,1.1,1.2,1.2,1.3,1.4$, $1.4,1.6,1.6,1.8,2.3)$. I believe it is reasonable to characterize erycines as having state 1, and the following review of outgroup variation (see also Kluge, 1991, character 58) suggests that state is diagnostic of erycines (Fig. 9). The plesiomorphic sister lineages in boines have equal size canals (Kluge, 1991, character 58), and the right is larger than the left only in a more derived clade (contra Underwood, 1976: table 1). I can confirm that approximately equal size canals characterize anilioids (Anilius and Cylindrophis), bolyeriines and tropidophiines (the canals are absent in Trachyboa and Tropidophis; Underwood, 1976: 164). In Xenopeltis, the posterior vidian canal diverges immediately into two foramina, the more anterior opening leads to the anterior vidian foramen, whereas the other enters the cranial vault. The equal-size state applies to 
Xenopeltis whether the posterior vidian canal or the more anterior foramen within the canal is measured. The left canal is larger than the right in Loxocemus and pythonines. Therefore, I assume state 1 diagnoses erycines, and that it is convergent with the condition observed in boines.

(48) Coronoid: The coronoid is present (0) or absent (1) on the prearticular portion of the compound bone. The coronoid, as a separate bone, is recorded as absent in bottae (McDowell, 1987: 27) and trivirgata; however, a distinctive ridge occurs on the anterodorsal surface of the prearticular of most representatives of those species (e.g. bottae: UMMZ 135015; trivirgata: CM 112374), which very likely indicates the coronoid has been fused, as opposed to lost. A small section of the coronoid is present on the anteromedial surface of the surangular portion of the compound bone in trivirgata; no such element is present in bottae. Among the booid outgroups, the coronoid is large in boines (Kluge, 1991: fig. 14, characters 60-63), bolyeriines, Loxocemus, pythonines and Xenopeltis, a small sliver of bone occurs on the anterodorsal surface of the prearticular in Trachyboa and Tropidophis, and it is absent in Exiliboa and Ungaliophis. Therefore, the simplest interpretation is that state 0 is plesiomorphic in erycines.

(49) Coronoid: The coronoid contacts (0) or is separated from (1) the splenial. I have recorded bottae and trivirgata as having state 1 , assuming the distinctive ridge on the anterodorsal surface of the prearticular portion of the compound bone they both exhibit is the fused remnant of the coronoid. The length of the coronoid is positively correlated with specimen size (and perhaps age), and therefore the condition was not recorded for somalicus because the only available specimen of that species is a subadult. Among the alethinophidian outgroups, state 0 characterizes Cylindrophis and all bolyeriines and pythonines. Most boines, including some of the more plesiomorphic sister taxa (Kluge, 1991: fig. 14, character 60), have the 0 condition. State 1 applies to Anilius, Loxocemus, those tropidophiines with a coronoid, Trachyboa and Tropidophis (contra Kluge, 1991), and Xenopeltis. Given this pattern of outgroup variation, it is equally parsimonious to interpret states 0 or 1 as plesiomorphic in erycines. Therefore, the polarity is left ambiguous. Unlike this character, erycines exhibit a great deal of individual variation in angular-coronoid contact (e.g. in 23 specimens of johnii, 9 and 10 are symmetrical for contact and no contact, respectively, while 4 are asymmetrical), and therefore no attempt has been made to document that transformation.

(50) Dentary: The model, or median, number of adult dentary teeth is 18 or more (0), $17-15$ (1), 14-12 (2), or 11 or less (3). The variation in dentary tooth number in erycines is summarized in Appendix I. The following modal, or median, values are characteristic of most of the booid outgroups (Underwood, 1976, character 60): Bolyeria (15), Casarea (22), Exiliboa (21), Loxocemus (19), Trachyboa (21-22), Tropidophis (21), Ungaliophis (16) and Xenopeltis (34). All boines have state 0, except Epicrates fordii (16) and the clade consisting of Corallus caninus, C. cropanii and $C$. enydris (15-16). All pythonines exhibit state 0, except Aspidites melanocephalus (15), Morelia amethistina (17), M. carinatus (16), M. oenpelliensis (16), $M$. papuanus (16) and $M$. viridis (16) and Python reticulata (17) and $P$. sebae (17). The simplest interpretation is that state 0 is plesiomorphic in erycines.

(51) Caudal vertebrae: The dorsal surface of the neural spine (Szyndlar, 1987: fig. 3) of a posterior caudal vertebra is oval or flat (0) or grooved (1). Sood (1941: figs 1-4) illustrated the apomorphic state in johnii, and Bogert (1968: fig. 12) provided 


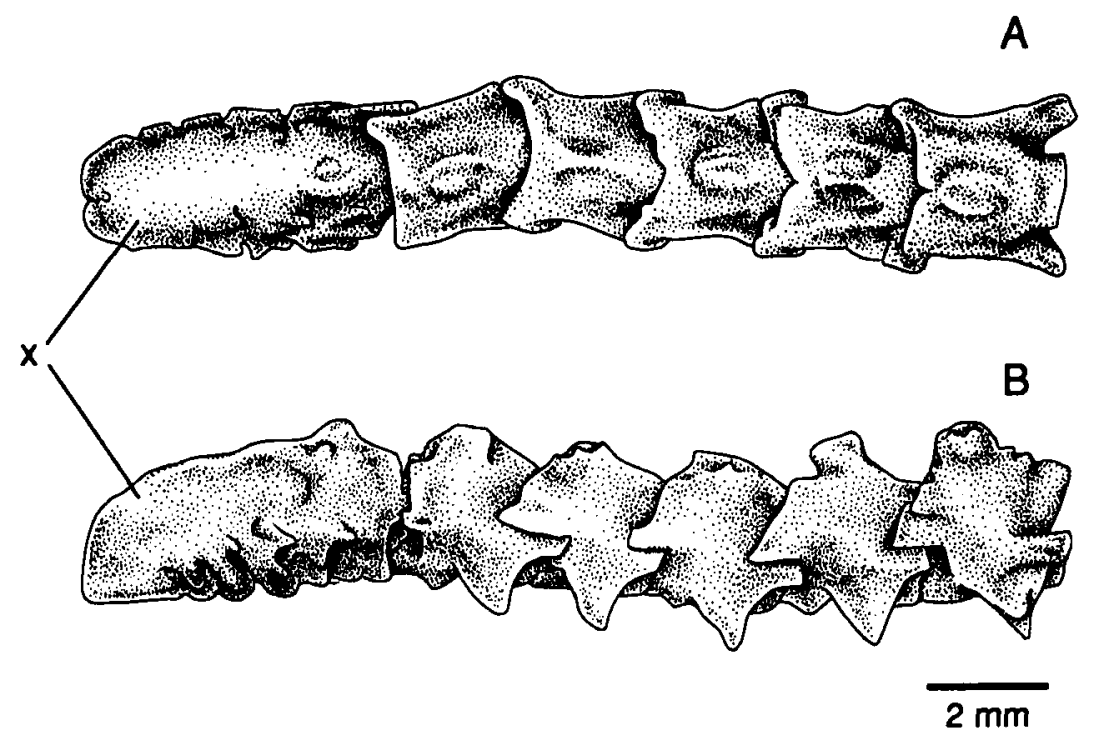

Figure 10. The caudal vertebrae of reinhardiii (UMMZ 149642). A, Dorsal view. B, Lateral view. $\mathrm{x}=$ posteriormost vertebra in the column.

excellent photographs of the specialized caudal vertebrae of bottae, colubrina, jaculus, johnii and trivirgata, where the grooved state is also evident (see also Hoffstetter \& Rage, 1972: figs 3-4). The grooved neural spine in bottae is filled in somewhat by an accessory spine. I am not confident that reinhardtii has state 1; however, its most caudal $1-3$ vertebrae are consistently separated into right and left halves by a deep indentation (Fig. 10A). The neural spine is not evident as a separate process in those caudal vertebrae, and I cannot be sure the grooves in reinhardtii and other erycines are comparable. Only rarely are grooves present in reinhardtii in more craniad caudal vertebrae (e.g. UMMZ 183242). This variable represents Underwood's (1976) character 82 (see below). Only state 0 occurs among the booid outgroups, and therefore I assume the grooved condition is apomorphic among erycines. Szyndlar's (1987) type of Bransateryx septentrionalis from the lower Miocene of Czechoslovakia is a posterior caudal vertebra with accessory processes (see characters $52-56$ ), which clearly indicates the species is an erycine. However, the presence of an oval neural spine (fig. 3) distinguishes the extinct form from all other parts of the group which have specialized caudal vertebrae, including Bransateryx vireti.

(52) Caudal vertebrae: An anteriorly projecting accessory process on the neural spine, presumably the accessory lateral process of Sood (1941: fig. 1), is absent (0) or present (1). There are several accessory processes on the caudal vertebrae of erycines, and it is important to distinguish them in order to understand the history of this highly specialized region of the skeleton (see Sood, 1941: figs 1-4). The process in question occurs high on the side of the neural spine, dorsal to the accessory process on the neural arch, and it is present only in the penultimate series of vertebrae. I do not believe this accessory process is the pterapophysis of Szyndlar (1987: fig. 3; see below). The accessory process does not characterize any of the outgroups, and therefore state 1 is assumed to be apomorphic among erycines. 
(53) Caudal vertebrae: The accessory process on the neural arch of a caudal vertebra, presumably the pterapophysis of Szyndlar (1987: fig. 3), is absent (0) or present (1). I believe the apomorphic condition in johnii was referred to as the 'alar plate of the zygapophysial ridge' by Sood (1941: fig. 1). This transformation appears to be equivalent (in part) to Underwood's (1976) character 83. The process in question originates dorsal to the posterior diapophysis. Its serial distribution, within an individual, is also peculiar (e.g. trivirgata) in that it gradually increases in size posteriorly along the vertebral column, but then decreases in size more posteriorly, often to be replaced by much elaborated posterior diapophyses. The serial pattern of change occurs over very few vertebrae in bottae, and it is also difficult to discern in johnii because of the elaborate surrounding processes (Sood, 1941). There is a faint swelling on the neural arch of reinhardtii, at the base of the neural spine, between the anterior and posterior diapophyses (e.g. it is particularly evident in UF 56403; see also Fig. 10B). No such swelling, or distinct accessory process, occurs among the booid outgroups (e.g. Loxocemus, UMMZ 128027), and I assume state 0 is plesiomorphic relative to the condition observed in erycines.

(54) Caudal vertebrae: The distal tip of the posterior diapophysis of a caudal vertebra is undifferentiated ( 0 ) or oriented nearly vertically into a thin, often convoluted, blade of bone (1). These character states, as well as those of characters 55-56, cannot be judged accurately on the posterior-most segments because those small vertebrae are usually co-ossified and have less differentiated processes. A simple diapophysis is typical of all outgroups, and therefore state 1 is assumed to be apomorphic in erycines.

(55) Caudal vertebrae: The distal tip of the anterior diapophyses of a caudal vertebra is undifferentiated $(0)$ or elaborated into a horizontal blade that also originates from the centrum (1). A simple diapophysis is typical of all outgroups, and therefore state 1 is assumed to be apomorphic in erycines.

(56) Caudal vertebrae: The transverse process of a caudal vertebra is simple and tapers gradually or is bulbous (0) or a large and rounded anteroposteriorly oriented blade (1). Sood's (1941: figs 1-4), Bogert's (1968: fig. 12), and Szyndlar's (1987: fig. 3) illustrations provide various perspectives on this disc of bone. A simple transverse process is typical of all alethinophidians, and therefore state 1 is assumed to be apomorphic in erycines.

(57) Caudal vertebrae: A caudal haemopophysis projects ventrolaterally (0), is nearly vertical, rounded terminally, and lies close to its counterpart (1), or is curved toward its counterpart of the opposite side, flattened terminally, and widely separated from its counterpart (2). Sood's (1941: figs 2 and 4) and Szyndlar's (1987: fig. 3) illustrations provide further details of this character. Caudal haemopophyses are absent, or nearly so, in reinhardtii, and therefore this character could not be scored for that species. The unique condition observed in jayakari appears to be correlated with that species' ability to flatten its tail. State $l$ is characteristic of all of the outgroups, and therefore states 0 and 2 are assumed to be apomorphic in erycines.

(58) Mental groove: A mental groove is conspicuous (0), inconspicuous (1) or absent (2). The presence of a groove in erycines is suggested by the occurrence of symmetrically arranged postmental scales on either side of the midline; all erycines without a groove have the asymmetrical pattern, with some scales occurring on the midline (Fig. 11). The distinction between conspicuous and inconspicuous grooves is based on the presence of relatively large, rhomboid- 
A

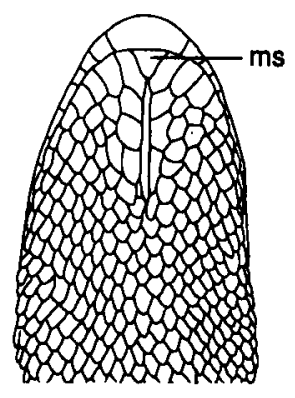

B
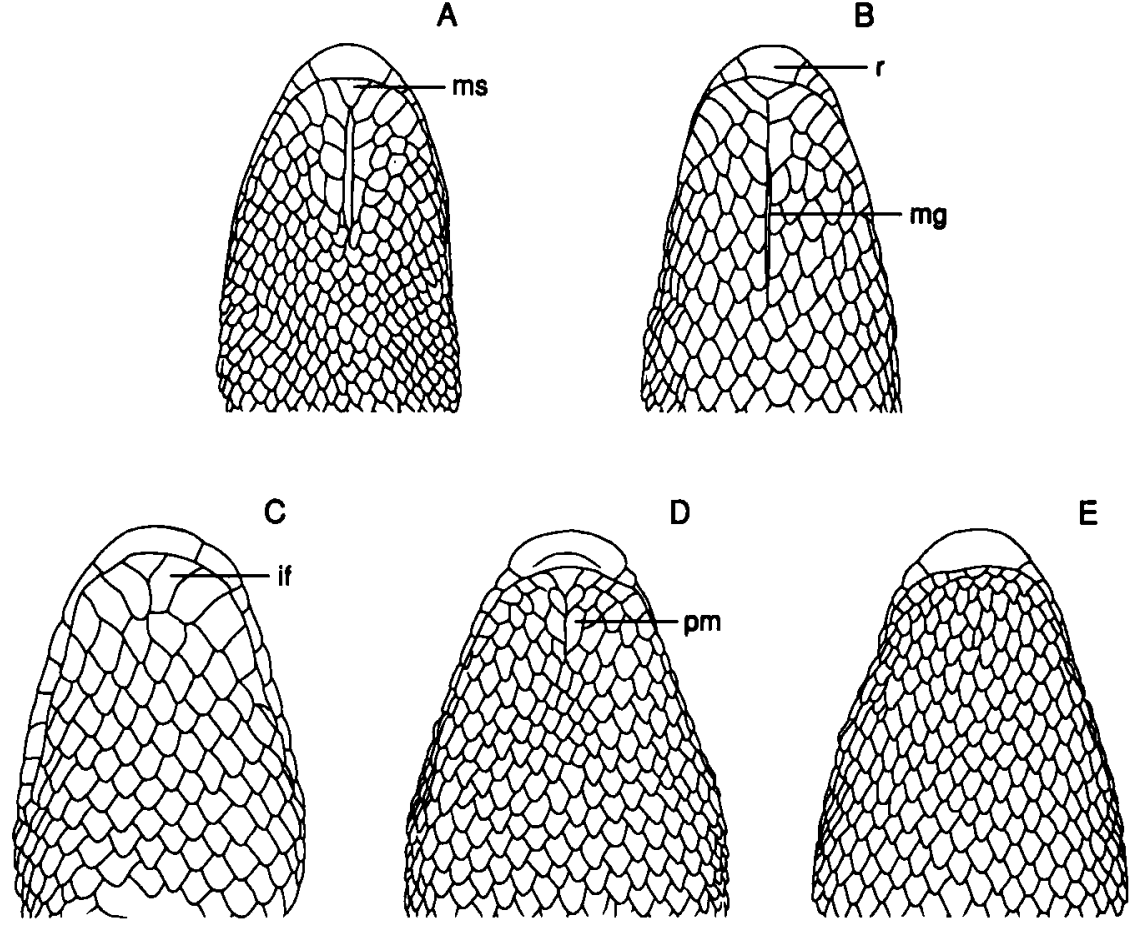

Figure 11 . Ventral view of the mental groove and chin shields of representative erycines. A, bottae; UMMZ 90180, and modified after Wright \& Wright (1957: fig. 13-3). B, trivirgata; UMMZ 68419. C, reinharditi; UMMZ 65868 [see also de Witte (1962: fig. 28)]. D, jaculus; BMNH 1928.12.20.3 [see also Fuhn \& Vancea (1961: fig. 191)]. E, colubrina; BMNH 1902.12.13.70. if = first infralabial scale; $\mathrm{mg}=$ mental groove; $\mathrm{ms}=$ mental scale; $\mathrm{pm}=$ second postmental scale; $\mathbf{r}=$ rostral scale.

shaped scales in the former state. Only a very slight groove is present in elegans. I do not disagree with Boulenger (1892), who also recognized the mental groove as present or absent in two sets of species, elegans, jaculus, jayakari and johnii (his reference to sennaariensis is obviously mistaken; see Jan, 1863), and colubrina, conica and muelleri, respectively; however, in my opinion the groove is not as conspicuous in the first group of taxa (Gasperetti, 1988: figs 6b, 19, 22) as it is in boltae and trivirgata. All booid outgroups have a distinct mental groove, and therefore states 1 and 2 are assumed to be apomorphic in erycines.

(59) Scalation: The first infralabial scale is large and closely approaches its counterpart posterior to the mental (0) or it is small and separated from its counterpart by one or more scales (1). The mental groove actually separates the large infralabials in bottae and trivirgata; however, there is no intervening scale (for alternate state see Gasperetti, 1988: figs 6b, 19, 22; see also Fig. 11). All of the booid outgroups are characterized by having large infralabial scales, and therefore $I$ assume state 1 is apomorphic in erycines.

(60) Scalation: The rostral scale is gently rounded (0), or moderately (1), or strongly (2) shovel-shaped in lateral view (Rieppel, 1978a: fig. 3). Jaculus and johnii tend toward a sharper rostral than all other state 1 taxa (jaculus familiaris and jaculus turcicus are more extreme in this regard than jaculus jaculus). Keratinization of the rostral also occurs in johnii and the two more shovel shaped subspecies of jaculus 

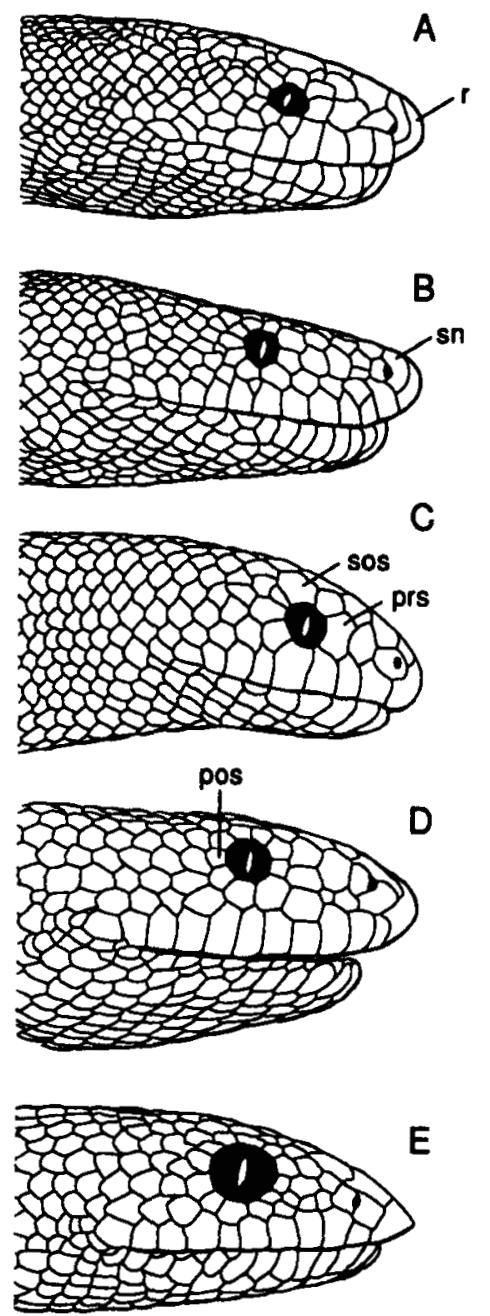

Figure 12. Right lateral view of the head scales of representative erycines. A, botiae; UMMZ 90180 and modified after Wright \& Wright (1957: fig. 13-1). B, trivirgata; UMMZ 68419. C, reinharditi; UMMZ 65868 [see also de Witte (1962: fig. 28)]. D, elegans; BMNH 92.11.28.5. E, somalicus; MZUF $525 \mathrm{l}$. pos = posterior ocular scale; prs = preocular scale; sn = supranasal scale; sos = supraocular scale; $\mathbf{r}=$ rostral scale.

(apparently not all Eryx species as suggested by Rieppel, 1978a: 196). I accept Rieppel's (1978a) hypothesis of polarity, a shovel-shaped rostral being apomorphic in erycines (Fig. 12). This variable may not be independent of character 1.

(61) Scalation: The dorsal head scales, between the supranasals and the interocular region, are large and symmetrically arranged $(0)$ or small and usually asymmetrically arranged (1). The booid outgroups, with the exception of some otherwise cladistically apomorphic boines (Kluge, 1991, character 74) and pythonines, are characterized by large and usually symmetrically arranged dorsal head scales posterior to the supranasals (Zacharias, 1897; Friederich, 1978). Therefore, I assume state 1 is apomorphic in erycines (Fig. 13).

(62) Scalation: A single, large supraocular scale is present ( 0 ) or absent (1). A single 

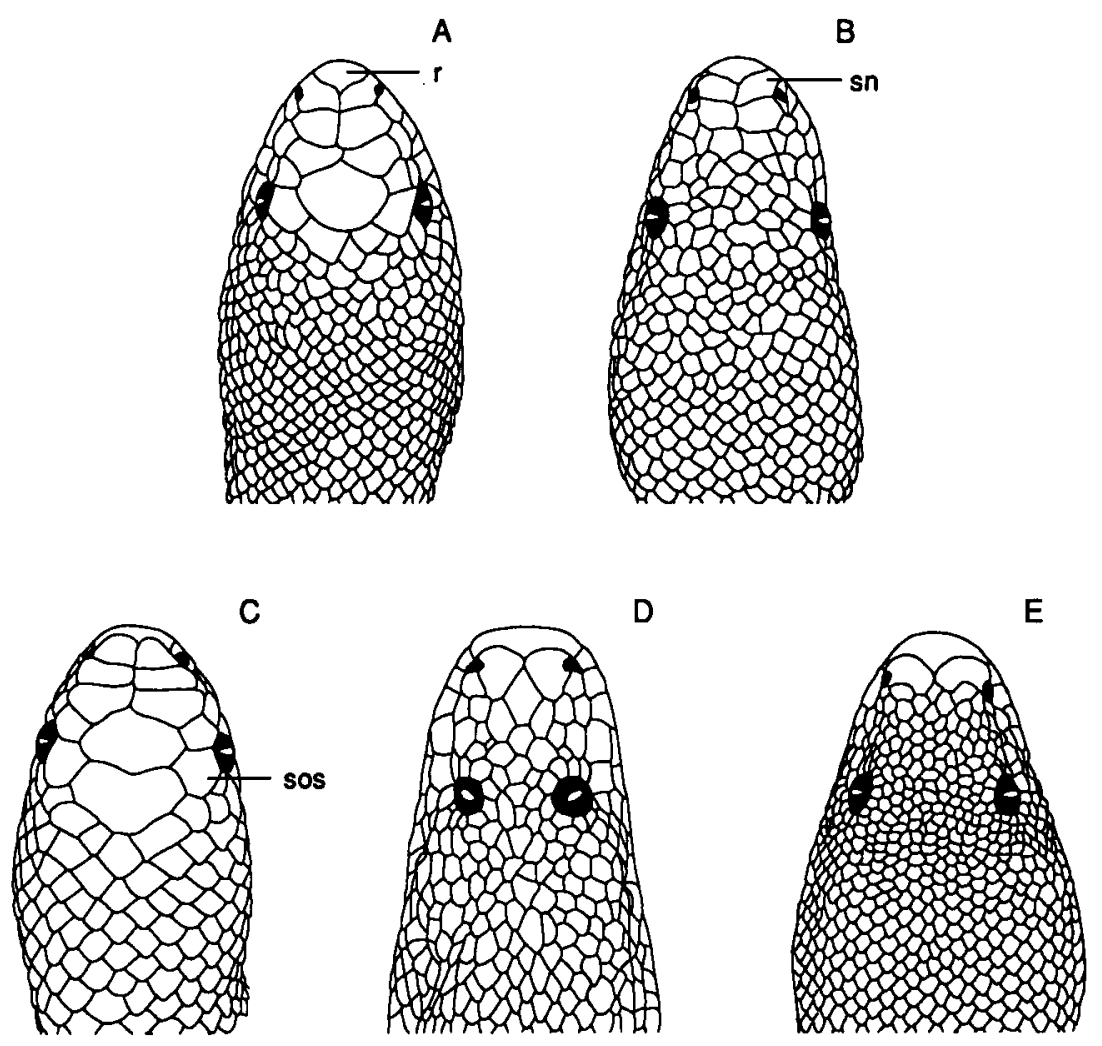

Figure 13. Dorsal view of the head scales of representative erycines. A, bottae; UMMZ 90180 , and modified after Zacharias (1897: fig. 40). B, trivirgata; UMMZ 68419, and modified after Wright \& Wright (1957: fig. 13-2). C, reinhardtii; UMMZ 65868 (and modified after Zacharias, 1897: fig. 55; see also de Witte, 1962: fig. 28). D, jayakari; BMNH 1971.1655 (see also Gasperetti [1988: fig. 22]). E, colubrina; BMNH 1902.12.13.70 (see also Gasperetti, 1988: fig. 20). sn = supranasal scale; sos = supraocular scale; $\mathbf{r}=$ rostral scale.

supraocular may be present in erycines (Hoyer, 1974: fig. 1), but it is small, and pre- and postoculars intrude into the supraocular region (Fig. 13). State 0 typifies bolyeriines, Loxocemus, all pythonines (except Morelia carinatus, $M$. spilota and $M$. viridis and Python sebae; contra Zacharias, 1897: fig. 33), all tropidophiines (except Trachyboa) and Xenopeltis, while state 1 characterizes all boines (except Epicrates and Eunectes). Therefore, the simplest explanation is that the presence of a single, large supraocular is plesiomorphic in erycines.

(63) Scalation: The number of preocular scales is one (0) or more (1). Underwood \& Stimson (1990: 576, their character 10) claimed that more than one preocular scale is apomorphic in pythonines, because state 0 occurs in the 'great majority' of snakes. One preocular scale characterizes Loxocemus, tropidophiines (except Trachyboa and at least one species of Tropidophis - T. laczanowskyi) and Xenopeltis and the alternative condition typifies bolyeriines. The more plesiomorphic boine lineages (Kluge, 1991) all have state 1, and I suspect that condition will also be found to diagnose pythonines (contra Underwood \& Stimson, 1990). Therefore, I believe the polarity of this character cannot be determined unambiguously in erycines (Fig. 12). 
(64) Scalation: The scales covering the parietal-neck region are smooth (0) or keeled (1). While johnii is recorded as having smooth scales, extremely faint keels may be present in a few subadults. Among the outgroups (Kluge, 1991, character 75; see also Underwood, 1976, character 14), the keeled state only characterizes bolyeriines, Candoia, and some tropidophiines (both Trachyboa species and some, but not all Tropidophis species). Therefore, state 0 is interpreted unambiguously as plesiomorphic in erycines (Fig. 13).

(65) Scalation: The anterior dorsal caudal scales are smooth (0), or slightly (1), or sirongly (2) keeled. The size of the keels varies with age, and only adults should be used in assessing the apomorphic states. The nature of a strongly keeled scale was illustrated by Gasperetti (1988: fig. 9g). An adult johnii (BMNH 1921.6.15.10) has little evidence of keels; however, such ridges are prominent on other specimens. State 1 represents more of a generally swollen area than it does a low keel. The arguments for polarity are the same as those discussed under character 64.

(66) Scalation: The ventral and subcaudal scales are very wide (0), moderately wide (1) or narrow (2). Distinguishing states 1 and 2 is often quite difficult owing to the absence of suitable landmarks against which to compare the width of the ventral and subcaudal scales (Fig. 14; see also Gasperetti, 1988: fig. 8c). For example, it is easy to miscode johnii when the width of the body is distorted by preservation. I assume state 1 is plesiomorphic in erycines because that condition seems to characterize all of the booid outgroups.

(67) Eye: The eyes are directed laterally (0) or more nearly dorsally (1). The eyes of jayakari are obviously located on the dorsal surface of the head, and that extreme position is reflected in the emarginated frontal bones that species possesses. It is also clear that the eyes of miliaris occupy a more dorsal position than is usual in all other erycines because its dorsal circumocular scales are hidden when viewed laterally. This species is also recorded as apomorphic, although its frontal bones do not seem to reflect this derived position. Laterally directed eyes characterize all alethinophidians (Kluge, 1991, character 72). Therefore, I assume state 0 is plesiomorphic in erycines (Fig. 13).

(68) Tail: The tail is long (0) or short (1). The tip of the tail of erycines often seems to be damaged, perhaps owing to predator attacks, and only unmutilated appendages should be scored. Tail length can be assessed as a function of number of subcaudals, a long tail being more than 34 subcaudals, a short tail 33 or less. It can also be judged in terms of the length of the tail relative to its width at the level of the vent, a short tail being less than c. 5.5 or longer than wide (Gasperetti, 1988: fig. 7d). A long tail, by this definition, characterizes all booid outgroup taxa, except Trachyboa. Therefore, I assume state 0 is plesiomorphic in erycines.

(69) Tail: The tip of the tail is pointed (0) or blunt (1). The nature of the terminal scale, conical or obtuse, characterizes these two states (Fig. 15). Again, many erycine tails appear to have been mutilated and these specimens cannot be used to assess the present character (Gasperetti, 1988: fig. 7d). The terminal, conical, scale seems to be developed into a strongly down-turned hook in muelleri. Such a condition is found in some, but not all jayakari (Gasperetti, 1988: fig. 22, pl. 4). The pointed condition is typical of all booid outgroups, and therefore I assume state 0 is plesiomorphic in erycines.

(70) Hemipenis: The hemipenis is markedly (0) or weakly (1) bilobed or unilobed (2). 

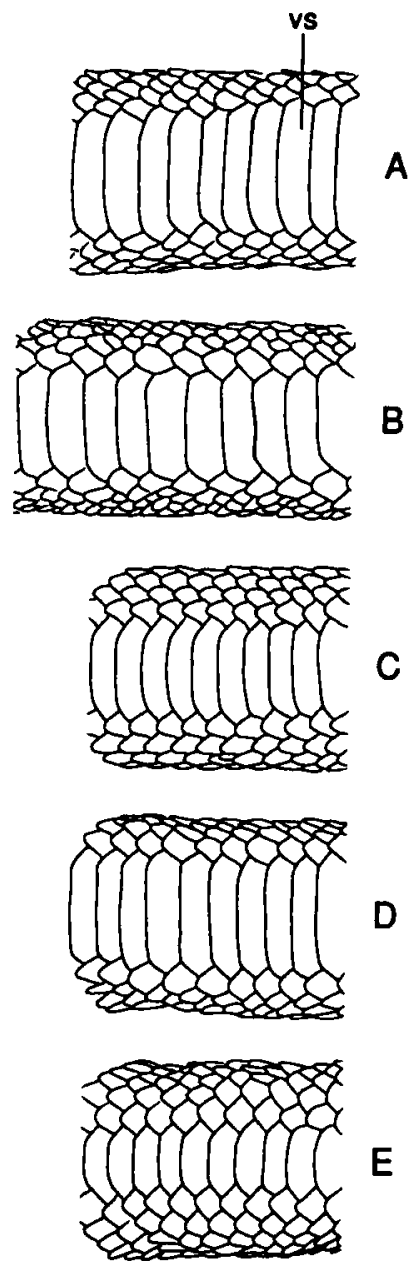

Figure 14. Ventral body scales of representative erycines. A, bottae; UMMZ 90180. B, trivirgata; UMMZ 68419. C, reinharditi; UMMZ 61160. D, colubrina; BMNH 1902.12.13.70. E, elegans; BMNH 92.11.28.5. vs = ventral body scale.

Branch (1986: 295; see also Cope, 1985; M. A. Smith, 1943; Dowling \& Savage, 1960; Dowling \& Gibson, 1970; Domergue, 1962; Doucet, 1963; Dowling, 1975b; Branch, 1981) stated that the only undivided booid hemipenes occur in reinhardtii, Eryx, Morelia viridis, and three species of Python: P. anchietae, $P$. curtus and $P$. regius. All other booid outgroup taxa appear to exhibit much more distinct lobation, and therefore I assume state 0 is plesiomorphic relative to the alternative conditions observed in erycines (Fig. 16).

(71) Hemipenis: The end (s) of a hemipenis, excluding the terminal awn, is oval ( 0$)$, or forms a shallow (1) or deep (2) lateral cup. According to Branch (1981; see also Dowling \& Savage, 1960; Dowling \& Gibson, 1970; Dowling, 1975b; Branch, 1986) the cups are prominent in bottae and trivirgata but less evident in other erycines (Fig. 16). More observations among the outgroups are required before this transformation can be polarized unambiguously.

(72) Intrapulmonary bronchus: The intrapulmonary bronchus is short (0) or long (1). 

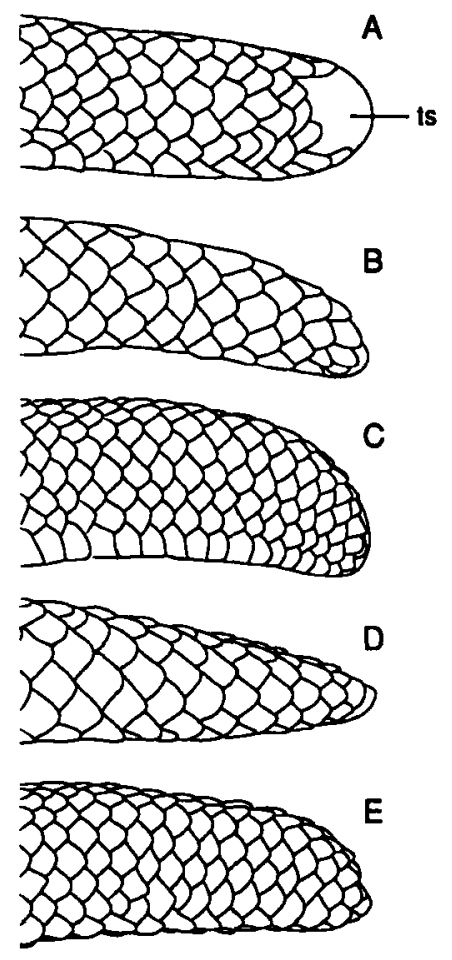

Figure 15. Tail shape in representative erycines, as seen from a left lateral view. A, bottae; UMMZ 90180. B, trivirgata; UMMZ 68419. C, reinhardtii; UMMZ 61160 [see also de Witte (1962: fig. 28)]. D, colubrina; BMNH 1902.12.13.70. E, jaculus; BMNH 1928.12.20.3 (see also Fuhn \& Vancea, 1961: fig. 192). ts = terminal dorsal caudal scale.

According to Underwood (1976: 155; see however, Kardong, 1972), the right intrapulmonary bronchus is of modest length in Boa, Calabaria, Charina, Eryx, Gongylophis and Lichanura (18-44\%, percentage of length of right lung). Trachyboa and Tropidophis have an even more derived state (64-97\%), which I have not designated as a character state. The plesiomorphic condition in erycines appears to be a length of $10 \%$ or less (see Underwood, 1976).

(73) Reproductive mode: Oviparous (0) or viviparous (1). According to Shaw \& Campbell (1974), Shine (1985), McDowell (1987) and Mehrtens (1987), acrochordids, anilioids, all boines (Corallus cropanii is unknown), Charina, Eryx (including Gongylophis), Lichanura and tropidophiines [including Trachyboa (Harry Greene, personal communication; contra Kluge, 1991: 43)] are viviparous, whereas Anomochilus (Brongersma \& Helle, 1951), bolyeriines (contra Kluge, 1991, but following S. Tonge, personal communication for Bolyeria, and Bloxam \& Tonge, 1986 and Ross \& Marzec, 1990 for Casarea), Calabaria, Loxocemus, all pythonines, almost all scolecophidians (M. A. Smith, 1943; Erasmus \& Branch, 1983; Shine \& Webb, 1990), and Xenopeltis are oviparous. Given this pattern of outgoup variation, the polarity is equivocal for erycines.

(74) Chromosome Number: The diploid number of chromosomes is 36 (0) or 34 (1). Ingroup variation was taken from Gorman (1973) and De Smit (1978). The following observations on the booid outgroup taxa suggest that state 0 is plesiomorphic in erycines (see also Gorman \& Gress, 1970): $2 n=36$ has been 

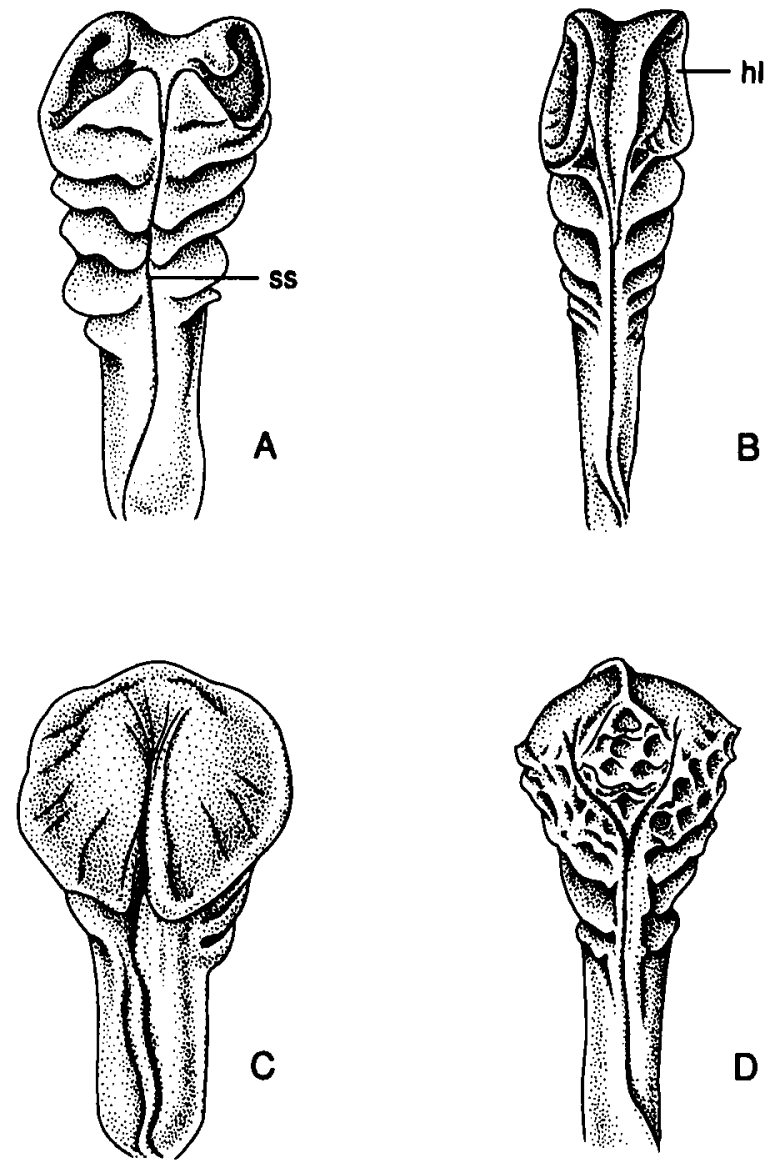

Figure 16. Hemipenes of representative erycines (redrawn from originals provided by $\mathbf{H}$. G. Dowling; see also Dowling, 1975b). A, boltae; left, HGD 178 (see also Cope, 1895: pl. 14, fig. 3; Dowling \& Savage, 1960: fig. 3D). B, trivirgata; right (see also Cope, 1895: pl. 15, fig. 5; Branch, 1986: fig. 5A). C, reinhardtii; right, HGD 529 (see also Doucet, 1963: fig. 4). D, johnii; right, HGD 559. Probably over-inflated [e.g. see jaculus illustrated by Cope, 1895: pl. 15, fig. 6; however, consistent with Domergue's (1962: fig. 1) drawing of jaculus]. $\mathrm{hl}=$ hemipenial lobe; ss = sulcus spematicus.

observed in Boa constrictor, Epicrates cenchria, E. striatus, Eunectes murinus, Exiliboa, Loxocemus, Morelia amethistina, M. boeleni, M. papuanus, Python molurus and Xenopeltis; $2 n=34$ in Boa dumerili and B. manditra; $2 n=44$ and 40 in Corallus caninus and C. enydris, respectively (Fischman et al., 1972; Gorman, 1973; De Smit, 1978; Mengden \& Stock, 1980; Bickham, 1984; Hardy, 1989).

(75) Muscle: Levator bulbi fibers, which insert on the palatine as the retractor arcus palatini muscle (McDowell, 1987), are present ( 0 ) or absent (1). McDowell (1987: 27, 29) stated the muscle is widespread among booids, including Eryx and Gongylophis, but absent in Calabaria, Charina and Lichanura. Further, he claimed (p. 29) the loss of the muscle relates to the palatine being 'erectile independently of [the] maxilla'. I accept McDowell's generalities concerning presence and absence of the muscle, and $I$ assume state 0 is plesiomorphic relative to the condition found in erycines. 


\section{Other variation}

The mesial frontal flange suture of the olfactory canal (Rieppel, 1979a: fig. 2) is present or absent in adult alethinophidians, and Underwood (1976: 158) stated the absence of that suture is limited to Calabaria, Casarea, caenophidians, Charina and Eryx. Underwood interpreted the absence as owing to 'fusion', and he implied it was correlated with a burrowing way of life. While it might seem reasonable to assume this state delimits part of erycines, there have been numerous erroneous observations and interpretations, which when corrected suggest another conclusion. The presence of a mesial frontal flange suture in so many of Rieppel's (1978a: figs 9, 11-13) illustrations of erycines and his explicit statement (p. 202) that the 'suture remains clearly visible' in trivirgata are difficult to explain in light of my observations. Underwood (1976: 158) also seems to have misjudged the condition in trivirgata. I examined nearly all of the skulls of erycines that Rieppel and Underwood studied (all of the trivirgata: AMNH 38721; BMNH 94.3.24.4, incorrectly cited as 94.3 .24 .2 by Underwood), and the entire sample of trivirgata available with one or both olfactory canals completely exposed (AMNH 75285; BMNH 94.3.24.4; CM 56093; FMNH 8043; MCZ 8966; UF 68316; UMMZ 131053, 134130, 189644) shows no evidence of a suture in the mesial wall of the frontal. The absence of a suture is clearest in those specimens where the paired frontals are separated and the mesial wall can be examined from all sides (e.g. UF 68316; UMMZ 131053). Rieppel's and Underwood's different interpretation concerning the presence or absence of the mesial frontal flange suture are not likely to be owing to age differences in the specimens examined. In fact, almost all of the subadult erycines provide no evidence of a suture along the anterior margin of the canal (e.g. reinhardtii, SVL $=870 \mathrm{~mm}$; bottae, SVL $=525 \mathrm{~mm}$; colubrina, juvenile; trivirgata, $\mathrm{SVL}=475 \mathrm{~mm}$ ). One bottae (BMNH 78.5.20.3) is exceptional. That specimen has the separated condition on the right side; however, the left is fused narrowly along the anterior margin of the canal. A few other subadult bottae have yet to realize complete fusion posteriorly, which appears to indicate an ontogenetic anterior to posterior sequence of mineralization. In addition to all erycines, I believe the fused condition is characteristic of Acrochordus, Bolyeria (erroneously scored by Underwood, 1976: 158 as having a long, unfused contact), caenophidians, Casarea (BMNH 70.11.30.4d, a subadult), Exiliboa and Ungaliophis. The nature of the contact cannot be determined in a second skull of Casarea (MCZ 49135) because that area was destroyed by its preparator. The only available adult Anilius (UMMZ 149661) exhibits the fused state, while two smaller specimens (KU 140152; UMMZ 183253) have a suture. The fact that adult Cylindrophis and uropeltines (e.g. Plecturus, BMNH 1930.5.8.105; Pseudotyphlops, BMNH 1978.1092; Uropeltis, BMNH 1930.5.8.78) possess a suture suggests the fused state observed in the one Anilius is not diagnostic of anilioids. The suture is present in boines, Loxocemus, pythonines, Trachyboa, Tropidophis and Xenopeltis. Given the current hypothesis of outgroup relationships (Fig. 1), there are equally parsimonious interpretations of the history of the mesial suture of the frontal. The fused condition can be hypothesized to have evolved independently in the advanced snake and erycine clades, or it originated earlier, and but once, with the suture in boines and pythonines being interpreted as a reversal.

Hoffstetter \& Rage (1972: 106-107, fig. 9E) noted the middle Miocene 
Albaneryx from France and the New World bottae and trivirgata have the stapedial facet located along the upper portion of the quadrate, near the supratemporal . Such a position is unlike other erycines (including the extinct Bransateryx vireti; Hoffstetter \& Rage, 1972: pl. 2, fig. 3), in which the facet is located more ventrally along the quadrate. I have been unable to confirm, in qualitative terms, a consistently dorsally or ventrally located facet in erycines. Only a detailed quantitative evaluation of larger series than are available to me will establish the phylogenetic informativeness of this variation.

The laterosphenoid is large in most snakes. In erycines, the laterosphenoid is wide, narrow or absent, and Rieppel (1978a: 190) cited this character as evidence of relationships. Unfortunately, there is considerable intraspecific variation, and both extremes may even occur in a single specimen (tatarica, NMB 17538). Therefore, I consider this character uninformative in erycines.

The shape of the pterygoid varies considerably among erycines, as it does among booids generally; however, I have been unsuccessful in consistently delimiting those states qualitatively. Multivariate quantitative descriptions (e.g. see Lombard, Marx \& Rabb, 1986) must be attempted before the shape of the pterygoid is discounted altogether as a source of erycine synapomorphies.

The width of mid-trunk vertebrae may be phylogenetically informative in erycines (Rage, 1977); however, many attempts to quantify that variation have been unsuccessful. It is likely that width may be affected by different aspects of vertebral anatomy, the centrum, the length of the pre- and/or postzygopophyses, and the shape of the area between those zygopophyses. Character states are difficult to define because the width variation observed among erycine mid-trunk vertebrae, and relevant outgroups, appears to be as great within a species as it is between species. Moreover, there is significant serial variation within an organism. For example, mid-trunk bottae vertebrae (Bogert, 1968: fig. 10) appear to be one of the narrowest observed among erycines, but that species' anterior and posterior trunk vertebrae are like many outgroups in being still narrower.

Szyndlar (1987: 60, fig. 4) used the similarity of the 'upswept neural arch in the zygantral area' as the basis for tentatively referring one cervical and 13 trunk vertebrae from the lower Miocene of Czechoslovakia to Gongylophis. I have examined the dorsoposterior margin of the neural arch of mid-trunk vertebrae, adjacent to the neural spine, and I have been unable to consistently identify nearly horizontal or 'unswept' states among erycines. Only vertebrae from adults were used because there is a conspicuous ontogenetic effect. Therefore, I cannot confirm Szyndlar's action.

The mid-trunk vertebrae of jayakari are peculiar in having an extremely long mammillary process, the distal extension of the prezygopophysis beyond the area of articulation with the postzygopophysis. Although, there is considerable interspecific variation in the length of this process, no other erycine seems to approach such an obviously specialized state. An equally long mammillary process was observed among the relevant outgroups only in Bolyeria (Underwood, 1976: fig. 6).

Szyndlar (1987) thought his lower Miocene vertebrae from Czechoslovakia were novel in having a low neural spine, a condition which he also attributed to conica. While his illustrations (fig. 4) do show a low spine, that state is not peculiar to conica among living erycines. Moreover, there appears to be considerable intraspecific variation, and therefore I am reluctant to recognize 
low and high states in neural spine elevation. Further, spine height is difficult to judge because of the shape of the neural arch, horizontal to unswept (see discussion above). The width and length of the spine varies among erycines, and that variation may also contribute to the appearance of greater height in the neural spines of some specimens.

Szyndlar emphasized (p. 60) 'the straight anterior border of the zygosphene, shifted downwards paradiapophyses, and presence of a prominent haemal keel' in some erycines. However, I have been unable to detect phylogenetic information in these descriptions in the available samples of extant species.

A prominent fleshy papilla is present or absent on the asulcal surface of the proximal flounce of snake hemipenes. It is absent in bottae, colubrina, conica, jaculus, jayakari, johnii, reinhardtii and trivirgata. According to Branch (1986), the papilla occurs in pythonines and most boines; however, the state must be determined in the other booid outgroups before the level of generality of this character can be estimated with confidence.

Underwood (1976) called attention to the absence of the splenic limb of the pancreas, which results in a gap between the spleen and the pancreas, in jaculus and johnii. I have had difficulty confirming these observations, and a much broader taxonomic survey is required before the phylogenetic informativeness of this variation can be estimated.

Greene's (1973) research on defensive tail displays in squamates suggests the erycine clade might be diagnosed by such a behaviour. Greene's evidence indicated that bottae, johnii and reinhardtii display their tails to misdirect the attacks of predators. He also implied (p. 155) that tatarica is similarly apomorphic. However, Greene speculated that conica does not exhibit the display, based on limited behavioural observations and the absence of tail damage in 28 specimens. Additional research is required, both among the ingroup and outgroups, in order to estimate the taxonomic level of generality of this interesting variation.

\section{Data analysis}

When the 75 characters summarized in Appendix II are treated as additive, four equally most parsimonious cladograms are obtained with an exact analysis (the implicit enumeration algorithm in Hennig86; $S=141, C=0.72, R=0.82$ ), the strict consensus of which is illustrated in Fig. $17(S=170, C=0.60)$. The first application of character weighting (the xs $w$ algorithm; Appendix III), with an exact analysis, led to the completely resolved branching pattern shown in Fig. $18(S=141)$. This hypothesis of sister group relationships requires 39 extra steps to explain the available evidence, whereas a completely unresolved topology requires 179 additional extra steps (Kluge, 1989).

Inspection of the four equally most parsimonious cladograms obtained above reveals that somalicus is solely responsible for the different topologies (Fig. 17). Its alternative relationships are: (somalicus, tatarica (jaculus, johnii)), (somalicus (jayakari (muelleri (colubrina, conica)))), (somalicus (colubrina, conica)) and (colubrina, somalicus). The fact that many characters ( 26 of 75 , or $35 \%$; Appendix II) could not be determined for somalicus may be the cause of the first of these four patterns of relationships (among the other living terminal taxa, elegans has the next largest 


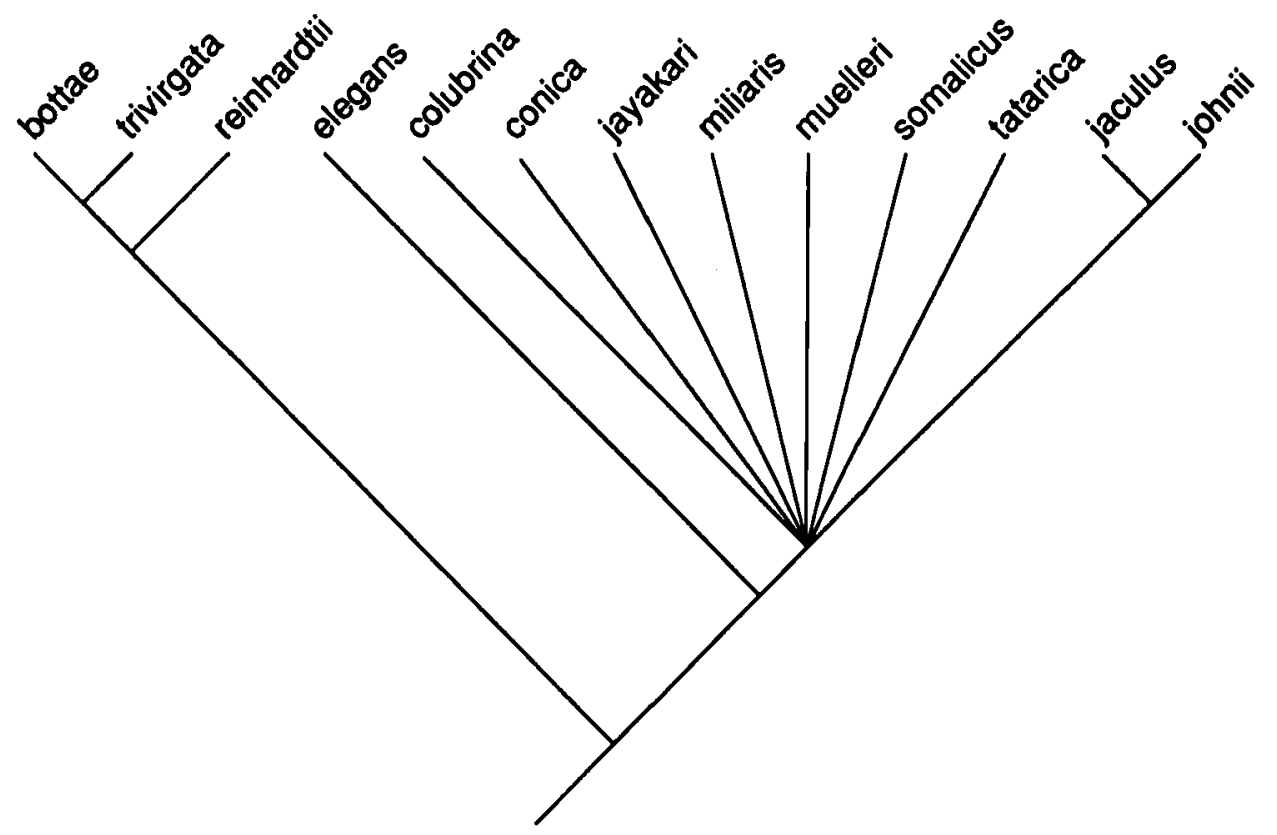

Figure 17. The strict consensus of the four best-fitting hypotheses of interspecific relationships among erycines based on an exact analysis of the synapomorphies summarized in Appendix II, under the assumption of multistate character additivity $(S=170, C=0.60)$. See text for further discussion.

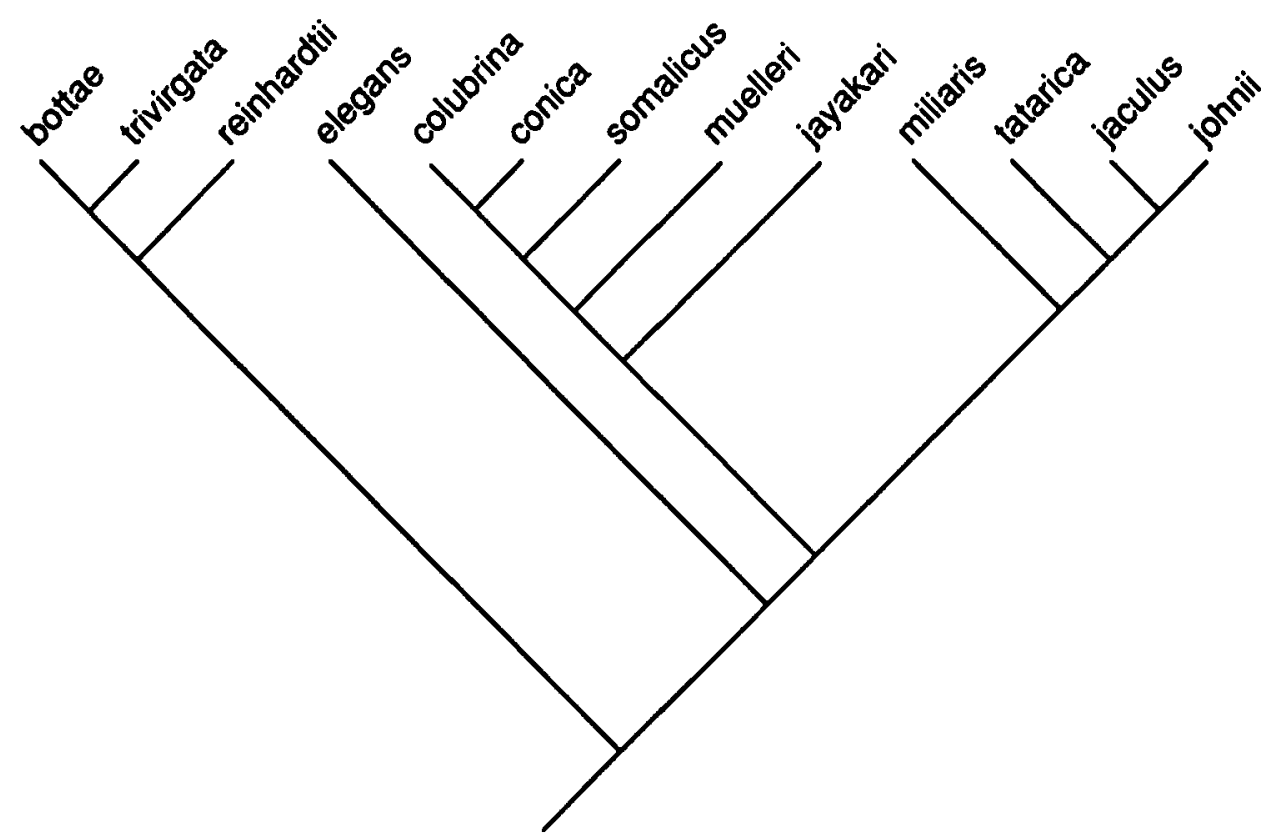

Figure 18. The complete resolution of the four best-fitting hypotheses of interspecific relationships among erycines (see Fig. 17) was accomplished with the first iteration of character weighting (the xs $w$ algorithm; Appendix III), with an exact analysis $(S=141)$. See text for further discussion. 


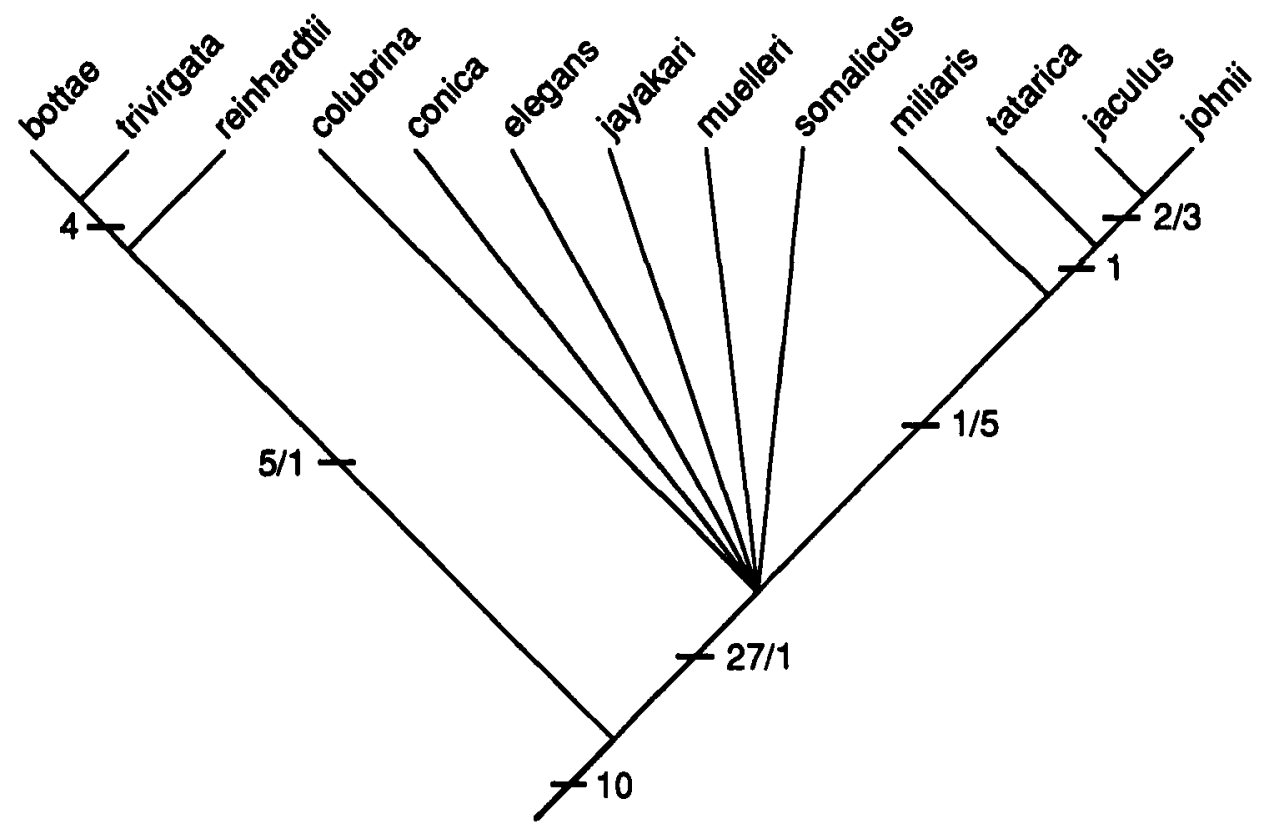

Figure 19. The strict consensus of the 13 best-fitting hypotheses of interspecific relationships among erycines based on an exact analysis of the synapomorphies summarized in Appendix II, under the assumption multistate character non-additivity $(S=126, C=0.81, R=0.86)$. See text for further discussion.

amount of missing data with $11 \%$ : seven unknown states and one variable set of states). However, character incongruence must be responsible for the remaining three topologies, and the contributing characters are 7, 11, 40, 49, 56, 58, 62-64 and 67 . All but 58 and $62-63$ probably vary ontogenetically in somalicus, as they appear to in the other terminal erycine taxa, and not being able to examine large (adult) somalicus in this study provides a simple explanation for the observed incongruence. No doubt, the availability of only a single skull (Appendix IV) is another contributing factor. A unique best fitting hypothesis ( $S=136, C=0.75, R=0.83$ ) is obtained, with the implicit enumeration algorithm, when somalicus is removed from the data matrix (Appendix II), and that topology is otherwise identical to the weighted results shown in Fig. 19.

When the characters (Appendix II) are treated as non-additive and analysed with the implicit enumeration algorithm in Hennig86, 13 equally most parsimonious cladograms are obtained $(S=126, C=0.81, R=0.86)$, the strict consensus of which is illustrated in Fig. $19(S=138, C=0.74)$. This hypothesis requires only 36 extra steps to explain the available evidence, whereas a completely unresolved topology requires 143 additional extra steps (Kluge, 1989). As noted in the Methods and materials section, successive weighting was not applied to non-additively coded characters because a computationally efficient parsimony algorithm is unavailable.

Inspection of the 13 equally most parsimonious cladograms obtained above reveals that somalicus is only partly responsible for the different topologies (Fig. 19). Indeed, when examined as an undirected network (Kluge, 1976: 
fig. 4; Frost \& Etheridge, 1989: fig. 7), somalicus' sister group affinities are variable, but those alternatives account for only 12 of the different patterns. The exceptional (13th) pattern exhibits only one node between jayakari and muelleri, while the 12 others require two or three, depending of the position of somalicus. In addition to the variable positions of two terminal taxa (somalicus and jayakari or muelleri), the 13 undirected networks are rooted in six different places, and it is not surprising that non-additivity is the remaining responsible factor (i.e. the loss of phylogenetic information in multistate characters $6,11,13,20,29,42-43,50$, $57-58,60,65$ and 70 ). When somalicus is removed from the data matrix and the exact analysis rerun, under the assumption of non-additivity, three equally most parsimonious cladograms are obtained $(S=123, C=0.82, R=0.87)$, the strict consensus of which is identical to the topology illustrated in Fig. 19 (except for the omitted somalicus; $S=136, C=0.74$ ).

Figures 18, 19 have six non-trivial ingroup clades in common. I use those consistently resolved components as my most conservative hypothesis of erycine sister group relationships (as summarized in Fig. 19).

\section{The reality of the ingroup}

Hoffstetter (1962: 267) appears to have been the first to suggest that Charina, Eryx and Lichanura form a clade (see also Hoffstetter \& Rage, 1972), while Underwood (1967: 76-77) concluded from his review of anatomy that Lichanura probably had other historical affinities, specifically among the Boini. My findings confirm the pattern of relationships suggested by Bogert (1968: 20, 30; see also Hoffstetter, 1962; Hoffstetter \& Rage, 1972), ((Charina, Lichanura) Eryx); however, it is the unambiguous erycine affinities of reinhardtii documented in this paper that have little (see Introduction), or no, basis in recent research, and which must be judged carefully (e.g. see alternative phylogenetic hypotheses in Frazzetta, 1975: fig. 2; Underwood, 1976: fig. 8). Such consideration is particularly important in light of Rieppel's (1978a: 206; see also McDowell, 1987: 28) claim that the similarities between reinhardtii and Eryx are owing to 'parallel evolution of a functionally correlated character [sic] responding to similar selective pressures'. Moreover, Rieppel conjectured (p. 206) that if reinhardtii 'were to be included within the Erycinae, it would have to be regarded as an early offshoot', not as the sister lineage to the (bottae, trivirgata) clade, as my evidence indicates (see following section).

According to the phylogenetic hypothesis illustrated in Fig. 19, erycines, including reinhardtii, can be delimited from other booids by 10 , unambiguously optimized, synapomorphies: (1) the lateral and medial heads on the anterior end of the ectopterygoid have been lost (character 24$)$; (2) the palatine contacts a wide ledge of bone projecting medially from the pterygoid (character 39 ); (3) the maxillary process of the palatine lies posteriorly, at the level of the palatinepterygoid contact (character 41); (4) the right posterior vidian canal is larger than the left (character 47); (5) caudal neural spines are grooved dorsally (character 51 ); (6) an accessory process occurs on the neural arch of a caudal vertebra (character 53); (7) a large supraocular scale has been lost (character $62) ;(8)$ the hemipenis is more or less unilobed (character 70); (9) there is a long intrapulmonary bronchus (character 72 ); (10) the retractor arcus palatini muscle 
has been lost (character 75). Four additional characters distinguish the erycine clade, including reinhardtii, although this additional evidence obtains only under the assumption of additivity: (11) the nasal process of the premaxilla is short or absent (character 5); (12) a small to large vertical wall of bone is present on the lateroposterior margin of the nasal (character 14); (13) the dorsoposterior process of the septomaxilla is reduced (character 36); (14) the modal, or median, number of palatine teeth is less than 6 (character 37 ).

The large number of both osteological and soft anatomical characters confirming the erycine clade (Fig. 19) inspires confidence in the historical reality of that entity; however, it must be admitted that some of the shared derived conditions recorded for reinhardtii (especially of characters 1, 5 and 6) are not as obvious as they are in other erycines. In fact, my judgement of the existence of caudal skeletal specializations in reinhardiii could be influenced by the fact that it has the apomorphic thick, blunt tail of most other erycines (see character 69). In any case, it is necessary to consider the nature of the evidence for a non-erycine placement of reinhardiii. The only incongruent synapomorphy of sufficient generality to qualify as a basis for an alternative classification is the presence of the supraorbital bone (character 21) in Dinilysia, Loxocemus, pythonines and reinhardtii (Frazzetta, 1959: 469; Underwood, 1976: 169). The presence of the supraorbital in those taxa is most simply interpreted on the hypothesis illustrated in Fig. 1 as an example of independent acquisition. Alternatively, the history of that bone would have to be explained as having been lost independently at least six times: once in each of the lineages leading to the advanced snake and boine clades, once in anilioids, once in Xenopeltis, and twice among erycines (see also M. A. Smith, 1943: 103). The fact that the so-called supraorbital bone contacts the prefrontal in Loxocemus and pythonines, but does not do so in reinhardtii (also Dinilysia), indicates a pattern of dissimilarity consistent with the former, more parsimonious, interpretation of convergent acquistion. Other characteristics shared by reinardtii and Loxocemus (Frazzetta, 1959: 469, fig. 7A-C), such as the unilobed nature of the dorsal end of the postorbital bone, are most simply interpreted as symplesiomorphies (see Underwood, 1976, his character 45; Kluge, 1991: 27). Underwood's (1976: fig. 8) treatment of reinhardiii as the sister lineage to the (advanced snakes (boines, erycines)) group, and more recently as the sister lineage to all other alethinophidians (Underwood, 1989), also seems to be based on misinterpreted polarities, as well as incorrectly observed taxonomic generalities. Thus, there appears to be sufficient evidence, much greater than alternative explanations, to consider reinhardtii an erycine.

\section{Relationships among the parts of the ingroup}

The six clades discovered among erycines (Fig. 19) are variously supported by synapomorphies. Without regard for either the assumption of multistate character additivity or non-additivity, most groups are delimited unambiguously by two or more novelties (see Diagnoses section). The nested ((bottae, trivirgata) reinhardtii) clades are characterized by four and six shared novel ties, respectively, and 28 synapomorphies confirm the clade that includes the species usually grouped together as Eryx (including Gongylophis). Unfortunately, there is relatively little resolution within the latter radiation. I suspect the difficulty I 
have had in discovering their relationships is simply a function of inadequate study material (only one or two subadult skulls were available for each species; see Appendices I-IV), and not mosaic evolution. Even so, the nested (miliaris, tatarica (jaculus, johnii)) assemblages are confirmed by five and six synapomorphies, respectively. The fact that the resolved relationship of tatarica, as the sister group to the (jaculus, johnii) clade, is based on a single apomorphy, although unique and unreversed, inspires little confidence in that part of the phylogenetic hypothesis.

Figure 19 provides a test of Rieppel's (1978a: 196-205; see Introduction) conclusion concerning the evolution of burrowing in erycines, as exemplified by his nearly linear ordering of species (trivirgata $\rightarrow$ bottae $\rightarrow$ tatarica $\rightarrow$ conica $\rightarrow$ jayakari and somalicus $\rightarrow$ colubrina and muelleri $\rightarrow$ miliaris $\rightarrow$ jaculus $\rightarrow$ johnii). This pattern can be translated into a cladistic hierarchy, largely ladder-like, assuming the living species are common ancestors of sister lineages. Such a phylogenetic hypothesis has little in common with the cladogram illustrated in Fig. 19 (or Figs 17-18). The only clade identified by both hypotheses is (jaculus, johnii). Thus, my findings substantially disconfirm Rieppel's views on the evolution of burrowing in erycines.

Tokar's (1989) generic reclassification of Eryx species was based on a phenetic analysis of numerous skull measurements, and he concluded there are four taxa: Gongylophis (conicus), Neogongylophis (colubrinus and muelleri), Eryx (elegans, jaculus, johnii, miliaris, somalicus, tataricus, vittatus), and Pseudogongylophis (jayakari). I have been unable to discover phylogenetic evidence for either of his two major assemblages, Neogongylophis or Eryx (Figs 18, 19).

\section{A monophyletic taxonomy}

There are three ways to maintain a monophyletic, binominal taxonomy for the ((bottae, trivirgata) reinhardtii) part of the erycine cladistic hypothesis (Fig. 19): (1) each species is given its own genus group name, e.g. Charina, Lichanura and Calabaria, respectively; (2) recognize Calabaria and synonymize Lichanura with Charina; or (3) use Charina for all three species. The first possibility is the least efficient taxonomically because a fourth name is needed to indicate the unity of the three species among the erycines. The second proposition also requires a suprageneric epithet for the same reason. The last of the three alternatives, a single name, Charina, is the most efficient in terms of number of genus group names required; however, like the first possibility, it must be accompanied by Wiley's (1981) sequencing convention in order to specify the hierarchy of species relationships. Thus, adopting that convention, I employ Charina for bottae, trivirgata and reinhardtii for reasons of taxonomic efficiency, and because it emphasizes evidence for a historical connection between the New and Old Worlds (see below).

The relationships, largely unresolved, among the remaining erycines (Fig. 19), can be effectively classified with a single genus group name, Eryx, plus the sequencing and sedis mutabilis conventions of Wiley (1981). I continue to use the informal name erycine, without reference to categorical rank (Gauthier et al., 1988), for the (Charina, Eryx) clade (see Fig. 19). The hierarchical, indented list, taxonomy is set out below. 


\section{Diagnoses*}

(Charina, Eryx): 24, 39, 41, 47, 51, 53, 62, 70(1-2), 72, 75.

Charina: 1, 26, 27, 32, 34, 69c.

C. reinhardtii.

C. (bottae, trivirgata): 22, 25, 31, 48.

Eryx: 3, 4, 6(2), 7, 8, 10, 11(2), 15, 16, 18(2), 19, 20, 23, 28, 29(2), 38, 40, $43(2), 44,45,52,54,55 \mathrm{c}, 56,57(2), 59,61,74$.

E. colubrinus, sedis mutabilis.

E. conicus, sedis mutabilis.

E. elegans, sedis mutabilis.

E. jayakari, sedis mutabilis.

E. muelleri, sedis mutabilis.

E. somalicus, sedis mutabilis.

E. (jaculus, johnii, miliaris, tataricus): 9c, 15(2), 29r, 30c, 66(2)c, 69c.

E. miliaris.

E. (jaculus, johnii, tataricus): 65 .

E. tataricus.

E. (jaculus, johnii): 2, 20(0)x, 43r, 44(2), 45(2)c.

\section{BIOGEOGRAPHY}

Dowling (1975b: 194; see also Szyndlar, 1991b) speculated that Charina bottae and C. trivirgata evolved from the Palaearctic erycine fauna in the Eocene, and entered the New World when North America and Europe were still joined. Rage (1977: 460; see also Hoffstetter \& Rage, 1972) stated that the erycine clade 'probably originated in North America', and spread from there into the Old World (Asia and Europe). The suggested earliest time of origin ranges from Paleocene (Rage, 1977: fig. 2) to Early Eocene (Rieppel, 1978a: 186). Rage's scenario involving a New World origin largely follows from his belief that New World erycine fossils belonging to Helagras, Calamagras and Ogmophis form an ancestor-descendent sequence, in that order (see, however, Auffenberg, 1963), leading to Charina bottae, and that Calamagras gave rise as well to the extinct Western European Cadurceryx. Further, Rage (1977: 462, fig. 2) speculated that the Eryx lineage dispersed independently into the Old World 'from the same stock as Calamagras-Ogmophis'. I have been unable to investigate the cladistic relationships of the most significant New World Calamagras-Ogmophis fossils (see Fossils section above); however, the simplest geographic interpretation, given the phylogenetic hypotheses of the extant taxa illustrated in Fig. 19, is that erycines radiated initially in the Old World. The geographic distribution of the West African Charina reinhardtii is not unusual among Old World erycines (e.g. see Eryx muelleri; Stafford, 1986: 39, 41); however, its phylogenetic relationships are

\footnotetext{
*The only diagnostic information summarized below is that obtained without regard to the assumptions of multistate character additivity or non-additivity. Numbers without parentheses refer to particular characters (1-75; see Character descriptions section and Appendix II), those within parentheses specify character states. Character state 1 can be assumed, unless indicated otherwise. The lower-case letter $c$ means convergence/ parallelism, $r$ equals reversal, and $x$ signifies both $c$ and $r$. Character state evolution can be assumed to be unique and unreversed in erycines, unless indicated otherwise. Autapomorphies are omitted.
} 
critical to the conclusion that erycines radiated initially in the Old World. For example, if $C$. reinhardtii were found to be the sister group to the Eryx clade then the interpretation is equivocal, the New and Old World hypotheses being equally parsimonious. A similar Old World radiation hypothesis can be found in eublepharine lizards (Grismer, 1988: fig. 54); however, opposing examples are also available (Wake et al., 1978; Lombard \& Wake, 1986).

\section{ACKNOWLEDGEMENTS}

I wish to thank L. Cagnolaro for information on the type material of Eryx jaculus sennaariensis in the Museo Civico di Storia Naturale di Milano, Steve Farris for assistance with Hennig86, Herndon Dowling for illustrations of erycine hemipenes (Fig. 16), Al Holman for information on erycine fossils, Margaret van Bolt for preparing the illustrations, and Olivier Rieppel for his insights into snake anatomy. I thank Nick Arnold, David Auth, Ellen Censky, Robyn Garcia, John Gasperetti, Jacques Gauthier, David Good, Harry W. Greene, Tom Huff, Mike Klemmens, Eugen Kramer, Benedetto Lanza, Al Leviton, Hy Marx, Jack McCoy, Chuck Myers, J. P. O'Brien, Greg Pregill, José Rosado, Greg Schneider, Steve Simpson, Andrew Stimson, N. N. Szczerbak, Anatoly Tokar, S. J. Tonge, Jens Vindum, Ed Wade and Dave Wake for information and assistance in obtaining specimens. Ken Frazer, Darrel Frost, and Olivier Rieppel read the manuscript. Garth Underwood was particularly helpful in that he laboured over the manuscript on two separate occasions. The criticisms of all the reviewers are greatly appreciated. This research was supported by National Science Foundation grant BSR-8822656, and it was initiated at the Natural History Museum, London, during my sabbatical leave from the University of Michigan (1989-90).

\section{REFERENCES}

Anthony J, Guibe J. 1952. Les affinities anatomiques de Bolyeria et de Casarea (Boides). Mémoires de l'Institut Scientifique de Madagascar 7: 189-201.

Auffenberg W. 1963. The fossil snakes of Florida. Tulane Studies in Zoology 10: 131-216.

Bannilkov AG, Darevskii IS, Ishcenko VG, Rustamov AK, Szczerbak NN. 1977. Guide to the amphibian and reptilian fauna of the U.S.S.R. (in Russian). Moscow: Prosveshchenie.

Bauer AM, Russell AP. 1989. Supraorbital ossifications in geckos (Reptilia: Gekkonidae). Canadian Journal of Zoology 67, 678-684.

Baumeister L. 1908. Beitrage zur anatomie und physiologie der Rhinophiden. Zoologische Jahrbücher. Abtheilung für Anatomie und Ontogenie der Tiere 26: 423-526.

Beddard FE. 1904. Notes upon the anatomy of certain snakes in the family Boidae. Proceedings of the Zoological Society of London 1904: 107-121.

Beddard FE. 1906. Contributions to the knowledge of the vascular and respiratory systems in the Ophidia, and to the anatomy of the genera Boa and Corallus. Proceedings of the Zoological Society of London 1906: $499-532$.

Bellairs Ad'A, Boyd JD. 1950. The lachrymal apparatus in lizards and snakes. II. The anterior part of the lachrymal duct and its relationship with the palate and with the nasal and vomeronasal organs. Proceedings of the Zoological Society of London 120: 269-310.

Bellairs Ad'A, Kamal AM. 1981. The chondrocranium and the development of the skull of Recent reptiles. In: Gans C, Parsons TS, eds. Biology of the Reptilia 11. New York: Academic Press, 1-263.

Bichham JW. 1984. Patterns and modes of chromosomal evolution in reptiles. In: Sharma AK, Sharma A, eds. Chromosomes in evolution of eukaryotic groups. Florida: Boca Raton, CRC Press, 13-40.

Blosham QMC, Tonge \$J. 1986. The round island boa Casarea dusumieri breeding programme at the Jersey Wildlife Preservation Trust. Dodo, Journal of the Fersey Wildlife Preservation Trust 23: 101-107.

Bogert CM. 1968. A new genus and species of dwarf boa from southern Mexico. American Museum Novitates, No. 2354: $1-38$. 
Boulenger GA. 1892. Description of a new snake from Nubia. Annals and Magazine of Natural History, Series 698 74-76.

Boulenger GA. 1893. Catalogue of the snakes in the British Museum (Natural History) 1. London: Taylor \& Francis.

Branch WR. 1981. Hemipenes of the Madagascan boas Acraniophis and Sanzinia, with a review of hemipeneal morphology in the Boinae. Journal of Herpetology 15, 91-99.

Branch WR. 1986. Hemipeneal morphology of African snakes: A taxonomic review. Part 1. Scolecophidia and Boidae. Joumal of Herpetology 20: 285-299.

Breithnupt BH, Duvall D. 1986. The oldest record of serpent aggregation. Lethaia 19: 181-185.

Brongeruma LD. 1951. Some notes upon the anatomy of Tropidophis and Trachyboa (Serpentes). Zoologische Mededelingen, Leiden 31: 107-124.

Brongersma LD, Helle W. 1951. Notes on Indo-Australian snakes. Proceedings Koninklijke Nederlandsche Akademie van Wetenschappen, Amsterdam, Series C 54:3-10.

Cadle JE, Dessauer HC, Gans C, Gartside DF. 1990. Phylogenetic relationships and molecular evolution in uropeltid snakes (Serpentes: Uropeltidae): allozymes and albumin immunology. Biological fournal of the Linnean Society 40, 293-320.

Carpenter JM. 1988. Choosing among equally parsimonious cladograms. Cladistics 4: 291-296.

Collins JT. 1990. Standard common and current scientific names for North American amphibians and reptiles. Herpetological Circular, Society for the Study of Amphibians and Reptiles, No. 19: 1-41.

Cope ED. 1895. The classification of the Ophidia. Transactions of the American Philosophical Society 18: $186-219$.

Cope ED. 1900. The crocodilians, lizards, and snakes of North America. Report of the United States National Museum 1898: 155-1270.

Cundall D, Irish FJ. 1989. The function of the intramaxillary joint in the Round Island boa, Casarea dussumieri. Journal of Zoology, London 217: 569-598.

De Silva PHDH. 1980. Snake fauna of Sri Lanka, with special reference to skull, dentition and venom in snakes. Colombo: National Museum of Sri Lanka.

De Smit WHO. 1978. The chromosomes of 23 species of snakes. Acta Zoologica et Pathologica Antverpiensia, No. 70: 85-118.

Dessauer HC, Cadle JE, Lawmon R. 1987. Patterns of snake evolution suggested by their proteins. Fieldiana, Zoology, No. 1376: 1-34.

De Witte GF. 1962. Genera des serpents du Congu et du Ruanda-Urundi. Annales Musee Rayal de L'Afrique Centrale, Terouren, Belgique, Sciences Zoologiques 104t 1-203.

Domergue CH. 1962. Observations sue les pénis des ophidiens. Bulletin de la Sociéte des Sciences Naturelles at Physiques du Maroc 12; 87-106.

Donoghue MJ. 1990. Why parsimony? Evolution 44: 1121-1123.

Doucet J. 1963. Les serpents de la Republique de Cote d'lvoire. Acta Tropica 20: 201-340.

Dowling HG. 1975a. A provisional classification of snakes 1. New York: Herpetological Information Search Services Publications, 1974 Herpetological Information Search Services Yearbook of Herpetology, 167-170.

Dowling HG. 1975b. The Nearctic snake fauna 1. New York: Herpetological Information Search Services Publications, 1974 Herpetological Information Search Services Yearbook of Herpetology, 191-202.

Dowling HG, Duellman WE. 1978. Systematic herpetology: A synopsis of families and higher categories. New York: Herpetological Information Search Services Publications.

Dowling HG, Gibeon FW. 1970. Relationships of the Asian sunbeam snake, Xenopeltis unicolor. Herpetological Review $2,51-52$.

Dowling HG, Savage JM. 1960. A guide to the snake hemipenis: A survey of basic structure and systematic characteristics. Zoologica $45 ; 17-28$.

Erasmus H, Branch WR. 1983. Egg retention in the South African blind snake Typhlops bibroni. Journal of Herpetology 17, 97-99.

Estes R, Frazsetta TH, Williams EE. 1970. Studies on the fossil snake Dinilysia patagonica Woodward: Part 1. Cranial morphology. Bulletin of the Museum of Comparative Zoology, Harvard University 140: 25-74.

Farris J8. 1969. A successive approximation approach to character weighting. Systematic Zoology 18: 374-385.

Farris J8. 1977. On the phenetic approach to vertebrate classification. In: Hecht M, Goody P, Hecht BM, eds. Major patterns in verlebrate evolution. New York: Plenum, 823-850.

Farris JS. 1982. Outgroups and parsimony. Systematic Zoology 31: 328-334.

Farris J8. 1988. Hennig 86 software, version 1.5, and Hennig86 reference. Privately printed and distributed.

Farris J8. 1989. The retention index and the rescaled consistency index. Cladistics 5: 417-419.

Farris J8. 1990. Phenetics in camouflage. Cladistics 6891-100.

Farris J\&, Kluge AG, Carpenter JM. ms. Successive and spectral weighting. Cladistics.

Fiechman HK, Mitra J, Dowling HG. 1972. Chromosome characteristics of 13 species in the order Serpentes. Mammalian Chromosomes Newsletler 13, 7-9.

Fitzinger LJ. 1843. Systema Reptilium. Wien: Braümuller \& Seidel.

Frazzetta TH. 1959. Studies on the morphology and function of the skull in the Boidae (Serpentes). Part 1. Cranial differences between Python sebae and Epicrates cenchria. Bulletin of the Museum of Comparative Zoology, Harvard University 119, 453-472.

Frazsetta TH. 1966. Studies on the morphology and function of the skull in the Boidae (Serpentes). Journal of Morphology 118, 217-296. 
Frazzetta TH. 1975. Pattern and instability in the evolving premaxilla of boine snakes. American Zoologist 15: $469-481$.

Friederich U. 1978. Der pileus der Squamata. Stutlgarter Beitrage zur Naturkunde, serie A (biologie) $307:$ 1-64.

Frost DR, Etheridge R. 1989. A phylogenetic analysis and taxonomy of iguanian lizards (Reptilia: Squamata). Miscellaneous Publications, The University of Kansas Museum of Natural History, No. 81: 1-65.

Fuhn IE, Vancea S. 1961. Fauna Republicii Populare Romine. Reptilia (Testoase, Sopirle, Serpi) 14. Editura Academiei Republicii Populare Romine.

Gasc J-P. 1974. L'interpretation fonctionelle de l'appareil musculosquelettique de l'axe vertebral chez les serpents (Reptilia). Mémoires du Muséum National d'Histoire Naturelle, Paris Série A 83: 1-182.

Gasc J-P. 1981. Axial musculature. In: Gans C, Parsons TS, eds. Biology of the Reptilia 11. Morphology. New York: Academic Press, 355-453.

Gasperetti J. 1988. Snake of Arabia. Fauna of Saudi Arabia 9: 169-450.

Gaupp E. 1908. Ueber Entwicklung und Bau der beiden ersten Wirbel und der Kopfgelenke von Echidne aculeata nebst allgemeinen Bemerkungen uber die Kopfgelenke der Amnioten. Jenaische Denkschriften 6: 483-538.

Gauthier J, Kluge AG, Rowe T. 1988. Amniote phylogeny and the importance of fossils. Cladistics 4: 105-209.

Gorman GC. 1973. The chromosomes of the Reptilia, a cytotaxonomic interpretation. In: Chiarelli AB, Capanna E, eds. Cylotaxonomy and vertebrate evolution. New York: Academic Press, 349-424.

Gorman GC, Gress F. 1970. Chromosome cytology of four boid snakes and a varanid lizard, with comments on the cytosystematics of primitive snakes. Herpetologica 26: 308-317.

Gray JE. 1849. Catalogue of the specimens of snakes in the collection of the British Museum. London: Edward Newman.

Gray JE. 1858. Description of a new genus of Boidae from Old Calabar, and a list of W. African reptiles. Proceedings of the Zoological Sociely of London 1858: 154-167.

Greene HW. 1973. Defensive tail display by snakes and amphisbaenians. Journal of Herpetology 7: 143-161.

Grismer LL. 1988. Phylogeny, taxonomy, classification, and biogeography of eublepharid geckos. In: Estes R, Pregill G, eds. Phylogenetic relationships of the lizard families: essays commemorating Charles L. Camp. California: Stanford University Press, 369-469.

Groombridge BC. 1979a. Variations in morphology of the superficial palate of henophidian snakes and some possible systematic implications. Journal of Nalural History, London 13: 447-475.

Groombridge BC. 1979b. Comments on the intermandibular muscles of snakes. Journal of Natural History, London 13: 477-498.

Groombridge BC. 1979c. On the vomer in Acrochordidae (Reptilia: Serpentes), and its cladistic significance. Journal of Zoology, London 189: 559-567.

Groombridge BC. 1984. The facial carotid artery in snakes (Reptilia, Serpentes): Variations and possible cladistic significance. Amphibia-Reptilia 5: 145-155.

Haas G. 1930. Ueber die Kaumuskulatur und die Schadelmechanik einiger Wühlschlangen. Zoologischen Jahrbücher. Abtheilung für Anatomie und Ontogenie der Tiere 52: 95-218.

Hardy LM. 1989. The karyotype of Exiliboa placata Bogert (Tropidopeidae), and comparisons with the family Boidae (Reptilia: Serpentes). Proceedings of the Biological Society of Washington 102: 1045-1049.

Hennig, W. 1966. Phylogenetic systematics. Chicago: University Illinois Press.

Higgins SB. 1873. Ophidians, zoological arrangement of the different genera, including varieties known in North and South America, the East Indies, South Africa, and Australia. Their poisons, and all that is known of their nature. Their galls, as antidotes to the snake-venom. Pathological, toxicological, and microscopical facts; together with much interesting matter hitherto nol published. New York: Boericke \& Tafel.

Hofistetter R. 1939. Sur l'articulation occipito-vertebrale des Uropeltidae (ophidiens fouisseurs). Bulletin du Muséum National d'Histoire Naturelle, Paris 11: 426-433.

Hoffstetter R. 1946. Remarques sur la classification des Ophidiens et particulierement des Boidae des Mascareignes (Bolyerinae subfam. nov.). Bulletin du Muséum National d'Histoire Naturelle, Paris 18: 432-435.

Hofistetter R. 1955. Sur les Boides fossiles de la sours-famille des Erycines. Compte Rendu des Séances de l'Académie des Sciences, Paris 240: 644-645.

Hoffstetter R. 1960. Sur la classification des boides de Madagascar et des Mascareignes. Bulletin du Muséum National d'Histoire Naturelle, Paris 32: 131-138.

Hoffstetter R. 1961. Squamates. Les gisement de Vertebres miocenes de Beni Mellal (Maroc). Noles et mémoires du Service des Mines et de la Carte géologigue du Maroc (Rabal) No. 155: 95-101.

Hoffstetter R. 1962. Revue des recéntes acquisitions concernant I'histoire et la systématique des Squamates. Colloques Internationaux du Centre National de la Recherche Scientifique, No. 104: 243-278.

Hofistetter R. 1968. [Review of] A contribution to the classification of snakes, by G. Underwood. Copeia 1968: 201-213.

Hoffotetter R, Gasc J-P. 1969. Vertebrae and ribs of modern reptiles. In: Gans C, Beliairs Ad'A, Parsons TS, eds. Biology of the Reptilia 1. Morphology A. New York: Academic Press, 201-310.

Hoffstetter R, Rage JC. 1972. Les Erycinae fossiles de France (Serpentes, Boidae). Comprehension et histoire de la sous-famille. Annales de Paleontologie (Vertebres) 58; 81-124.

Hoyer RF. 1974. Description of a rubber boa (Charina bottae) population from Western Oregon. Herpetologica 30: 275-283.

Jan G. 1863. Elenco sistematico degli Ofidi descritti e disegnati per l'Iconographia Generale. Milano: A. Lombardi. 
Jayne BC. 1982. Comparative morphology of the semispinalis-spinalis muscle of snakes and correlations with locomotion and constriction. Journal of Morphology 171: 83-96.

Johnson RG. 1955. The adaptive and phylogenetic significance of vertebral form in snakes. Evolution 9: 367-388.

Kamal AM, Hammouda HG. 1965. The chondrocranium of the snake Eryx jaculus. Acla Zoologica, Stockholm 46: $167-208$.

Kardong KV. 1972. Morphology of the respiratory system and its musculature in different snake genera (Part II). Charina bottae. Gegenbaurs Morphologisches Jahrbüch, Leipzig 117: 364-376.

Kluge AG. 1976. Phylogenetic relationships in the lizard family Pygopodidae: An evaluation of theory, methods and data. Miscellaneous Publications, Museum of Zoology, University Michigan, No. 152: 1-72.

Kluge AG. 1988. Relationships of the Cenozoic boine snakes Paraepicrates and Pseudoepicrates. Joumal of Vertebrate Paleontology 8: 229-230.

Kluge AG. 1989. A concern for evidence and a phylogenetic hypothesis of relationships among Epicrates (Boidae, Serpentes). Systematic Zoology 38, 7-25.

Kluge AG 1990. Species as historical individuals. Biology and Philosophy 5: 417-431.

Kluge AG. 1991. Boine phylogeny and research cycles. Miscellaneous Publications, Museum of Zoology, University Michigan, No. 178: 1-58.

Kluge AG. MS. Aspidites and the phylogeny of pythonine snakes. Records of the Australian Museum.

Kluge AG, Farris JS. 1969. Quantitative phyletics and the evolution of anurans. Systematic Zoology 18: 1-32.

LaDuke TG. 1991. The fossil snakes of pit 91, Rancho La Brea, California. Contributions in Science, Natural History Museum of Los Angeles County, No. 424: 1-28.

Langebartel DA. 1968. The hyoid and its associated muscles in snakes. Illinois Biological Monographs 38: 1-156.

Lesson F. 1950. Identification of snakes of the Gold Coast. Edinburgh: Oliver \& Boyd

Lombard RE, Marx H, Rabb GB. 1986. Morphometrics of the ectopterygoid in advanced snakes (Colubroidea): A concordance of shape and phylogeny. Biological Joumal of the Linnean Society 27: 133-164.

Lombard RE, Wake DB. 1986. Tongue evolution in the lungless salamanders, family Plethodontidae. IV. Phylogeny of plethodontid salamanders and the evolution of feeding dynamics. Systematic Zoology 35: $532-551$.

Maddison WP, Donoghue MJ, Maddison DR. 1984. Outgroup analysis and parsimony. Systematic Zoology 33. 83-103.

Marx H, Rabb GB. 1970. Character analysis: An empirical approach applied to advanced snakes. Journal of Zoology, London 161: 528-548.

Maslin TP. 1952. Morphological criteria of phyletic relationships. Systematic Zoology 1: 49-70.

McDowell SB. 1972. The evolution of the tongue of snakes and its bearing on snake origins. In: Dobzhansky T, Hecht MK, Steere WC, eds. Evolutionary biology 6. New York: Appleton-Century-Crofts, 19l-273.

McDowell SB. 1975. A catologue of the snakes of New Guinea and the Solomons, with special reference to those in the Bernice P. Bishop Museum. Part 2. Anilioidea and Pythoninae. Journal of Herpetology 9: 1-79.

McDowell SB. 1979. A catologue of the snakes of New Guinea and the Solomons, with special reference to those in the Bernice P. Bishop Museum. Part 3. Boinae and Acrochordoidea (Reptilia, Serpentes). Journal of Herpetology 13: 1-92.

McDowell 8B. 1987. Systematics. In: Seigel RA, Collins JT, Novak SS, eds. Snakes: ecology and evolutionary biology. New York: Macmillan, 3-50.

Mehrtens JM. 1987. Living snakes of the world. New York: Sterling.

Mengden GA, Stock AD. 1980. Chromosomal evolution in serpentes; A comparison of $G$ and $C$ chromosome banding patterns of some colubrid and boid genera. Chromosoma 79, 53-64.

Patterson C. 1982. Morphological characters and homology. In: Joysey KA, Friday AE, eds. Problems in phylogenetic reconstruction. New York: Academic Press, 21-74.

Peters W. 1858. Uber eine neue schlangengattung, Rhoptrura. Monatsberichte der Königlich Preussischen Akademie der Wissenschaften zu Berlin 1858: 340-341.

Platnick NI. 1999. An empirical comparison of microcomputer parsimony programs, II. Cladistics 5: 145-161.

Rage J-C. 1972. Eryx Daudin et Gongylophis Wagler (Serpentes, Boidae): Etude osteologique. Bulletin du Mustum National d'Histoire Naturelle, Paris 57, 894-898.

Rage JC. 1977. An erycine snake (Boidae) of the genus Calamagras from the French Lower Eocene, with comments on the phylogeny of the Erycinae. Herpetologica 33: 459-463.

Rieppel O. 1976. The homology of the laterosphenoid bone in snakes. Herpelologica 32: 426-429.

Rieppel O. 1977. Studies on the skull of the Henophidia (Reptilia: Serpentes). Joumal of Zoology, London 181: $145-173$.

Rieppel O. 1978a. A functional and phylogenetic interpretation of the skull of the Erycinae (Reptilia, Serpentes). Journal of Zoology, London 186: 185-208.

Rieppel 0. 1978b. The evolution of the naso-frontal joint in snakes and its bearing on snake origins. Zeitschrift fuer Zoologische Systematik Evolutionsforschung 16: 14-27.

Rieppel O. 1979a. The classification of primitive snakes and the testability of phylogenetic theories. Biologisches Zentralblatt 98; 537-552.

Rieppel O. 1979b. A cladistic classification of primitive snakes based on skull structure. Zeitschrift fuer Zoologische Systematik Evolutionsforschung 17: 140-150. 
Rieppel O. 1979c. The evolution of the basicranium in the Henophidia (Reptilia: Serpentes). Zoological Joumal of the Linnean Society 66: 411-431.

Rieppel O. 1979d. A cladistic classification of primitive snakes based on skull structure. Zeitschrift fuer Zoologische Systematik Evolutionsforschung 17: 140-150.

Rieppel O. 1980. The sound-transmitting apparatus in primitive snakes and its phylogenetic significance. Zoomorphology 96: 45-62.

Rieppel O. 1987. Pattern and Process: The early classification of snakes. Biological Journal of the Linnean Society 31: $405-420$.

Rieppel O. 1988. A review of the origin of snakes. In: Hecht MK, Wallace B, Prance GT, eds. Evolutionary biology 22. New York: Plenum, 37-130.

Romer AS. 1956. Osteology of the reptiles. Chicago: University of Chicago Press.

Ross RA, Marzec G. 1990. The reproductive husbandry of pythons and boas. California: Standford, Institute for Herpetological Research.

Sankof DD, Rousseau P. 1975. Locating the vertices of a Steiner tree in arbitrary space. Mathematical Programing 9: 240-246.

Schlegel H. 1851. Description d'une nouvelle espèce du genre eryx. Eryx reinhardtii. Bijdragen tol de Dierkunde, Amsterdam 1: 1-3.

Schmidt KP. 1953. A check list of North American amphibians and reptiles. 6th ed. American Society of Ichthyologists \& Herpetologists.

Seberg O. 1989. The Seventh Annual Meeting of the Willi Hennig Society. Cladistics 5: 183-191.

Shaw CE, Campbell s. 1974. Snakes of the American West. New York: Knopf.

Shine R. 1985. The evolution of viviparity in reptiles: An ecological analysis. In: Gans G, Billett F, eds. Biology of the Reptilia 15B. New York: Wiley, 605-694.

Shine R, Webb JK. 1990. Natural history of Australian typhlopid snakes. Journal of Herpetology 24: 357-363.

Smith HM, Warner R. 1948. Evolution of the ophidian hyobranchium and its bearing on classification. Herpetologica 4: 189-193.

Smith MA. 1943. The fauna of British India, Ceylon and Burma. Reptilia and Amphibia. Serpentes 3. London: Taylor \& Francis.

Sood MS. 1941. The caudal vertebrae of Eryx johnii (Russell). Proceedings of the Indian Academy of Sciences 14: 390-394.

Spiteri DE. 1991. The subspecies of Lichanura trivirgata: Why the confusion? Bulletin of the Chicago Herpetological Society 26: $153-156$.

Stafford PJ. 1986. Pythons and boas. New Jersey: Neptune City, T. F. H. Publications.

Stebbins RC. 1985. A field guide to western reptiles and amphibians. Boston: Houghton Mifflin.

Stewart GR. 1977. Charina, C. bottae. Catalogue of American Amphibians and Reptiles, No. 205: 1-2.

Stimson AF. 1969. Liste der rezenten Amphibien und Reptilien. Boidae (Boinae + Bolyeriinae + Loxoceminae + Pythoninae). Das Tierreich, No. 89: 1-49.

Swofford DL, Olsen GJ. 1990. Phylogeny reconstruction. In: Hillis DM, Moritz C, eds. Molecular systematics. Massachusetts: Sinauer Associates, 411-501.

Szyndlar Z. 1987. Snakes from the lower Miocene locality of Dolnice (Czechoslovakia). Journal of Vertebrate Paleontology 7: 55-71.

Sxyndlar Z. 1991a. A review of Neogene and Quaternary snakes of Central and Eastern Europe. Part I: Scolecophidia, Boidae, Colubrinae. Estudios Geologicos 47: 103-126.

Szyndlar Z. 1991b. A review of Neogene and Quaternary snakes of Central and Eastern Europe. Part II: Natricinae, Elapidae, Viperidae. Estudios Geologicos 47: 237-266.

Tolar AA. 1989. A revision of the genus Eryx using osteological data. Vesinik Zoologii, No. 4: 46-55. [In Russian.]

Underwood G. 1950. On the distribution of snakes of the family Boidae. Proceedings of the Zoological Society of London 120: 713-714.

Underwood G. 1967. A contribution to the classification of snakes. London: British Museum (Natural History) Publications.

Underwood G. 1976. A systematic analysis of boid snakes. In: Bellairs Ad'A, Cox CB, eds. Morphology and biology of reptiles. Linnean Society Symposium Series, No. 3. [List of specimens examined and data matrix on file in the Reptile Section, British Museum (Natural History).]

Underwood G. 1989. A phylogeny of snakes. First World Congress of Herpetology (Abstracts): R8 (also Poster 226).

Underwood G, Stimson AF. 1990. A classification of the pythons (Serpentes, Pythoninae). Journal of Zoology, London 221: 565-603.

Villiere A. 1963. Les Serpents de l'Ouest Africain. Second edition. Senegal: Dakar, l'Institut Fondamental d'Afrique Noire.

Wake DB, Maxson LR, Wurat GZ. 1978. Genetic differentiation, albumin evolution, and their biogeographic implications in plethodontid salamanders of California and Southern Europe. Evolution 32: 529-539.

Welch KRG. 1982. Herpetology of Africa: A checklist and bibliography of the orders Amphisbaenia, Sauria and Serpentes. Florida: Krieger Publications. 
Welch KRG. 1983. Herpetology of Europe and Southwest Asia: A checklist and bibliography of the orders Amphisbaenia, Sauria and Serpentes. Florida: Krieger Publications.

Welch KRG. 1988. Snakes of the Orient: A checklist. Florida: Krieger Publications.

Wiley EO. 1981. Phylogenetics: The theory and practice of phylogenetic systematics. New York: Wiley-Interscience Publications.

Williams EE. 1959. The occipito-vertebral joint in the burrowing snakes of the family Uropeltidae. Breviora, No, 106: 1-10.

Wright AH, Wright AA. 1957. Handbook of snakes of the United Stales and Canada 1. New York: Ithaca, Comstock Publishing Associates.

Yingling RP. 1982. Lichanura, L. trivirgata. Catalogue of American Amphibians and Reptiles No. 294: 1 2 .

Zacharias HCE. 1897. Die phylogenese der kopfschilder bei den boiden. Zoologischen Jahrbüchern. Abtheilung für Systematik, Geographie und Biologie der Thiere 10: 56-90.

Zerova, GA. 1989. The first find of a fossil sand boa of the genus Albaneryx (Serpentes, Boidae) in the U.S.S.R. Vestnik Zoologii 1989: 30-35. 


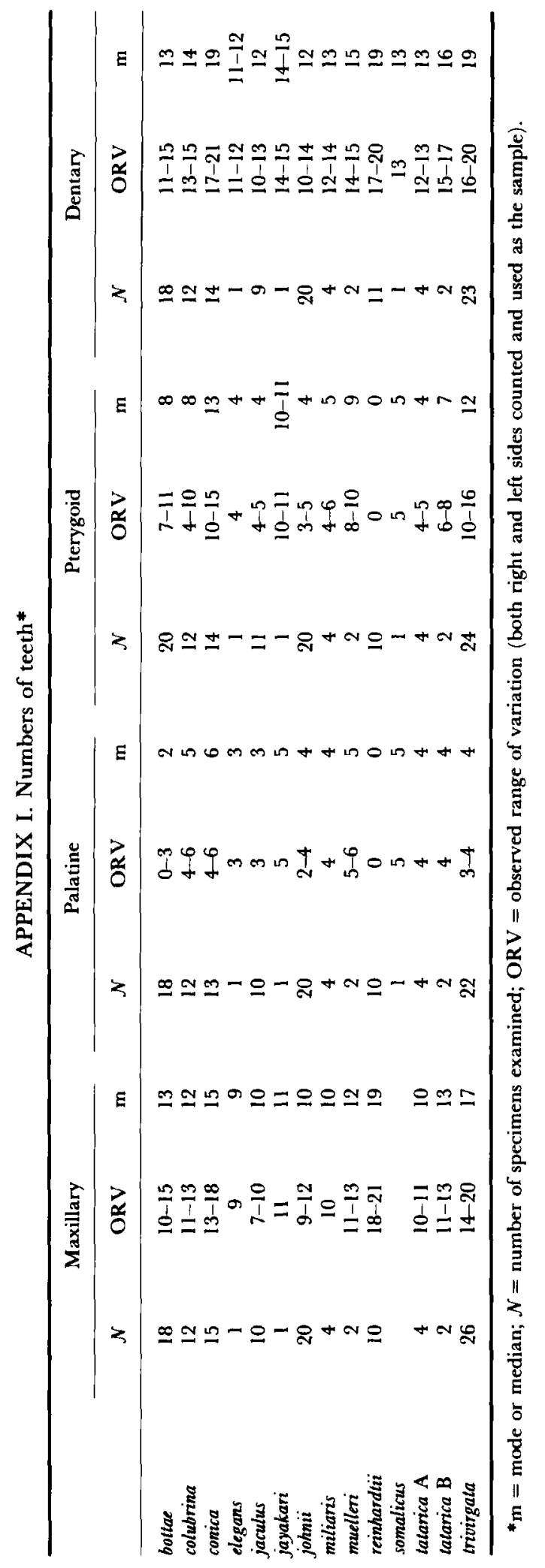




\begin{tabular}{|c|c|c|c|c|c|c|c|c|c|c|c|c|c|c|}
\hline & \multicolumn{14}{|c|}{ Taxa* } \\
\hline & A & B & $\mathrm{C}$ & D & $E$ & $\mathbf{F}$ & G & $\mathbf{H}$ & I & $\mathrm{J}$ & $\mathbf{K}$ & $\mathrm{L}$ & $\mathbf{M}$ & $\mathbf{N}$ \\
\hline 1. & 0 & l & 0 & 0 & 0 & 0 & 0 & 0 & 0 & 0 & 1 & 0 & 0 & I \\
\hline 2. & 0 & 0 & 0 & 0 & 0 & 1 & 0 & 1 & 0 & 0 & 0 & 0 & 0 & 0 \\
\hline 3. & 0 & 0 & 1 & 1 & l & 1 & 1 & 1 & 1 & I & 0 & $?$ & 1 & 0 \\
\hline 4 & 0 & 0 & 1 & 1 & 1 & 1 & 1 & l & 1 & 1 & 0 & 1 & 1 & 0 \\
\hline 5. & 0 & 1 & 2 & 2 & 2 & 2 & 2 & 2 & 2 & 2 & 1 & 2 & 2 & 1 \\
\hline 6. & 0 & 0 & 2 & 2 & 2 & 2 & $?$ & 2 & 2 & 1 & 0 & 2 & 2 & 1 \\
\hline 7. & 0 & 0 & 1 & 1 & 1 & 1 & 1 & 1 & 1 & 1 & 0 & 1 & 1 & 0 \\
\hline 8. & 0 & 0 & l & 1 & l & 1 & $\mathrm{l}$ & l & 1 & 1 & 0 & i & 1 & 0 \\
\hline 9. & 0 & 0 & 0 & 0 & 1 & 1 & 0 & 1 & 1 & 0 & 0 & 1 & 1 & 0 \\
\hline 10. & 0 & 0 & 1 & 1 & i & 1 & l & i & $i$ & 1 & 0 & $i$ & $i$ & 0 \\
\hline 11. & 0 & 0 & 2 & 2 & 2 & 2 & 2 & 2 & 2 & 2 & 1 & $?$ & 2 & 0 \\
\hline 12. & ? & 0 & 1 & 1 & $\vec{l}$ & l & 1 & $\vec{l}$ & $\overrightarrow{1}$ & $\overrightarrow{1}$ & 0 & 1 & $i$ & 0 \\
\hline 13. & 0 & 2 & 2 & 1 & 3 & 3 & 3 & 3 & 3 & 2 & 0 & [3] & $2 / 3$ & 1 \\
\hline 14. & 0 & I & 2 & 2 & 2 & 2 & 2 & 2 & 2 & 2 & 1 & ? & 2 & l \\
\hline 15. & 0 & 0 & 1 & 1 & 1 & 2 & l & 2 & 2 & 1 & 0 & $?$ & 2 & 0 \\
\hline 16. & 0 & 0 & 1 & 1 & 1 & 1 & 1 & 1 & 1 & 1 & 0 & $?$ & 1 & 0 \\
\hline 17. & ? & 0 & 1 & 1 & 1 & 1 & 1 & 1 & 1 & l & 0 & ? & 1 & 0 \\
\hline 18. & 1 & l & 2 & 2 & 2 & 2 & 2 & 2 & 2 & 2 & 0 & ? & 2 & l \\
\hline 19. & 0 & 0 & 1 & 1 & 1 & 1 & 1 & 1 & 1 & 1 & 0 & $?$ & 1 & 0 \\
\hline 20. & 0 & 0 & 2 & 2 & 0 & 0 & 1 & 0 & 1 & 1 & 0 & 1 & 1 & 0 \\
\hline 21. & ? & 1 & 1 & 1 & 1 & 1 & 1 & 1 & 1 & 1 & 0 & 1 & 1 & 1 \\
\hline 22. & 0 & 1 & 0 & 0 & 0 & 0 & 0 & 0 & 0 & 0 & 0 & 0 & 0 & 1 \\
\hline 23. & 0 & 0 & 1 & 1 & 0 & 1 & 1 & 1 & 1 & 1 & 0 & 1 & 1 & 0 \\
\hline 24. & 0 & 1 & 1 & 1 & 1 & 1 & 1 & 1 & 1 & 1 & 1 & ? & 1 & 1 \\
\hline 25. & 0 & 1 & 0 & 0 & 0 & 0 & 0 & 0 & 0 & 0 & 0 & $?$ & 0 & 1 \\
\hline 26. & 0 & 1 & 0 & 0 & 0 & 0 & 0 & 0 & 0 & 0 & 1 & 0 & 0 & 1 \\
\hline 27. & 0 & 1 & 0 & 0 & 0 & 0 & 0 & 0 & 0 & 0 & 1 & $?$ & 0 & 1 \\
\hline 28. & 0 & 0 & 1 & 1 & 1 & 1 & 1 & 1 & 1 & 1 & 0 & $?$ & 1 & 0 \\
\hline 29. & 0 & 0 & 2 & 2 & 0 & 1 & 2 & l & 1 & 2 & 0 & $?$ & 1 & 0 \\
\hline 30. & 0 & 0 & 0 & 0 & 0 & 1 & 1 & l & 1 & 0 & 0 & $?$ & 1 & 0 \\
\hline 31. & 0 & I & 0 & 0 & 0 & 0 & 0 & 0 & 0 & 0 & 0 & 0 & 0 & l \\
\hline 32. & 0 & i & 0 & 0 & 0 & 0 & 0 & 0 & 0 & 0 & 1 & 0 & 0 & 1 \\
\hline 33. & 0 & 2 & 0 & 0 & 0 & 0 & 0 & 0 & 0 & 0 & 1 & 0 & 0 & 2 \\
\hline 34. & 0 & l & 0 & 0 & 0 & 0 & 0 & 0 & 0 & 0 & $i$ & $?$ & 0 & 1 \\
\hline 35. & 0 & 0 & 1 & 1 & $?$ & 1 & $?$ & 1 & 1 & 1 & 1 & 1 & 1 & 0 \\
\hline 36. & 0 & 1 & 2 & 2 & 2 & 2 & 2 & 2 & 2 & 2 & 1 & 2 & 2 & I \\
\hline 37. & 0 & 2 & 1 & 0 & 1 & 1 & 1 & 1 & 1 & 1 & 2 & 1 & 1 & I \\
\hline 38. & 0 & 0 & 1 & 1 & 1 & l & 1 & 1 & 1 & l & 0 & I & 1 & 0 \\
\hline 39. & 0 & l & 1 & 1 & 1 & l & 1 & l & 1 & 1 & 1 & I & 1 & I \\
\hline 40. & 0 & 0 & 1 & 1 & 1 & 1 & 1 & 1 & 1 & 1 & 0 & 1 & 1 & 0 \\
\hline 41. & 0 & 1 & 1 & 1 & 1 & I & 1 & 1 & 1 & 1 & 1 & l & 1 & I \\
\hline 42. & ? & 2 & 2 & 0 & 3 & 3 & $i$ & 3 & 3 & i & 4 & 3 & $2 / 3$ & 0 \\
\hline 43. & 0 & 0 & 2 & 2 & 2 & 1 & 2 & 1 & 2 & 2 & 0 & 2 & 2 & 0 \\
\hline 44. & 0 & 0 & 1 & 1 & 1 & 2 & $\overrightarrow{1}$ & 2 & 1 & $i$ & 0 & 1 & l & 0 \\
\hline 45. & 0 & 0 & 1 & 1 & 1 & 2 & 2 & 2 & 1 & l & 0 & 1 & 1 & 0 \\
\hline 46. & ? & 0 & 1 & 1 & 1 & 1 & 1 & 1 & 1 & 1 & 0 & 1 & 1 & 0 \\
\hline 47. & 0 & 1 & 1 & 1 & 1 & 1 & 1 & 1 & 1 & 1 & l & 1 & 1 & 1 \\
\hline 48. & 0 & i & 0 & 0 & 0 & 0 & 0 & 0 & 0 & 0 & 0 & 0 & 0 & I \\
\hline 49. & $?$ & 1 & 0 & 0 & 0 & 0 & 0 & 0 & 0 & 0 & l & $?$ & 0 & l \\
\hline 50. & 0 & 2 & 2 & 0 & $2 / 3$ & 2 & $1 / 2$ & 2 & 2 & 1 & 0 & 2 & $1 / 2$ & 0 \\
\hline 51. & 0 & 1 & 1 & 1 & $?$ & 1 & 1 & 1 & 1 & 1 & ? & $?$ & 1 & 1 \\
\hline 52. & 0 & 0 & 1 & 1 & $?$ & 1 & $i$ & $i$ & i & $i$ & 0 & ? & $\mathrm{l}$ & 0 \\
\hline 53. & 0 & 1 & 1 & 1 & $i$ & 1 & 1 & 1 & 1 & 1 & 1 & ? & 1 & I \\
\hline 54. & 0 & 0 & 1 & 1 & $i$ & 1 & i & i & i & $i$ & 0 & ? & 1 & 0 \\
\hline 55. & 0 & 0 & 1 & 1 & $?$ & $i$ & $\mathrm{i}$ & 1 & 1 & 1 & 0 & ? & 1 & 1 \\
\hline 56. & 0 & 0 & 1 & 1 & 1 & 1 & i & 1 & $i$ & l & 0 & ? & $i$ & 0 \\
\hline 57. & 1 & 1 & 2 & 2 & $?$ & 2 & 0 & 2 & 2 & 2 & ? & $?$ & 2 & I \\
\hline 58. & 0 & 0 & 2 & 2 & 1 & l & 1 & $i$ & $i$ & 2 & 2 & 2 & 1 & 0 \\
\hline 59. & 0 & 0 & 1 & 1 & 1 & 1 & 1 & 1 & 1 & 1 & 0 & 1 & 1 & 0 \\
\hline
\end{tabular}


APPENDIX II.--continued

\begin{tabular}{|c|c|c|c|c|c|c|c|c|c|c|c|c|c|c|}
\hline & \multicolumn{14}{|c|}{ Taxa* } \\
\hline & $\mathrm{A}$ & B & $\mathrm{C}$ & D & E & $\mathbf{F}$ & G & $\mathbf{H}$ & I & $\mathbf{J}$ & $\mathbf{K}$ & $\mathrm{L}$ & $\mathbf{M}$ & $N$ \\
\hline 60. & 0 & 0 & 2 & 1 & 1 & 1 & 2 & 1 & 1 & 2 & 0 & 2 & 1 & 0 \\
\hline 61. & 0 & 0 & $i$ & $i$ & 1 & $i$ & 1 & i & $i$ & 1 & 0 & $i$ & $i$ & 0 \\
\hline 62. & 0 & I & 1 & 1 & 1 & 1 & 1 & 1 & 1 & 1 & 1 & 1 & 1 & 1 \\
\hline 63. & ? & 0 & $i$ & $i$ & $i$ & i & $i$ & $i$ & $i$ & $i$ & 0 & i & $i$ & 0 \\
\hline 64. & 0 & 0 & 1 & 1 & 0 & 0 & 0 & 0 & 0 & 0 & 0 & 0 & 0 & 0 \\
\hline 65. & 0 & 0 & 2 & 2 & 0 & 1 & 0 & 1 & 0 & 0 & 0 & 2 & 1 & 0 \\
\hline 66. & 1 & 1 & 1 & 1 & 2 & 2 & 2 & 2 & 2 & 1 & 0 & 1 & 2 & 1 \\
\hline 67. & 0 & 0 & 0 & 0 & 0 & 0 & $i$ & 0 & 1 & 0 & 0 & 0 & 0 & 0 \\
\hline 68. & 0 & 0 & 1 & 1 & 1 & 1 & $i$ & 1 & $i$ & 1 & 1 & 1 & 1 & 0 \\
\hline 69. & 0 & 1 & 0 & 0 & 1 & $i$ & 0 & $i$ & $i$ & 0 & $i$ & 0 & $i$ & 1 \\
\hline 70 . & {$[0]$} & [1] & [2] & [2] & ? & [2] & [2] & $?$ & ? & [2] & [2] & ? & $?$ & {$[1]$} \\
\hline 71. & ? & [2] & [1] & [1] & ? & [1] & [I] & ? & ? & [1] & {$[0]$} & ? & ? & [2] \\
\hline 72 . & {$[0]$} & [1] & [i] & [1] & {$[1]$} & [1] & [1] & [1] & {$[1]$} & [1] & [1] & {$[1]$} & [1] & [1] \\
\hline 73. & ? & [1] & [1] & [1] & {$[1]$} & [1] & [1] & [1] & [1] & [1] & {$[0]$} & [1] & [1] & [I] \\
\hline 74. & {$[0]$} & {$[0]$} & ? & [1] & ? & [1] & $?$ & [1] & ? & $?$ & ? & ? & $?$ & [0] \\
\hline 75. & {$[0]$} & [1] & {$[1]$} & [1] & [I] & [1] & {$[1]$} & [1] & {$[1]$} & {$[1]$} & {$[1]$} & {$[1]$} & [1] & [1] \\
\hline
\end{tabular}

*A $=$ ancestor $; \mathrm{B}=$ bottae $; \mathrm{C}=$ colubrina $; \mathrm{D}=$ conica $; \mathrm{E}=$ elegans $; \mathrm{F}=$ jaculus; $\mathrm{G}=$ jayakari; $H=$ johnii; $\mathrm{I}=$ miliaris; $\mathrm{J}=$ muelleri $; \mathbf{K}=$ reinhardtii; $\mathrm{L}=$ somalicus; $\mathbf{M}=$ tatarica $; \mathbf{N}=$ trivirgata; [ ] = literature observation; I = and; ? = unknown. 
APPENDIX III. Character metrics

\begin{tabular}{|c|c|c|c|c|c|c|c|c|c|c|c|c|c|c|}
\hline & \multicolumn{14}{|c|}{ Characters } \\
\hline & 1 & 2 & 3 & 4 & $5 a$ & $5 b$ & $6 a$ & $6 \mathrm{~b}$ & 7 & 8 & 9 & 10 & Ila & $1 \mathrm{lb}$ \\
\hline$s$ & 1 & 1 & 1 & 1 & I & 1 & 2 & 2 & 1 & 1 & 3 & 1 & 2 & 1 \\
\hline$c$ & 1.0 & 1.0 & 1.0 & 1.0 & 1.0 & 1.0 & 0.50 & 0.50 & 1.0 & 1.0 & 0.33 & 1.0 & 0.50 & 1.0 \\
\hline \multirow[t]{2}{*}{$r$} & 1.0 & 1.0 & 1.0 & 1.0 & 1.0 & 1.0 & 0.50 & 0.75 & 1.0 & 1.0 & 0.60 & 1.0 & 0.50 & 1.0 \\
\hline & 12 & $13 a$ & $13 b$ & $13 c$ & $14 a$ & $14 \mathrm{~b}$ & $15 a$ & $15 b$ & 16 & 17 & $18 \mathbf{a}$ & $18 \mathrm{~b}$ & 19 & $20 a$ \\
\hline$s$ & 1 & 2 & 3 & 3 & 1 & 1 & 1 & 1 & 1 & 1 & 1 & 1 & 1 & 2 \\
\hline$c$ & 1.0 & 0.50 & 0.33 & 0.33 & 1.0 & 1.0 & 1.0 & 1.0 & 1.0 & 1.0 & 1.0 & 1.0 & 1.0 & 0.50 \\
\hline \multirow[t]{2}{*}{$r$} & 1.0 & 0.00 & 0.33 & 0.60 & 1.0 & 1.0 & 1.0 & 1.0 & 1.0 & 1.0 & 1.0 & 1.0 & 1.0 & 0.83 \\
\hline & $20 \mathrm{~b}$ & 21 & 22 & 23 & 24 & 25 & 26 & 27 & 28 & $29 a$ & $29 b$ & 30 & 31 & 32 \\
\hline$s$ & 1 & 1 & 1 & l & 1 & 1 & 1 & 1 & 1 & I & 1 & 2 & 1 & 1 \\
\hline$c$ & 1.0 & 1.0 & 1.0 & 1.0 & 1.0 & 1.0 & 1.0 & 1.0 & 1.0 & 1.0 & 1.0 & 0.50 & 1.0 & 1.0 \\
\hline \multirow[t]{2}{*}{$r$} & 1.0 & 1.0 & 1.0 & 1.0 & 1.0 & 1.0 & 1.0 & 1.0 & 1.0 & 1.0 & 1.0 & 0.75 & 1.0 & 1.0 \\
\hline & $33 \mathbf{a}$ & $33 b$ & 34 & 35 & $36 \mathbf{a}$ & $36 \mathrm{~b}$ & $37 a$ & $37 \mathrm{~b}$ & 38 & 39 & 40 & 41 & $42 a$ & $42 \mathrm{~b}$ \\
\hline$s$ & 1 & 1 & 1 & 2 & 1 & 1 & 2 & 2 & 1 & 1 & 1 & 1 & 2 & 4 \\
\hline$c$ & 1.0 & 1.0 & 1.0 & 0.50 & 1.0 & 1.0 & 0.50 & 0.50 & 1.0 & 1.0 & 1.0 & 1.0 & 0.50 & 0.25 \\
\hline \multirow[t]{2}{*}{$r$} & 1.0 & 1.0 & 1.0 & 0.50 & 1.0 & 1.0 & 0.00 & 0.00 & 1.0 & 1.0 & 1.0 & 1.0 & 0.00 & 0.00 \\
\hline & $42 c$ & $42 \mathrm{~d}$ & $43 a$ & $43 b$ & $44 a$ & $44 b$ & $45 a$ & $45 b$ & 46 & 47 & 48 & 49 & $50 \mathfrak{a}$ & $50 \mathrm{~b}$ \\
\hline$s$ & 3 & 1 & 1 & 2 & 1 & 1 & 1 & 2 & 1 & 1 & 1 & 1 & 3 & 4 \\
\hline$c$ & 0.33 & 1.0 & 1.0 & 0.50 & 1.0 & 1.0 & 1.0 & 0.50 & 1.0 & 1.0 & 1.0 & 1.0 & 0.33 & 0.25 \\
\hline \multirow[t]{2}{*}{$r$} & 0.60 & 1.0 & 1.0 & 0.80 & 1.0 & 1.0 & 1.0 & 0.50 & 1.0 & 1.0 & 1.0 & 1.0 & 0.33 & 0.25 \\
\hline & $50 \mathrm{c}$ & 51 & 52 & 53 & 54 & 55 & 56 & $57 a$ & $57 \mathrm{~b}$ & $58 a$ & $58 \mathrm{~b}$ & 59 & $60 \mathrm{a}$ & $60 \mathrm{~b}$ \\
\hline$s$ & 0 & 1 & 1 & 1 & 1 & 2 & 1 & 2 & 1 & 2 & 2 & 1 & 1 & 2 \\
\hline$c$ & 1.0 & 1.0 & 1.0 & 1.0 & 1.0 & 0.50 & 1.0 & 0.50 & 1.0 & 0.50 & 0.50 & 1.0 & 1.0 & 0.50 \\
\hline \multirow[t]{2}{*}{$r$} & 1.0 & 1.0 & 1.0 & 1.0 & 1.0 & 0.50 & 1.0 & 0.66 & 1.0 & 0.50 & 0.75 & 1.0 & 1.0 & 0.66 \\
\hline & 61 & 62 & 63 & 64 & $65 a$ & $65 b$ & $66 a$ & $66 \mathrm{~b}$ & 67 & 68 & 69 & $70 a$ & $70 \mathrm{~b}$ & $71 \mathrm{a}$ \\
\hline$s$ & 1 & 1 & 1 & l & 2 & 1 & 2 & 1 & 2 & 2 & 2 & 1 & 2 & 1 \\
\hline$c$ & 1.0 & 1.0 & 1.0 & 1.0 & 0.50 & 1.0 & 0.50 & 1.0 & 0.50 & 0.50 & 0.50 & 1.0 & 0.50 & 1.0 \\
\hline \multirow[t]{2}{*}{$r$} & 1.0 & 1.0 & 1.0 & 1.0 & 0.80 & 1.0 & 0.80 & 1.0 & 0.00 & 0.50 & 0.80 & 1.0 & 0.50 & 1.0 \\
\hline & $71 b$ & 72 & 73 & 74 & 75 & & & & & & & & & \\
\hline$s$ & 1 & 1 & 1 & 1 & 1 & & & & & & & & & \\
\hline$c$ & 1.0 & 1.0 & 1.0 & 1.0 & 1.0 & & & & & & & & & \\
\hline$r$ & 1.0 & 1.0 & 1.0 & 1.0 & 1.0 & & & & & & & & & \\
\hline
\end{tabular}

*The actual number of steps $(s)$, and consistency $(c)$ and retention $(r)$ indices for each character (Appendix II) used to construct the phylogenetic hypothesis illustrated in Fig. 19 (Kluge \& Farris, 1969; Kluge, 1989). See Methods and materials section for further explanation. All multistate characters (Appendix II) are assumed to be additive, and their binary factors are treated separately. 


\section{APPENDIX IV}

\section{Ingroup skeletal material examined}

bottae: AMNH 63487 (skull); BMNH 78.5.20.3 (skull), 1969.2948; CAS 28323 (skull, incomp. vert. col.); CM 36539, 38708 (disartic.); FMNH 1218 (skull), 22348, 31300 (skull, caudal vert.); MCZ 6785; MVZ 11198, 11925, 111599; UF 11756; UMMZ 135013-16, 149643 (skull), 173360, 190733 (incomp. vert. col.).

colubrina: AMNH 61633 (skull); FMNH 75214, 223196; MCZ 40304 (skull, incomp. vert. col.), 150436 (skull); NMB 447 (skull, incomp. vert. col.); UF 52891 (disartic.); UMMZ 186019, 190339-40, 190384, 190412-3, 190738 (incomp. vert. col.).

conica: AMNH 2259 (skull); BMNH 52.11.3.1 (skull, incomp. vert. col.), 1930.5.8.9 (lower mand.), 1930.5.8.10 (skull), 1930.5.8.12 (skull), 1930.5.8.14 (skull), 1964.1224; CM 43833, 91863; MCZ 18380 (part. skull, incomp. vert. col.); MVZ 95992; NMB 5756 (skull); UF 42558, 66431; UMMZ 128037, 190737 (incomp. vert. col.), 190949.

elegans: IZANU 1650/415। (part. skull, comp. vert. col.), 1674/4200 (skull).

jaculus: AMNH 38168 (skull); BMNH 1920.1.20.1526, 1930.5.8.17-18 (skulls), 1930.5.8.19 (skull, incomp. vert. col.); FMNH 19624 (skull); MCZ 56870 (skull); NMB 15212 (skull, incomp. vert. col.); UF 14282; UMMZ 190419-20, 190739 (incomp. vert. col.), 192847 (skull).

jayakari: BMNH 1909.10.15.8 (skull).

johnii: AMNH 43441 (skull), 99700-701 (skulls), 102221-22 (skulls), 108525 (skull); BMNH IV.22.1, 1930.5.8.22, 1930.5.8.24-25 (skulls), 1930.5.8.31 (skull), 1930.5.8.34 (skull), 1964.1227; CAS unnumbered (cl/st), 446 (skull); CM 56094; FMNH 23534 (skull, caudal vert.), 31319; MCZ 4211 (skull), 6675 (skull); MVZ 172375; NMB 6085 (disartic skull); UF 24204, 44169, 47847, 61046, 66432; UMMZ 190740 (incomp. vert. col.).

miliaris: AMNH 84494 (skull); MCZ 34043 (skull); UMMZ 190696-7.

muelleri: CAS 136230; NMB 454 (skull).

reinhardtii: BMNH 96.3.9.3 (skull, incomp. vert. col.), 1911.10.28.17; FMNH 19478 (skull), 31372 (skull, caudal vert.); MCZ 22501 (skull), 49014 (skull, incomp. vert. col.); NMB 402 (skull), 20589 (skull, incomp. vert. col.); UF 53669, 54072, 56403, 61977; UMMZ 149642 (skull), 183242, 190728 (incomp. vert. col.).

somalicus: MZUF c.5250 (part. skull).

talarica A: IZANU 4152, 4153, 4155 (disartic. skull, mand.); UMMZ 190414.

tatarica B: IZANU 4154 (disartic. skull, mand.); NMB 17538 (skull).

trivirgata: AMNH 38721 (skull), 73360 (skull, part. vert. col.), 75285 (skull, part. vert. col.); BMNH 94.3.24.4 (skull); CM 56093, 112366, 112374; FMNH 8043 (skull), 31342 (vert. col.), 31365 (skull); MCZ 8966 (incomp. vert. col.); MVZ 95991, 137796; SDSNH 48506, 59499, 63349, 64978, 65172, 65467, 65487, 6582I; UF 68309, 68316 (disartic.); UMMZ 131053 (disartic.), 134130, 189644, 190748 (incomp. vert. col.), 193256-57.

*Abbreviations: $\quad \mathrm{cl} / \mathrm{st}=$ cleared and stained; $\quad$ col. $=$ column; $\quad$ disartic. = disarticulated; incomp. $=$ incomplete; mand. = mandible; part. = partial; vert. = vertebrae or vertebral. See p. 303 for museum abbreviations. 